Florida International University FIU Digital Commons

$1-22-2014$

\title{
Enhanced Anchorage of Tissue-Engineered Cartilage Using an Osteoinductive Approach
}

Rupak Dua

Florida International University, rdua001@fiu.edu

DOI: $10.25148 /$ etd.FI14071120

Follow this and additional works at: https://digitalcommons.fiu.edu/etd

\section{Recommended Citation}

Dua, Rupak, "Enhanced Anchorage of Tissue-Engineered Cartilage Using an Osteoinductive Approach" (2014). FIU Electronic Theses and Dissertations. 1459.

https://digitalcommons.fiu.edu/etd/1459 


\title{
FLORIDA INTERNATIONAL UNIVERSITY
}

Miami, Florida

\section{ENHANCED ANCHORAGE OF TISSUE-ENGINEERED CARTILAGE USING AN OSTEOINDUCTIVE APPROACH}

\author{
A dissertation submitted in partial fulfillment of \\ the requirements for the degree of \\ DOCTOR OF PHILOSOPHY \\ in \\ BIOMEDICAL ENGINEERING \\ by \\ Rupak Dua
}

2014 
To: Dean Amir Mirmiran

College of Engineering and Computing

This dissertation, written by Rupak Dua, and entitled Enhanced Anchorage of TissueEngineered Cartilage using an Osteoinductive Approach, having been approved in respect to style and intellectual content, is referred to you for judgment.

We have read this dissertation and recommend that it be approved.

Yen-Chih Huang

Norman Munroe

Arvind Agarwal

Lidia Kos

Sharan Ramaswamy, Major Professor

Date of Defense: January 22, 2014

The dissertation of Rupak Dua is approved.

Dean Amir Mirmiran

College of Engineering and Computing

Dean Lakshmi N. Reddi

University Graduate School

Florida International University, 2014 
(C) Copyright 2014 by Rupak Dua

All rights reserved. 


\section{DEDICATION}

I would like to dedicate this dissertation to my family-without their energetic support and love; it would have been very difficult to complete this research. 


\section{ACKNOWLEDGMENTS}

I sincerely thank my advisor and mentor, Dr. Sharan Ramaswamy, for his extensive support throughout the span of my $\mathrm{PhD}$ research - without his continued, enthusiastic and critical guidance, it would not have been possible for me to write this page today. He has always had my best interest at heart and has provided me with every opportunity to grow. I am grateful for all the kindness and patience that he has shown me over the years. He has devoted long hours of discussions during the course of this research, which helped me immensely to understand the issues much thoroughly. Apart from mentoring to sharpen my technical abilities, he was equally careful for my personality development. He was always happy to send me to different conferences, national or international so that I can gain confidence. He also helped me in sharpening my writing skills. He had guided me at every step whenever I needed him, whether it's academically or personally. I am thankful for his efforts, time and dedication for completion of my dissertation and developing my career.

I would also like to express my sincere gratitude to Dr. Yen-Chih Huang, Dr. Norman Munroe, Dr. Arvind Agarwal and Dr Lidia Kos for serving in my committee and providing their continuous support and always being ready to help me out whenever I needed their guidance.

I would also like to thank Dr Anthony McGoron, for believing in me that I have the capability of pursing and completing the doctoral study. Without his help and guidance, it would have been very difficult to even start off with the $\mathrm{PhD}$ program at FIU.

I wish to thank Dr James Byrne who just retired in August 2013 but he has seen my progress since 2009 . He is like a walking encyclopedia. He has helped me all throughout my research, be it any problem he has some solution for it. 
My special thanks to all my current and ex-lab mates-Jerry Centano, Catalina Martinez, Sasmita Rath, Manuel Salinas, Stephanie Van Gulden whom I worked with and were always ready to help me out whenever I needed them.

I thank my friends Abhay Zutshi, Pratik Shah, Punnet Gill, Kumpal Madrasi, Tushar Gadaki, Abhignyan Nagesetti, Tingjun Lei, Debrupa Lahiri, Ujwal Chaudhary, Jaimit Parikh, Varun Jain, and Alicia Fernandez for extending their hands whenever I needed help from them during my research.

A special word of thanks goes to Claudia Estrada, who has been very helpful and caring and has never disappointed me with any academic problem I had.

I would like to extend my heartiest thanks to my cousins Shailja, Divyanshu, Ankit, Mohit, Akshay, Anu, Devu, Bhawana for providing moral support and encouragement during the course of my $\mathrm{PhD}$ Program.

I would like to acknowledge the Biomedical Department for supporting me through Graduate and Teaching Assistantship awards. I am thankful to University Graduate School, FIU for supporting me through Dissertation Year Fellowship (DYF) award.

I would like to thank my lovely and caring grandmother Kailash Budhraja, my parents (H.K. Dua and Neena Dua), brother Nipun, his wife Pratiksha, my cute little niece Aadya and my parents- in-laws (B.K. and D.K Khurana) and sister in law, Priyanka who supported me with their love, in every moment, during ups and downs of my research.

Last but not the least, I would like to thank my wife Indu, without her moral support and love I would not have been able to complete my research and thesis work successfully. Even though she has an economics background, she knows the ins and outs of my research and has always been there to support me and help me out in any way she can. 


\section{ABSTRACT OF THE DISSERTATION \\ ENHANCED ANCHORAGE OF TISSUE-ENGINEERED CARTILAGE USING AN OSTEOINDUCTIVE APPROACH \\ by \\ Rupak Dua}

Florida International University, 2014

Miami, Florida 


\section{Professor Sharan Ramaswamy, Major Professor}

Articular cartilage injuries occur frequently in the knee joint. Several methods have been implemented clinically, to treat osteochondral defects but none have been able to produce a long term, durable solution. Photopolymerizable cartilage tissue engineering approaches appear promising; however, fundamentally, forming a stable interface between the tissue engineered cartilage and native tissue, mainly subchondral bone and native cartilage, remains a major challenge. The overall objective of this research is to find a solution for the current problem of dislodgment of tissue engineered cartilage at the defect site for the treatment of degraded cartilage that has been caused due to knee injuries or because of mild to moderate level of osteoarthritis. For this, an in-vitro model was created to analyze the integration of tissue engineered cartilage with the bone, healthy and diseased cartilage over time. We investigated the utility of hydroxyapatite (HA) nanoparticles to promote controlled bone-growth across the bone-cartilage interface in an in vitro engineered tissue model system using bone marrow derived stem cells. We also investigated the application of HA nanoparticles to promote enhance integration between tissue engineered cartilage and native cartilage both in healthy and diseased states. Samples incorporated with HA demonstrated significantly higher interfacial shear strength (at the junction between engineered cartilage and engineered bone and also with diseased cartilage) compared to the constructs without HA ( $p<0.05)$, after 28 days of culture. These findings indicate that the incorporation of HA nanoparticles permits more stable anchorage of the injectable hydrogel-based engineered cartilage construct via augmented integration between bone and cartilage. 
TABLE OF CONTENTS

CHAPTER PAGE

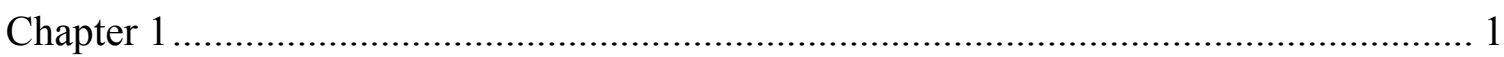

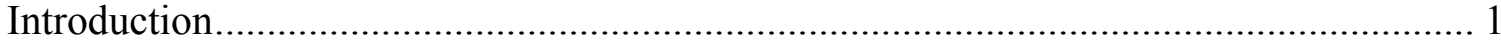

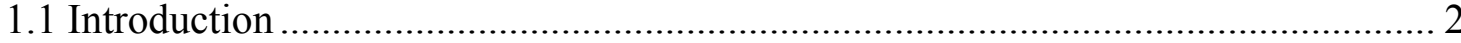

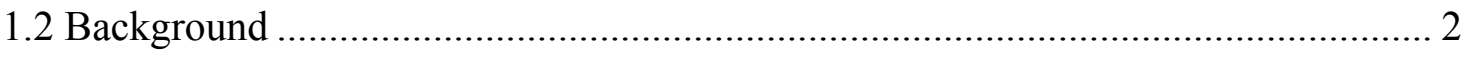

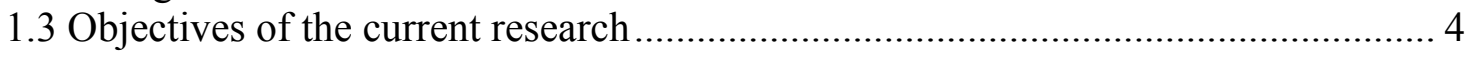

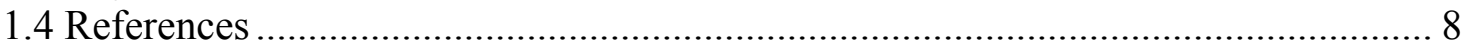

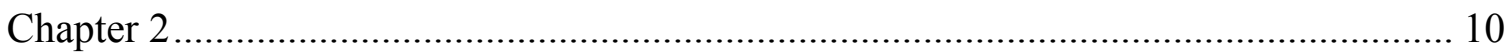

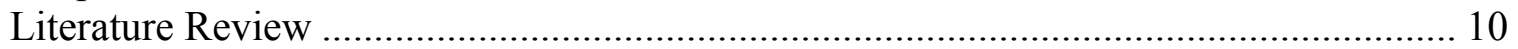

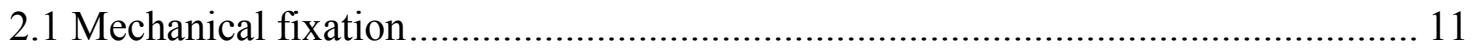

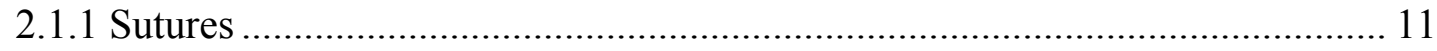

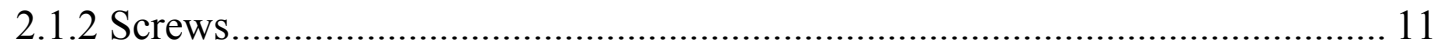




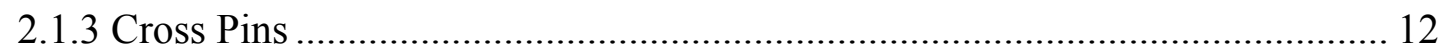

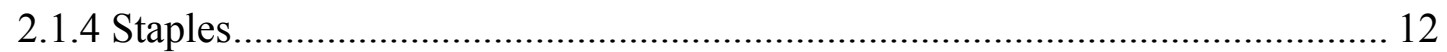

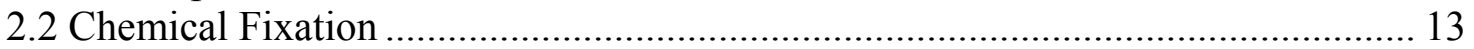

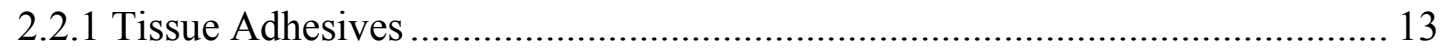

2.2.2 Enzymatic Approaches .............................................................................. 14

2.2.3 Signaling Pathway /Biochemical Approaches................................................. 15

2.3 Biological Fixation .................................................................................. 16

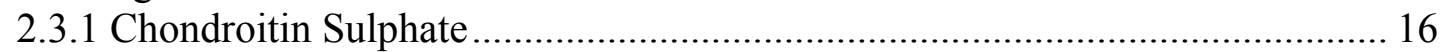

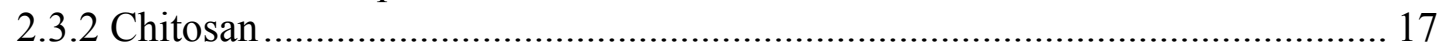

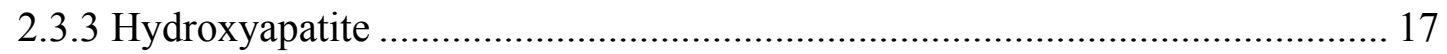

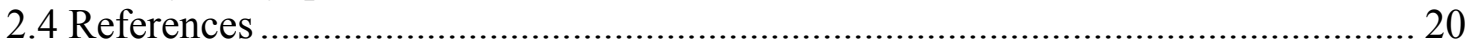

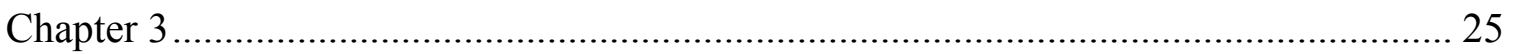

Relative survivability of different human cell types after exposure to

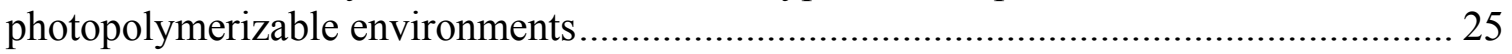

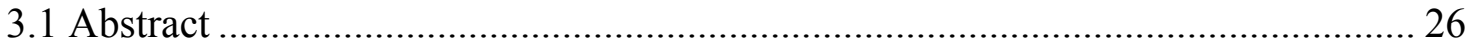

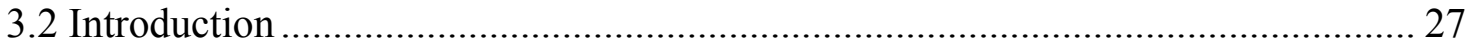

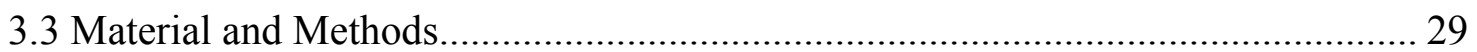

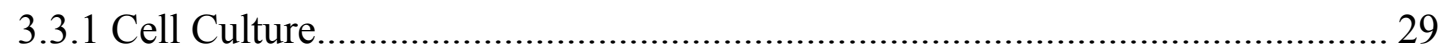

3.3.1.1 Human Bone marrow derived Mesenchymal Stem Cells (HBMSCs)....... 29

3.3.1.2 Human Pulmonary Artery Endothelial Cells (HPAEC) ………………..... 30

3.3.1.3 Human Pulmonary Artery Smooth Muscle Cells (HPASMC) ………….... 30

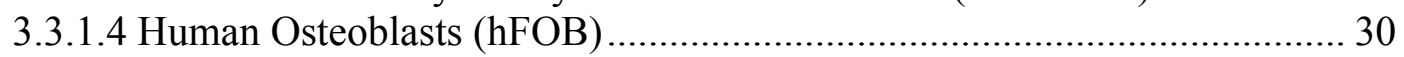

3.3.1.5 Human periodontal ligament cells (HPDLCs) ............................................ 30

3.3.2 Effect of UV light at different exposure times ............................................... 30

3.3.3 Effect of Photoinitiator concentration on different cell lines ............................ 31

3.3.4 Combined effects of UV exposure times and Photoinitiator concentration ..... 31

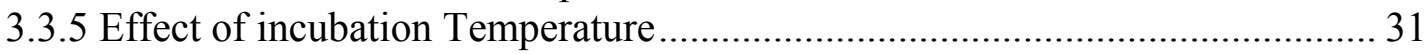

3.3.5.1 Effect of temperature on the osteoblast phenotype.................................... 32

3.3.5.1.1 Alkaline Phosphatase Activity ......................................................... 32

3.3.5.1.2 Calcium Distribution ........................................................................ 33

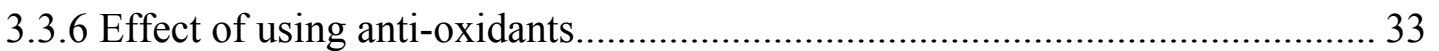

3.3.7 Cytotoxicity evaluation using sulforhodamine B (SRB) assay ........................ 33

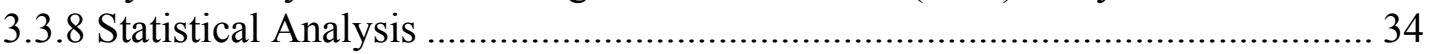

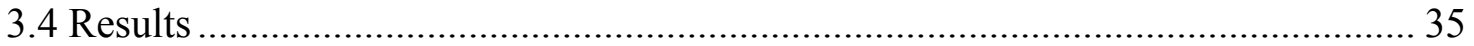

3.4.1 Effect of UV light at different exposure times …………………………........ 35

3.4.2 Effect of Photoinitiator Concentration .............................................................. 36

3.4.3 Combined effect of UV exposure and Photoinitiator ........................................ 36

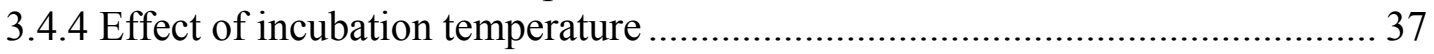

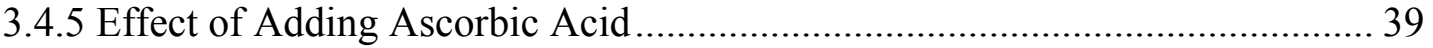

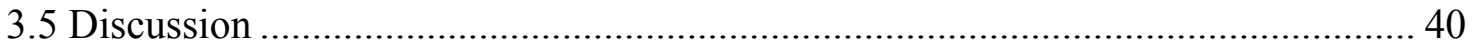

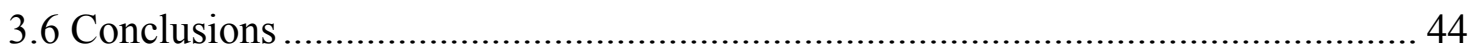

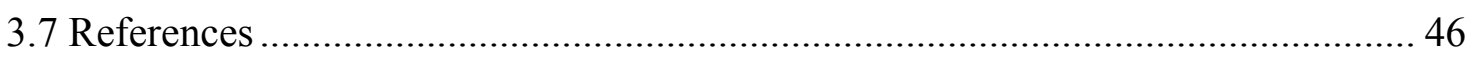

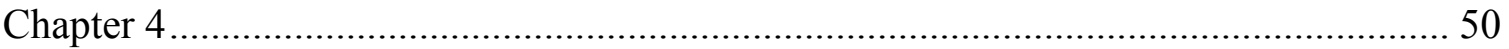


Improvements in Integration of Engineered Cartilage to Bone Matrix Using

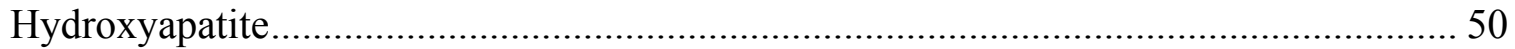

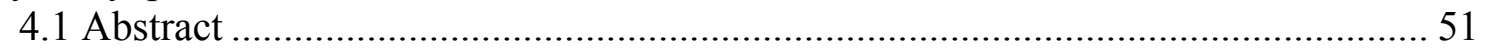

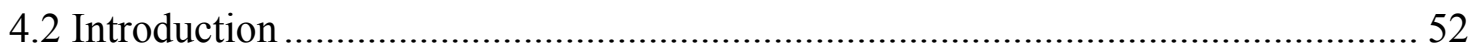

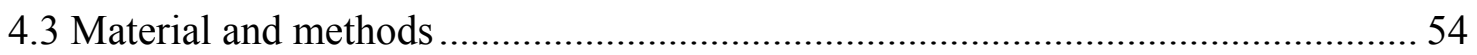

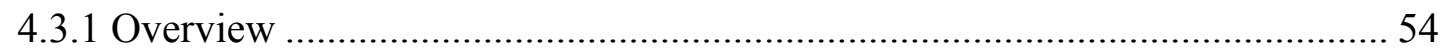

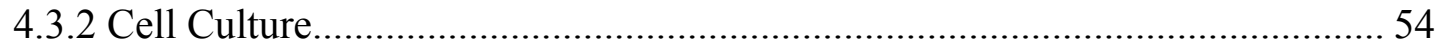

4.3.2.1 Human Bone marrow derived Mesenchymal Stem Cells (HBMSCs)....... 54

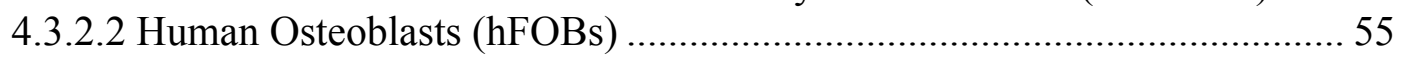

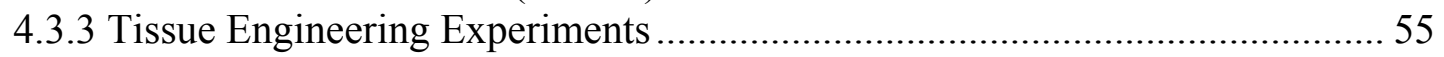

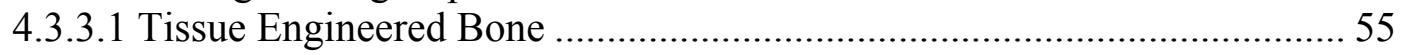

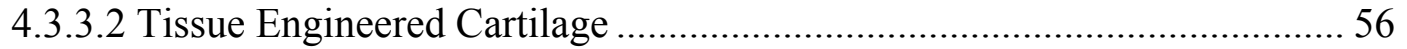

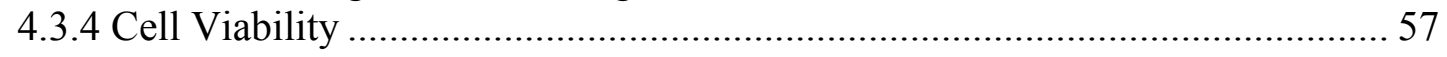

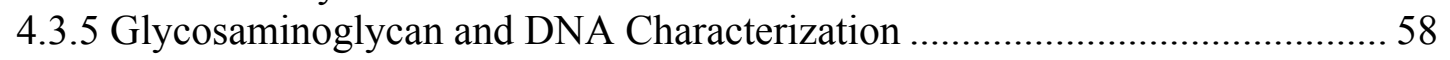

4.3.6 Quantitative Real-Time Polymerase Chain Reaction (qRT-PCR) ................... 60

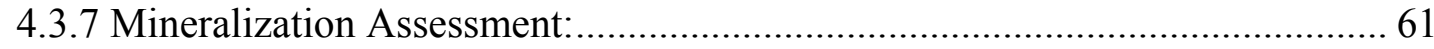

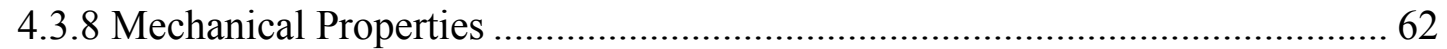

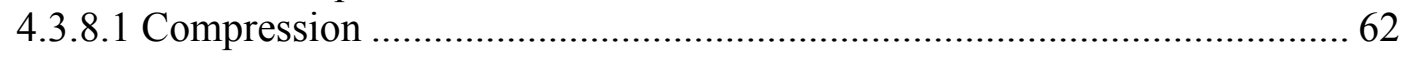

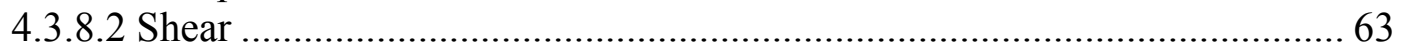

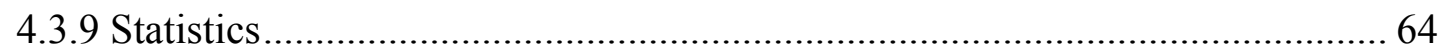

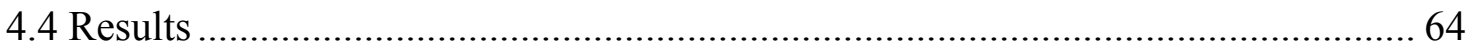

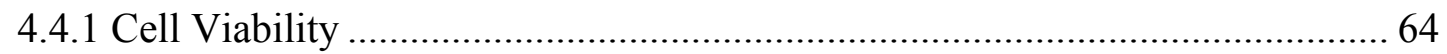

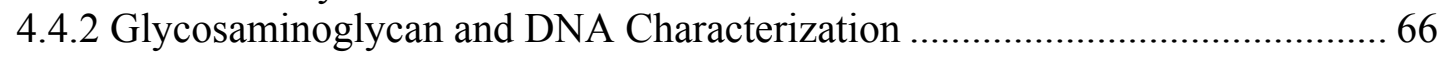

4.4.3 Quantitative Real-Time Polymerase Chain Reaction (qRT-PCR) ................... 68

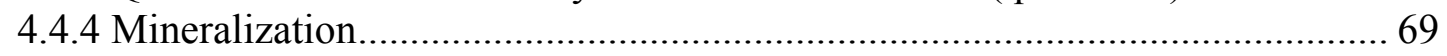

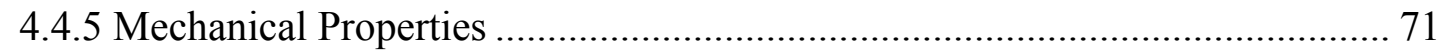

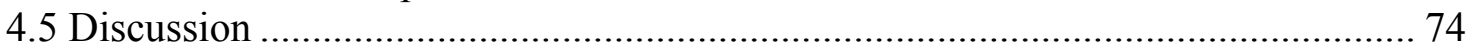

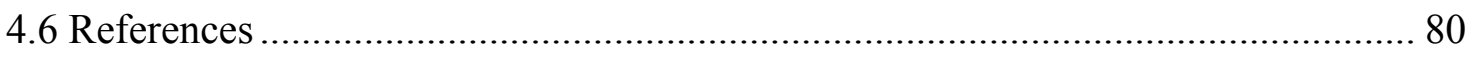

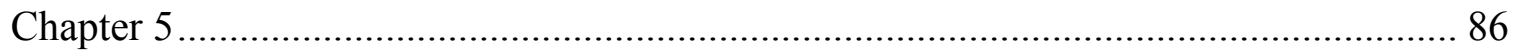

Improvement in integration of engineered cartilage with native cartilage matrix

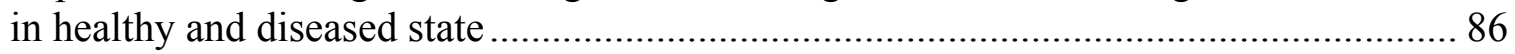

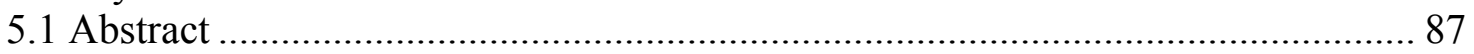

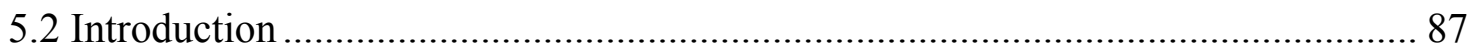

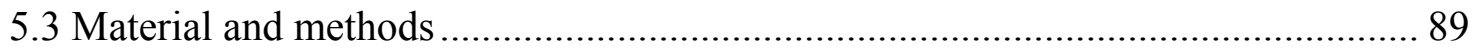

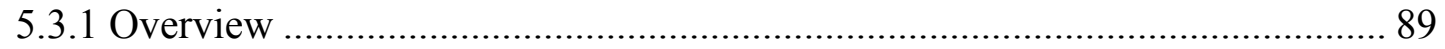

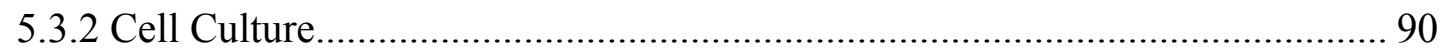

5.3.2.1 Human Bone marrow derived Mesenchymal Stem Cells (HBMSCs)...... 90

5.3.2.2 Healthy Human Chondrocytes (HC)................................................... 90

5.3.2.3 Human Chondrocytes-Osteoarthritis (HCOA) …................................... 91

5.3.3 Tissue Engineered Healthy Cartilage ......................................................... 91

5.3.4 Tissue Engineered Diseased Cartilage ......................................................... 91

5.3.5 Stem-Cell derived Tissue Engineered Cartilage ......................................... 91

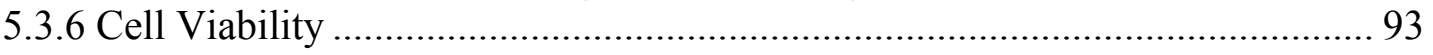

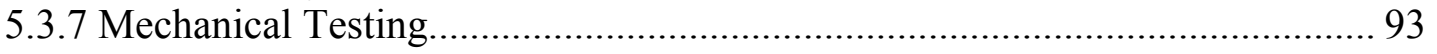




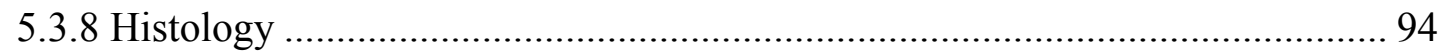

5.3.9 Quantitative Real Time-Polymerase Chain Reaction q(RT-PCR) .................. 95

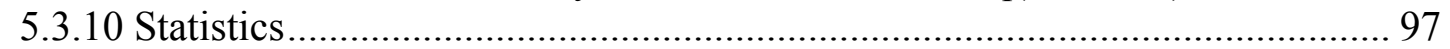

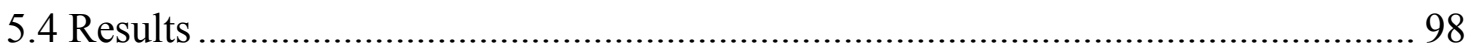

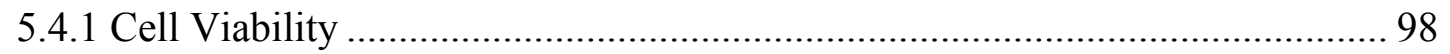

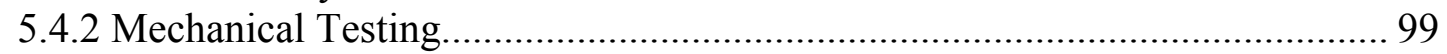

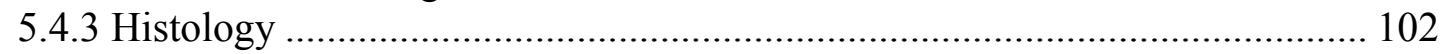

5.5.4 Quantitative Real-Time Polymerase Chain Reaction (qRT-PCR) ................. 104

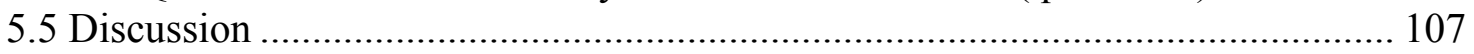

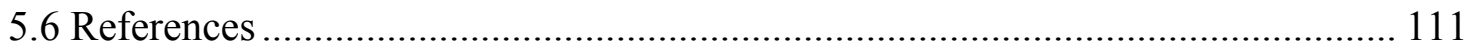

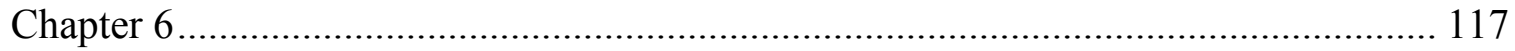

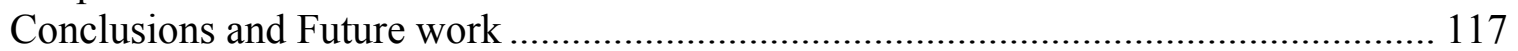

6.1 Conclusions, limitations and future work …………......................................... 117

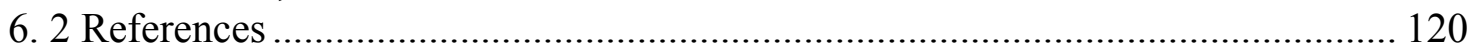

VITA ………

\section{LIST OF TABLES}

TABLE $\quad$ PAGE

Table 2.1: $\quad$ Summary of the advantages and disadvantages of different types of integration techniques [1-36] ............................................................ 18

Table 3.1: $\quad$ Osteoblast Relative Survivability with and without Ascorbic Acid antioxidant at $37^{\circ} \mathrm{C}$ and $39^{\circ} \mathrm{C}$ incubation temperatures

Table 4.1: Quantitative RT-Polymerase Chain Reaction primer sequences used in this study

Table 4.2: Quantitative assessment of percentage cell viability in samples subjected to the live-dead assay 
Table 5.1: Quantitative RT-Polymerase Chain Reaction Primer Sequences............ 97

Table 5.2 Quantitative assessment of percentage cell viability in samples subjected to the live-dead assay

\section{LIST OF FIGURES}

FIGURE

PAGE

Figure 1.1: Zonal structure of articular cartilage ................................................. 4

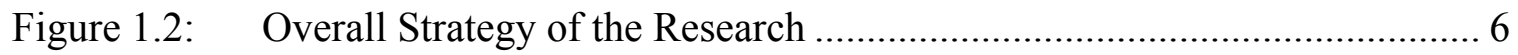

Figure 3.1: Cell toxicity results for different human cell sources after different UV exposure times. Cells were incubated at $37^{\circ} \mathrm{C}$ 36

Figure 3.2 Cell toxicity results for different human cell sources incubated at $37{ }^{\circ} \mathrm{C}$ for 48 hours after exposure to different photoinitiator concentrations 36 
Figure 3.3: Cell toxicity results for different human cell sources after exposure to different UV exposure time concentrations and a fixed photoinitiator concentration of $0.05 \%(\mathrm{w} / \mathrm{v})$.

Figure 3.4: Cell toxicity results for human osteoblasts as a function of incubator temperature. Cells were exposed for a total of 10 minutes under UV light and using a fixed photoinitiator concentration of $0.05 \%(\mathrm{w} / \mathrm{v}) \ldots \ldots . .38$

Figure 3.5: Survivability of osteoblasts with and without ascorbic acid.................... 39

Figure 3.6: Von-Kossa staining conducted at $37^{\circ} \mathrm{C}$ and $39^{\circ} \mathrm{C}$ after 3 days of osteoblast culture.

Figure 4.1 (a): Live Dead assay over a 4 week period for Osteoblasts in agar scaffold.. 64

Figure 4.1 (b): Live Dead assay over a 4 week period for HBMSCs in PEGDA............ 65

Figure 4.1 (c): Live Dead assay over a 4 week period for HBMSCs in PEGDA-HA...... 65

Figure 4.2: $\quad$ S-GAG content in HBMSC seeded-PEGDA and PEGDA-HA constructs.

Figure 4.3: DNA concentration of HBMSC encapsulated in PEGDA and PEGDA HA scaffolds. 68

Figure 4.4: $\quad$ qRT-PCR of HBMSC grown over a period of 4 weeks in BMSC media and chondrogenic media.

Figure 4.5 (a): ALP Activity using colorimetric method......................................... 70

Figure 4.5 (b): Von Kossa - Alcin Blue histology images of 2 layer constructs............. 71

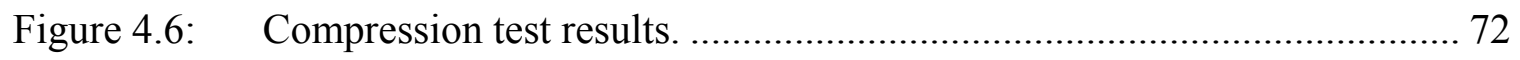

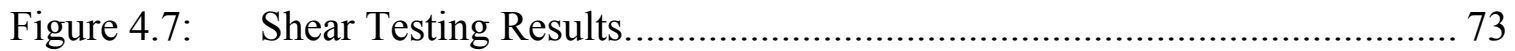

Figure 5.1 (a): Live Dead assay over a period of 28 days for HCs encapsulated in agar scaffold. 98

Figure 5.1 (b): Live Dead assay over a period of 28 days for HCOAs encapsulated in agar scaffold. 99

Figure 5.2: Interfacial shear test results of tissue engineered cartilage joined with healthy cartilage mimics with and without the presence of HA. 100 
Figure 5.3: Interfacial shear test results of tissue engineered cartilage joined with osteoarthritic cartilage mimics with and without presence of HA........... 101

Figure 5.4: Von Kossa - Alcian Blue histology of tissue engineered cartilage derived from HBMSCs integrated to $\mathrm{HC}$-secreted cartilage matrix with and without HA incorporation.

Figure 5.5: Von Kossa - Alcian Blue histology of tissue engineered cartilage derived from HBMSCs integrated to HCOA-secreted cartilage matrix with and without HA incorporation.

Figure 5.6: $\quad \mathrm{q}$ (RT-PCR) of HBMSCs derived engineered cartilage integrated to HC-secreted cartilage matrix at a region of $1 \mathrm{~cm}$ (proximal) and $4 \mathrm{~cm}$ (distal) from the interface within the HBMSC portion.

Figure 5.7: $\quad \mathrm{q}$ (RT-PCR) of HBMSCs derived engineered cartilage integrated to HCOA-secreted cartilage matrix at a region of $1 \mathrm{~cm}$ (proximal) and $4 \mathrm{~cm}$ (distal) from the interface within the HBMSC portion. 106

Figure 5.8: Elementary composition of the transition zone using Energy-Dispersive X-ray Spectroscopy 109 
Chapter 1

Introduction 


\subsection{Introduction}

The aim of the study was to develop a photo polymerizable injectable tissue engineered cartilage model. This model possesses enhanced integration properties for the treatment of focal cartilage injuries and mild to moderate level of osteoarthritis $\left(\leq 50 \mathrm{~mm}^{2}\right)$. Our central hypothesis was that an osteoinductive approach will overcome the existing limitations of securing engineered cartilage within the defect space for the complete healing period. To test this hypothesis, we conducted an in-depth analysis of the integration of the newly formed tissue engineered cartilage to bone as well as to diseased and healthy cartilage tissues.

\subsection{Background}

Articular cartilage defects and lesions are one of the most common injuries that occur in the knee joint $[1,2]$. Curl et al [1], demonstrated in their study of consecutive knee arthroscopies that up to $63 \%$ of the patients with knee-related symptoms suffered from chondral or osteochondral defects [3]. These defects may also progress to osteoarthritis if left untreated [4], which further involves degradation of articular cartilage, the sub chondral bone, the synovial capsule and membrane as well as the periarticular tissues [5].

Cartilage provides a cushioning mechanism to minimize the impact to bone at joint locations, by completely covering its free surface. Conversely, the degradation of articular cartilage leads to the exposure of bone and eventually, bone-to-bone contact which can cause considerable pain and stiffness in the joints. The extra cellular matrix of articular cartilage is composed of collagen-II and proteoglycans which are maintained and synthesized by chondrocyte cells. The tissue does not contain any vasculature hence, attributing to the slow rate of growth and repair [6, 7]. Architecturally, cartilage is 
composed of 3 zones (Fig. 1.1) and can be classified according to the orientation of collagen fibers within the tissue $[8,9]$. The superficial layer has a tangential orientation with respect to the free surface, while the middle transitional layer is more random. Finally, the deep zone is orientated orthogonally to the free surface.

Several methods have been implemented clinically to treat osteochondral defects but none have been able to produce a long term, durable solution [10-12]. Current clinically used strategies involve permanent modification of the damaged articular surface using abrasion arthoplastry or shaving of chondral bone to remove any loosen bits or parts to ease out the pain. Another popular technique in severe cases of OA makes use of grafting procedures, such as mosaicplasty $[13,14]$ or osteochondral allograft transplantation. In situations of complete cartilage loss and/or severe pain, total joint replacement is carried out, such that an implant consisting of artificial materials is implanted. While these implants have demonstrated durability $>10$ years, revisions are required and the procedure is expensive [15]. From a regenerative medicine standpoint, autologous chondrocyte transplantation $(\mathrm{ACT})$ has been used to promote $[16,17]$ chondrogenesis. In addition, of keen interest in cartilage tissue engineering, several approaches involve leveraging bone marrow derived stem cell (BMSC) release from the subchondral bone, which involve drilling [18] or microfracture [19] of the same with the hope that BMSCs will migrate in the defect area and promote cartilage repair. While these tissue engineering approaches seem promising, fundamentally, there is still a need to better integrate the biomaterial to the host to allow for sufficient repair and regeneration of new cartilage tissue. 


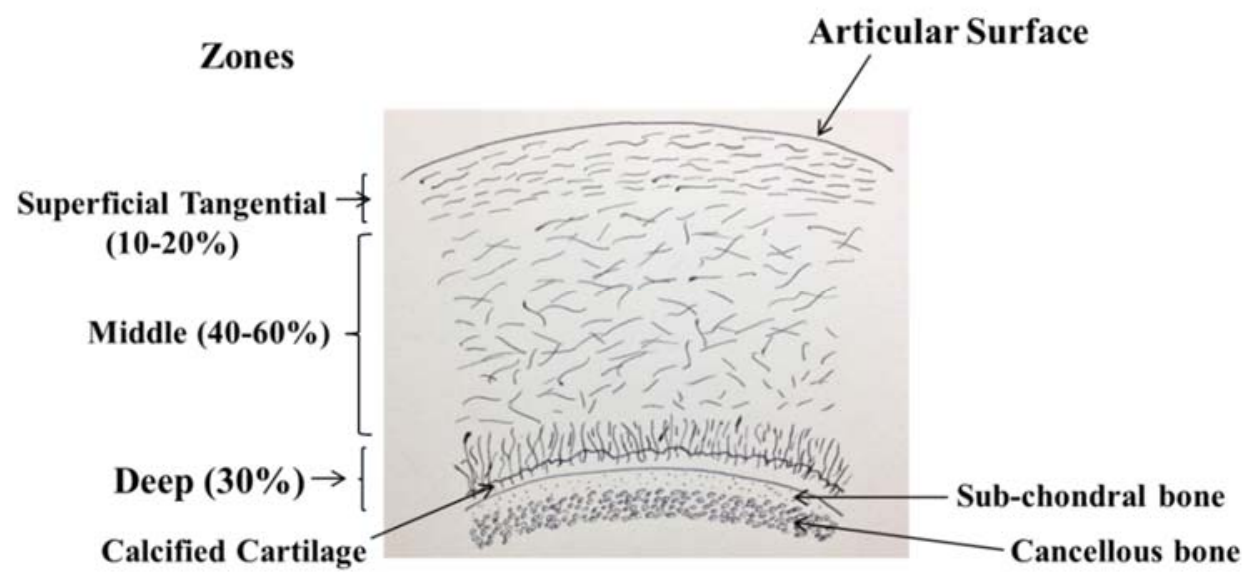

Figure 1.1: Zonal structure of articular cartilage. The superficial zone contains collagen fibers aligned tangentially to the joint surface, whereas the intermediate zone has a more random orientation. Finally, the deep zone of cartilage is characterized by a perpendicular arrangement of collagen fibers

Successful integration will require overcoming the following two major challenges: 1) the biomaterial scaffold that is used must initially be harmonized in the joint, and the ensuing developing tissue must amalgamate with the existing native tissue that surrounds it; 2) the mechanically hostile environment of the joint poses further challenges and thus must be overcome by tailoring suitable interfacial mechanical properties after integration of the biomaterial to subchondral bone, so that de novo cartilage tissue can adequately form.

\subsection{Objectives of the current research}

The overall objective of this research (Fig. 1.2) is to find a solution for the current problem of dislodgment of tissue engineered cartilage at the defect site for the treatment of degraded cartilage that has been caused due to knee injuries or because of mild to moderate level of osteoarthritis. For this, an in-vitro model is created to analyze the integration of 
tissue engineered cartilage with the bone, healthy and diseased cartilage over time. This overall objective is achieved through the following specific aims:

Aim 1: Promote integration between engineered cartilage to subchondral bone using hydroxyapatite nanoparticles in an optimized photopolymerizable hydrogel environments, which will permit controlled bone in-growth into a modest region $(5-15 \%)$ of the engineered cartilage space, thereby providing enhanced anchorage.

Aim 2: Enhance the integration between tissue engineered cartilage and surrounding native cartilage, again with hydroxyapatite nanoparticle incorporation in photopolymerizable hydrogel environments.

Aim 3: Demonstrate the sustenance of engineered cartilage in presence of osteoarthritic diseased states, using approaches utilized in aim 2 and to show their integration in diseased state under hydroxyapatite nanoparticles environments. 


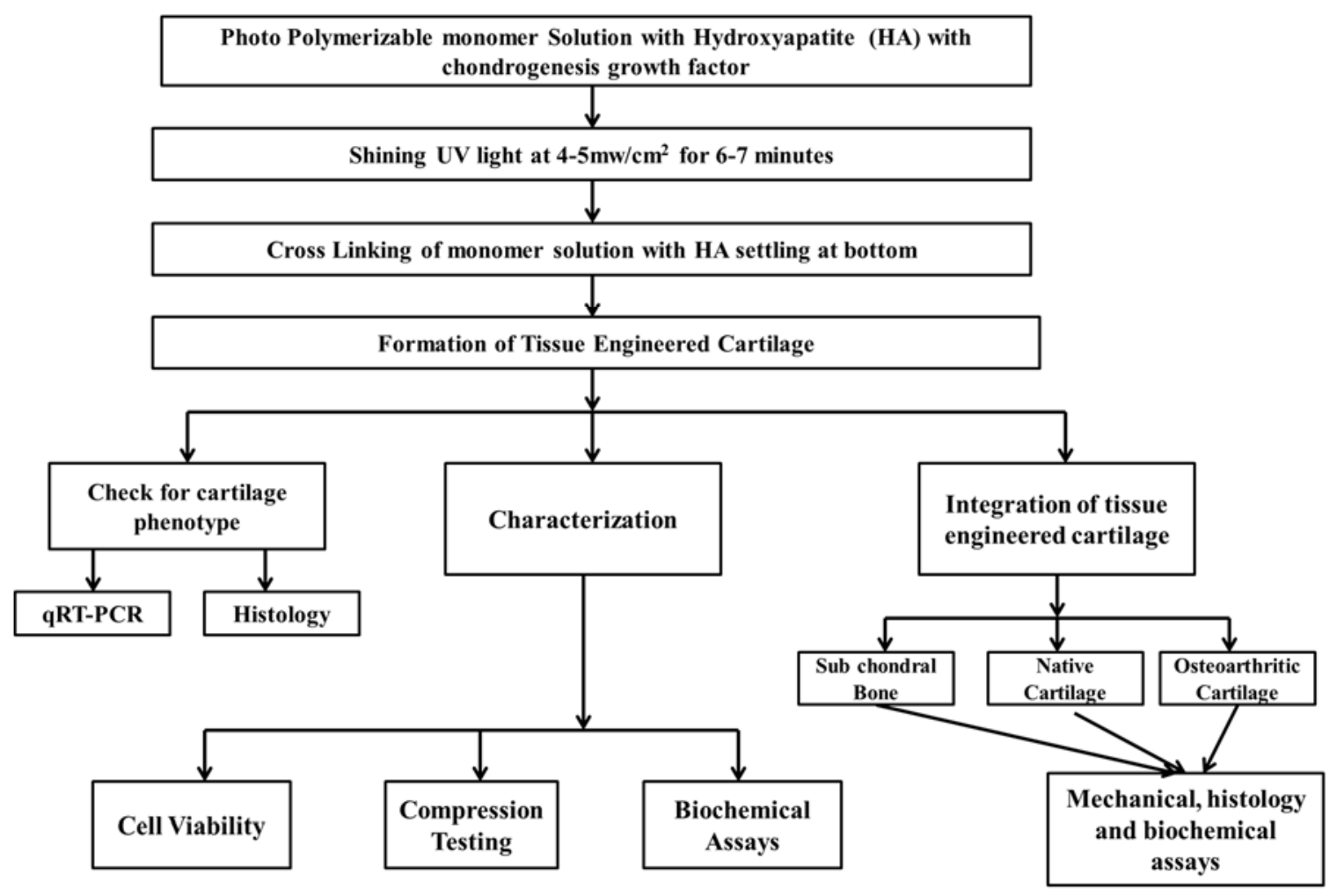

Figure 1.2: Overall Strategy of the Research

As observed by the reader, this chapter gives the background information and motivation for the ongoing project. The subsequent organization of this dissertation is as follows: Chapter 2 provides a comprehensive literature review of investigations that has been done by other researchers in the field of integrating and fixing the tissue engineering cartilage. It also provides the ideas of research areas that can be further exploited. Chapter 3 presents a study of the cellular cytotoxicity of five different human cell sources at different UV exposure times, with and without a commercially used photoinitiator. This chapter provides insights on the relative survivability of the different cells under UV light and photo initiator environments and forms a foundation for subsequent usage of some of these cell types (bone marrow stem cells and osteoblasts) for our tissue engineering experiments. Chapter 4 describes the study for the investigation of the utility of hydroxyapatite (HA) 
nanoparticles to promote controlled bone-growth across the bone-cartilage interface in an in vitro engineered tissue model system, using bone marrow derived stem cells. Chapter 5 describes the integration of tissue engineering cartilage with healthy and diseased cartilage tissues when HA nanoparticles are utilized. Conclusions and scope of future research for this study will be discussed in Chapter 6. Recommendations will also be provided so that this research can enter into the next stage for in vitro model. 


\subsection{References}

1. Curl WW, Krome J, Gordon ES, Rushing J, Smith BP, Poehling GG. Cartilage injuries: a review of 31,516 knee arthroscopies. Arthroscopy : the journal of arthroscopic \& related surgery : official publication of the Arthroscopy Association of North America and the International Arthroscopy Association 1997;13:456-60.

2. Kreuz PC, Muller S, Ossendorf C, Kaps C, Erggelet C. Treatment of focal degenerative cartilage defects with polymer-based autologous chondrocyte grafts: four-year clinical results. Arthritis research \& therapy 2009;11:R33.

3. Hjelle K, Solheim E, Strand T, Muri R, Brittberg M. Articular cartilage defects in 1,000 knee arthroscopies. Arthroscopy : the journal of arthroscopic \& related surgery : official publication of the Arthroscopy Association of North America and the International Arthroscopy Association 2002;18:730-4.

4. Wang Y, Ding C, Wluka AE, Davis S, Ebeling PR, Jones G, et al. Factors affecting progression of knee cartilage defects in normal subjects over 2 years. Rheumatology 2006;45:79-84.

5. Henrotin Y, Kurz B, Aigner T. Oxygen and reactive oxygen species in cartilage degradation: friends or foes? Osteoarthritis and cartilage / OARS, Osteoarthritis Research Society 2005;13:643-54.

6. Hunter W. Of the structure and disease of articulating cartilages. 1743. Clinical orthopaedics and related research 1995:3-6.

7. Newman AP. Articular cartilage repair. The American journal of sports medicine 1998;26:309-24.

8. Sharma B, Elisseeff JH. Engineering structurally organized cartilage and bone tissues. Annals of biomedical engineering 2004;32:148-59.

9. Kim TK, Sharma B, Williams CG, Ruffner MA, Malik A, McFarland EG, et al. Experimental model for cartilage tissue engineering to regenerate the zonal organization of articular cartilage. Osteoarthritis and cartilage / OARS, Osteoarthritis Research Society 2003;11:653-64.

10. Spalazzi JP, Doty SB, Moffat KL, Levine WN, Lu HH. Development of controlled matrix heterogeneity on a triphasic scaffold for orthopedic interface tissue engineering. Tissue engineering 2006;12:3497-508.

11. Van Valburg AA, van Roermund PM, Marijnissen AC, van Melkebeek J, Lammens J, Verbout AJ, et al. Joint distraction in treatment of osteoarthritis: a two-year 
follow-up of the ankle. Osteoarthritis and cartilage / OARS, Osteoarthritis Research Society 1999;7:474-9.

12. Buckwalter JA, Mankin HJ. Articular cartilage repair and transplantation. Arthritis \& Rheumatism 1998;41:1331-42.

13. Hangody L, Kish G, Karpati Z, Udvarhelyi I, Szigeti I, Bely M. Mosaicplasty for the treatment of articular cartilage defects: application in clinical practice. Orthopedics 1998;21:751-6.

14. Feczko P, Hangody L, Varga J, Bartha L, Dioszegi Z, Bodo G, et al. Experimental results of donor site filling for autologous osteochondral mosaicplasty. Arthroscopy : the journal of arthroscopic \& related surgery : official publication of the Arthroscopy Association of North America and the International Arthroscopy Association 2003;19:755-61.

15. Brotherton SL, Roberson JR, de Andrade JR, Fleming LL. Staged versus simultaneous bilateral total knee replacement. The Journal of arthroplasty $1986 ; 1: 221-8$.

16. Brittberg M, Lindahl A, Nilsson A, Ohlsson C, Isaksson O, Peterson L. Treatment of deep cartilage defects in the knee with autologous chondrocyte transplantation. The New England journal of medicine 1994;331:889-95.

17. Brittberg M, Peterson L, Sjogren-Jansson E, Tallheden T, Lindahl A. Articular cartilage engineering with autologous chondrocyte transplantation. A review of recent developments. The Journal of bone and joint surgery American volume 2003;85-A Suppl 3:109-15.

18. Beiser IH, Kanat IO. Subchondral bone drilling: a treatment for cartilage defects. The Journal of foot surgery 1990;29:595-601.

19. Frisbie DD, Trotter GW, Powers BE, Rodkey WG, Steadman JR, Howard RD, et al. Arthroscopic subchondral bone plate microfracture technique augments healing of large chondral defects in the radial carpal bone and medial femoral condyle of horses. Veterinary surgery : VS 1999;28:242-55. 
Chapter 2

Literature Review 
This chapter presents a critical review of investigations that have been conducted in integrating engineered cartilage to host tissue. The process of integration of tissue engineered constructs can be broadly classified into three main categories.

a) Mechanical fixation

b) Chemical Fixation

c) Biological fixation

\subsection{Mechanical fixation}

\subsubsection{Sutures}

Sutures have been extensively used to stabilize implants [1]. An ideal suture has characteristics of high tensile strength, excellent knot security, minimal tissue inflammation, and biocompatibility $[2,0]$. Sutures are made of a variety of textile materials, including, Dexon, silk, nylon, polyethylene and Chitin $[0,5]$. However sutures alone are not able to enable total fixation. Robertson et al [6], reported that the suturing process normally leads to the tearing of tissue when load is applied. Moreover premature suture breakage frequently occurs during application of a load. In some cases the suture threads actually pulled the implant away from the defect site resulting in dislodgement [6].

\subsubsection{Screws}

Screws have been utilized to anchor tissue engineered constructs to bone [7]. They act as a stabilizing device that helps to retain the construct in the defect. The main disadvantage of screws is that they possess protruding components which create regions of stress shielding and can alter bone material properties. In addition the protrusion may interfere with the seamless movement of joints at the articulating surfaces. 


\subsubsection{Cross Pins}

To overcome the limitations of screws, cross pins were utilized so as to augment stability to the implant. Cross pins are much thinner than screws, thus enabling them to fix the tissue engineered constructs to the bone without eliciting substantial tearing [8]. In this technique, many research groups $[8,9]$ used a pin fixture which degrades over time. Pins offer many advantages over screws, in that they prevent graft laceration and their heads are softer than screws, which reduces damage to the engineered constructs.

\subsubsection{Staples}

Robertson et al [6], reported that use of staples is the most effective method of mechanical fixation of tissue engineered constructs to bone. However the most common mode of failure for staples was their dislodgment after application of load. In addition, Shall et al [10], reported that staple breakage and pull-out were the two main reasons for fixation inadequacies.

Mechanical fixation manifests itself through a direct physical connection between implant and the bone. However the primary limitation in these approaches are that they form a sharp interface rather than a natural, graded integration between engineered to native tissue structures, which ultimately leads to implant loosening over a period of time. Considerable efforts have gone into determining novel ways of mechanically fixing implants to host tissue. Nonetheless, true integration of engineered to native tissues such as bone cannot be achieved without biological growth and assimilation across the interface. In addition, mechanical fixation alone may cause secondary tissue damage owing to new defect creation during processes such as suturing and stapling, which cannot be easily repaired [11]. 


\subsection{Chemical Fixation}

There are a number of chemical-based methods that have been attempted to fix tissue engineered constructs to bone in animal models such as tissue adhesives $[0,13]$, treating the construct with enzymes[25, 26] and blocking signaling pathways [29]. These methods have shown some success in terms improving the mechanical stability and durability of the implant. Some of the approaches which have used a chemical approach are described below:

\subsubsection{Tissue Adhesives}

Tissue adhesives have been used for minor wound repair [0]. They have been implemented in place of sutures and staplers for enabling improved outcomes for wound closure [13]. There are a variety of tissue adhesives that have been used clinically. The primary adhesives are described as follows:

Cyanoacrylates are a class of tissue adhesives that have been extensively used. There are many derivatives of cyanoacrylates such as N-butyl cyanoacrylate, 2-Octylcyanoacrylate, butyl-2-cyanoacrylate and N-butyl-2-cyanoacrylate $[14,15,16]$. These cyanoacrylates are commonly referred to as "superglues". They are liquid monomers which cause an exothermic reaction and form a flexible film at the tissue surface that will subsequently hold the two parts together [17]. Vote et al [18], reported that cyanoacrylate prevents the re-occurrence of epithelialization within the damaged area and the connective tissue. Cyanoacrylates also minimize infection because of their bacteriostatic properties which serve to inhibit the growth of gram positive organisms $[15,18]$.

Bioglue is another type of tissue adhesive that consists of albumin gluteraldehyde. It is composed of purified bovine serum albumin cross linked with gutaraldehyde. Herget et al 
[0], suggested that this glue was suitable for sealing lung parenchyma and bronchial anastomosis defects. They furthermore reported that bioglue is durable and its adhesive capability is effective [0]. Several surgical procedures utilize fibrin glue. This tissue adhesive is composed of fibrinogen and thrombin linked together with a bond formed via the coagulation reaction [20]. Fibrin glue also consists of antifibrinolytic agents, aprotinin and calcium chloride in addition to the primary fibrinogen and thrombin components [21]. It has been successfully and actively used as a sealant for pulmonary air leaks [22]. In addition, although fibrin glue is found to be chemically less toxic then cyanoacrylates, they possess less adhesive strength properties [23], thus limiting their use in tissue integration processes.

\subsubsection{Enzymatic Approaches}

Enzymatic treatment approaches work on the principle that selective enzymatic treatment of tissue engineered constructs will promote integration to the host tissue and thereby provide better fixation. Many enzymatic treatments have been attempted and have demonstrated improved integration outcomes. For example, Hunziker et al [25], suggested that the removal of proteoglycans from the surface would enhance the repair of cartilage. Their hypothesis was based on the fact that the cells that are responsible for repairing and regenerating the tissue in cartilage injury do not adhere to proteoglycan rich surfaces. Thus the removal of these proteoglycan molecules from the surface of defects by the use of the enzyme, chondroitinase $\mathrm{ABC}$ would enhance the cartilage repair process. From their experiments, they were able to show that the repair cells adhered to the defect surface considerably better on removal of proteoglycan molecules; however, they were not able to show that the chondroitinase treatment actually enhanced the healing of the injured tissue. 
Lee et al [26], reported that chondroitinase treatment at various concentrations of the enzyme and exposure durations altered adhesion behavior of transplanted cells for the repair of the injured tissue. However, low concentrations of the enzyme $(0.25 \mathrm{U} / \mathrm{mL})$ for 15 minutes (and alternatively, $0.5 \mathrm{U} / \mathrm{mL}$ for 5 minutes) had no effect in improving adhesion of the cells. Bravenboer et al [27], suggested that integration of engineered cartilage constructs can be enhanced by enzymatic treatment of collagenase and hyaluronidase. They furthermore reported that treatment of these enzymes on the implanted tissue construct will increase the mechanical properties at the interface of engineered to host tissues. The same group had also previously showed that treatment with collagenase and hyaluronidase increased the cell density to the wound site [28]. Although there was significant increase in the integration strength of the implanted tissue model to native tissue using this dual enzymatic treatment, the reported values were $\sim$ seven times lower than the actual strength of intact cartilage to subchondral bone [27]. Nonetheless, enzymatic treatments may offer a very promising addition when used in conjunction with potential tissue integration strategies that utilize biological fixation methodologies.

\subsubsection{Signaling Pathway /Biochemical Approaches}

A blocking signaling pathway responsible for degrading tissue may indirectly promote the integration of the tissue engineered construct to native tissue. Recently Djouad et al [29], conducted experiments involving the blocking of the signaling pathway of extracellular regulated kinases (ERK). They found that disintegration of the extracellular matrix in native cartilage is aggravated by the degradative signaling cascades which were initiated by proinflammatory cytokines. Thus blockage of extracellular regulated kinases 1 and 2 were thought to improve the integration processes between engineered to host cartilage. 
Elsewhere [30,31], it was reported that interleukin $1-\beta($ IL1- $\beta)$ and tumor necrosis factor$\alpha(\mathrm{TNF}-\alpha)$ are two important factors that are mainly responsible for causing the extracellular matrix (ECM) degradation and that they stimulate the formation of ERK 1/2, a protein molecule which is responsible for cartilage degradation. Djouad et al [29], were successful in blocking IL1- $\beta$ and TNF- $\alpha$ signaling and subsequently were able to measure improved biochemical and mechanical properties at the interface of engineered cartilage and native tissue. However the de novo cartilage tissue as a whole had lower mechanical properties; for example, their control samples had a Young's modulus of 17.7- $5.5 \mathrm{kPa}$ while their samples treated with IL1-b- and TNF- $\alpha$ recorded values of 7.30-2.8 $\mathrm{kPa}$ and 11.5-1.7 $\mathrm{kPa}$, respectively. These results suggests that integration processes using signaling pathway alteration approaches may improve at the cost of deteriorated engineered tissue bulk mechanical properties. Overall, a variety of chemical-based approaches have been used, but none of them have been capable of achieving durable integration with native tissues. Thus the demand for strong and durable integration of the engineered implant to native tissues [24] may only be possible with biological fixation measures.

\subsection{Biological Fixation}

Biological fixation approaches serve to enhance integration of tissues by true biological ingrowth and amalgamation. Some of the techniques that are used have been categorized below.

\subsubsection{Chondroitin Sulphate}


The incapability of tissue adhesives to provide a stable and durable fixation over a period of time without causing any infection and maintaining the biocompatibility, particularly in the area of cartilage tissue engineering, led to integration studies involving multifunctional chondroitin sulphate [24]. Wang et al [24], reported that this material was chemically functionalized by two groups, methacrylate and aldehyde which can form a covalent bond to adhere to native cartilage on one side and the biomaterial scaffold on other side, thus

forming a strong primer between the host and engineered tissues [24]. They also suggested that the material was bioactive as chondroitin sulphate is a principal component of cartilage ECM which would thereby serve to augment tissue repair.

\subsubsection{Chitosan}

Chitosan is a polysaccharide which is biocompatible, biodegradable, non-toxic and allergen free. Chitosan has a hydrophilic surface which promotes both cell adhesion and proliferation [32]. Hoemann et al [33], indicated that Chitosan glycerol phosphate when mixed with blood in the cartilage defect space not only greatly improved integration with sub-chondral bone, but also resulted in enhanced hyaline cartilage tissue formation. However, chitosan has low strength [34], so it cannot be used alone in the fixation process.

\subsubsection{Hydroxyapatite}

Hydroxyapatite (HA) (or calcium phosphate) is a bioactive material found in the bone and teeth. A few research groups have been working on providing enhanced engineered cartilage to bone anchorage through the use of this bio active material $[35,52]$. One of the research group Lu et al [51], evaluated the potential of HA in alginate gel for regeneration of osteochondral interface and they were able to demonstrate successfully the formation of calcified cartilage like with the use of HA in their system. 
A summary of the different integration methods for engineered cartilage tissue constructs to bone, which were presented in this chapter, is described in Table 2.1:

Table 2.1: Summary of the advantages and disadvantages of different types of integration techniques [1-36]

\begin{tabular}{|c|c|c|c|}
\hline $\begin{array}{c}\text { Fixation } \\
\text { type }\end{array}$ & $\begin{array}{c}\text { Specific } \\
\text { approaches }\end{array}$ & Advantages & Disadvantages \\
\hline \multirow[t]{4}{*}{$\begin{array}{l}\text { Mechanical } \\
\text { Fixation }\end{array}$} & Sutures & $\begin{array}{l}\text { - Extensively used for } \\
\text { retaining construct with the } \\
\text { bone } \\
\text { - Inexpensive }\end{array}$ & $\begin{array}{l}\text { - Premature suture } \\
\text { Breakage } \\
\text { - Tearing of Tissue } \\
\text { engineered constructs }\end{array}$ \\
\hline & Screws & $\begin{array}{l}\text { - Help in retaining the } \\
\text { constructs with the bone }\end{array}$ & $\begin{array}{l}\text { - Protruding heads } \\
\text { leads to the tearing of } \\
\text { tissue and affects the } \\
\text { bone shear }\end{array}$ \\
\hline & Cross Pin & $\begin{array}{l}\text { - Thinner than screws and soft } \\
\text { heads } \\
\text { - prevents graft laceration }\end{array}$ & - Breakage \\
\hline & Staples & $\begin{array}{l}\text { - Most effective method for } \\
\text { mechanical fixation }\end{array}$ & $\begin{array}{l}\text { - Dislodgement of } \\
\text { staples after the } \\
\text { application of load. } \\
\text { - } \quad \text { Staple breakage } \\
\text { - } \quad \text { Staple pull out }\end{array}$ \\
\hline $\begin{array}{l}\text { Chemical } \\
\text { Fixation }\end{array}$ & Tissue Adhesives & - Durable & $\begin{array}{l}\text { - Some are not bio- } \\
\text { compatible } \\
\text { - They prevent the } \\
\text { epithelialization within } \\
\text { the damaged area and } \\
\text { connective tissue }\end{array}$ \\
\hline
\end{tabular}




\begin{tabular}{|c|c|c|c|}
\hline & & & $\begin{array}{c}\text { - They may cause } \\
\text { infection }\end{array}$ \\
\hline & $\begin{array}{l}\text { Enzymatic } \\
\text { treatment }\end{array}$ & $\begin{array}{c}\text { - promote integration between } \\
\text { the implant and the native } \\
\text { tissue }\end{array}$ & $\begin{array}{l}\text { - Alone this treatment } \\
\text { cannot provide enough } \\
\text { strength }\end{array}$ \\
\hline & $\begin{array}{l}\text { Biochemical } \\
\text { Approach }\end{array}$ & $\begin{array}{l}\text { - indirectly promote the } \\
\text { integration of the tissue } \\
\text { engineered constructs with } \\
\text { native tissue }\end{array}$ & $\begin{array}{l}\text { - They deteriorate } \\
\text { engineered tissue bulk } \\
\text { mechanical properties }\end{array}$ \\
\hline \multirow[t]{3}{*}{$\begin{array}{l}\text { Biological } \\
\text { Fixation }\end{array}$} & $\begin{array}{l}\text { Chondroitin } \\
\text { Sulphate }\end{array}$ & - Bioactive material & $\begin{array}{l}\text { Was not able to form a } \\
\text { strong force of } \\
\text { interaction between the } \\
\text { host and the tissue } \\
\text { engineered constructs }\end{array}$ \\
\hline & Chitosan & $\begin{array}{l}\text { - Biocompatible } \\
\text { - Biodegradable } \\
\text { - Allergy free } \\
\text { - Non toxic }\end{array}$ & - Low Strength \\
\hline & Hydroxyapatite & $\begin{array}{c}\text {-Bioactive material } \\
\text { - Help in the formation of deep } \\
\text { layer of cartilage from bone } \\
\text { marrow derived stem cells }\end{array}$ & $\begin{array}{c}\text { - Ceramic, may break } \\
\text { at a sudden load }\end{array}$ \\
\hline
\end{tabular}

In summary, current paradigms in cartilage tissue engineering do not sufficiently address the issue of integrating engineered construct to native host tissue. The different approaches relating to this critical area, which are mechanically, chemically or biologically driven, have been discussed in this chapter and these techniques alone have not been able to provide a durable integration with the host tissue and fixation in the defect area. 
Hence, the primary objective of the proposed research was to focus on the use of injectable polymers as a model system to assess integration processes and efficacy, leveraging a biological-fixation-based strategy. In line with other investigators [37, 38], my motivation for such an approach is that injectable approaches have the ability to introduce a monomer solution to fill arbitrarily-shaped defects while concomitantly incorporating any secondary substance; Polymerization (e.g. via UV exposure and photoinitiator inclusion) can then occur in situ [39].

For biological fixation we chose to experiment with hydroxyapatite nanoparticles in a photopolymerizable hydrogel system owing to its well-established osteoinductive properties The effects of hydroxyapatite incorporation were then assessed not only in the context of integration to bone, but also with healthy and disease cartilage tissues.

\subsection{References}

1. Matthews LS, Lawrence SJ, Yahiro MA, Sinclair MR.Fixation strengths of patellar tendon-bone grafts. Arthroscopy. 1993;9(1):76-81.

2. John B. Herrmann, Richard J. Kelly, George A. Higgins. Polyglycolic Acid Sutures. AMA Arch Surg. Vol. 100 No. 4 1970. P: 486-490. 
3. Field JR, Stanley RM. Suture characteristics following incubation in synovial fluid or phosphate buffered saline. Injury. 2004 Mar;35(3):243-8.

4. Mouzas GL, Yeadon A. Does the choice of suture material affect the incidence of wound infection? A comparison of dexon (polyglycolic acid) sutures with other commonly used sutures in an accident and emergency department. Br J Surg. 1975 Dec;62(12):952-5.

5. Nakajima M, Atsumi K, Kifune K, Miura K, Kanamaru H. Chitin is an effective material for sutures. Jpn J Surg. 1986 Nov;16(6):418-24.

6. Daniel B. Robertson, Dale M. Daniel, Edmund Biden. Soft tissue fixation of bone. Am J Sports Med. 1986;14(5):398-40.

7. Stengel D, Casper D, Bauwens K, Ekkernkamp A, Wich M. Bioresorbable pins and interference screws for fixation of hamstring tendon grafts in anterior cruciate ligament reconstruction surgery: a randomized controlled trial. Am J Sports Med. 2009 Sep;37(9):1692-8. Epub 2009 May 29.

8. Zantop T, Welbers B, Weimann A, Rümmler M, Hedderich J, Musahl V, Petersen W. Biomechanical evaluation of a new cross-pin technique for the fixation of different sized bone-patellar tendon-bone grafts. Knee Surg Sports Traumatol Arthrosc. 2004 Nov;12(6):520-7. Epub 2004 Jun 19.

9. Zantop T, Weimann A, Rümmler M, Hassenpflug J, Petersen W. Initial fixation strength of two bioabsorbable pins for the fixation of hamstring grafts compared to interference screw fixation: single cycle and cyclic loading. Am J Sports Med. 2004 Apr-May;32(3):641-9.

10. Shall LM, Cawley PW. Soft Tissue Reconstruction in the Shoulder. Am J Sports Med. 1994 Sep-Oct;22(5):715-8.

11. Hunziker, E. B. Articular cartilage repair: Basic science and clinical progress. A review of the current status and prospects. Osteoarthritis Cartilage. 2002 Jun;10(6):432-63.

12. Bruns TB, Worthington JM. Using tissue adhesive for wound repair: a practical guide to dermabond. Am Fam Physician. 2000 Mar 1;61(5):1383-8.

13. Coulthard P, Esposito M, Worthington HV, van der Elst M, van Waes OJ, Darcey J. Tissue adhesives for closure of surgical incisions. Cochrane Database Syst Rev. 2010 May 12;(5):CD004287. 
14. Leahey AB, Gottsch JD, Stark WJ. Clinical experience with N-butyl cyanoacrylate (Nexacryl) tissue adhesive. Ophthalmology. 1993 Feb;100(2):173-80.

15. Singer AJ, Hollander JE, Valentine SM, Turque TW, McCuskey CF, Quinn JV. Prospective, randomized, controlled trial of tissue adhesive (2-octylcyanoacrylate) vs standard wound closure techniques for laceration repair. Stony Brook Octylcyanoacrylate Study Group. Acad Emerg Med. 1998 Feb;5(2):94-9.

16. Woodward SC, Herrmann JB, Cameron JI, Brandes G, Pulaski EJ, Leonard F. Histotoxicity of cyanoacrylate tissue adhesive in the rat. Ann Surg. 1965 Jul;162:113-22.

17. Singer AJ. A review of the literature on octylcyanoacrylate tissue adhesive. Am J Surg. 2004 Feb;187(2):238-48.

18. Vote BJ, Elder MJ. Cyanoacrylate glue for corneal perforations: a description of a surgical technique and a review of the literature. Clin Experiment Ophthalmol. 2000 Dec;28(6):437-42.

19. Herget GW, Kassa M, Riede UN, Lu Y, Brethner L, Hasse J. Experimental use of an albumin-glutaraldehyde tissue adhesive for sealing pulmonary parenchyma and bronchial anastomoses. Eur J Cardiothorac Surg. 2001 Jan;19(1):4-9.

20. Mizrahi B, Weldon C, Kohane DS. Tissue Adhesives as Active Implants. Stud Mechanobiol Tissue Eng Biomater (2011) 8: 39-56.

21. Dunn CJ, Goa KL. Fibrin sealant: a review of its use in surgery and endoscopy. Drugs. 1999 Nov;58(5):863-86.

22. Kjaergard HK, Weis-Fogh US, Sørensen H, Thiis J, Rygg I. Autologous fibrin glue--preparation and clinical use in thoracic surgery. Eur $\mathrm{J}$ Cardiothorac Surg. 1992;6(1):52-4; discussion 54.

23. Lauto AA. Adhesive biomaterials for tissue reconstruction. Journal of chemical technology and biotechnology (1986). 2008 -04;83(4):464-72.

24. Wang DDA. Multifunctional chondroitin sulphate for cartilage tissue-biomaterial integration. Nature materials. 2007 -05;6(5):385-92.

25. Hunziker EB, Kapfinger E. Removal of proteoglycans from the surface of defects in articular cartilage transiently enhances coverage by repair cells. J Bone Joint Surg Br. 1998 Jan;80(1):144-50. 
26. Lee MC, Sung KL, Kurtis MS, Akeson WH, Sah RL. Adhesive force of chondrocytes to cartilage. Effects of chondroitinase ABC. Clin Orthop Relat Res. 2000 Jan;(370):286-94.

27. Van de Breevaart Bravenboer J, In der Maur CD, Bos PK, Feenstra L, Verhaar JA, Weinans $H$, van Osch GJ. Improved cartilage integration and interfacial strength after enzymatic treatment in a cartilage transplantation model. Arthritis Res Ther. 2004;6(5):R469-76. Epub 2004 Aug 6.

28. Bos PK, DeGroot J, Budde M, Verhaar JA, van Osch GJ: Specific enzymatic treatment of bovine and human articular cartilage: implications for integrative cartilage repair. Arthritis Rheum 2002, 46:976-985.

29. Djouad F, Rackwitz L, Song Y, Janjanin S, Tuan RS. ERK1/2 Activation Induced by Inflammatory Cytokines Compromises Effective Host Tissue Integration of Engineered Cartilage. Tissue Eng Part A. 2009 Oct;15(10):282535 .

30. Goldring MB, Berenbaum F. The regulation of chondrocyte function by proinflammatory mediators: prostaglandins and nitric oxide. Clin Orthop Relat Res. 2004 Oct;(427 Suppl):S37-46.

31. Lianxu C, Hongti J, Changlong Y. NF-kappaBp65-specific siRNA inhibits expression of genes of COX-2, NOS-2 and MMP-9 in rat IL-1beta-induced and TNF-alpha-induced chondrocytes. Osteoarthritis Cartilage. 2006 Apr;14(4):36776. Epub 2005 Dec 22.

32. Li Z, Ramay HR, Hauch KD, Xiao D, Zhang M.Chitosan-alginate hybrid scaffolds for bone tissue engineering. Biomaterials. 2005 Jun;26(18):3919-28.

33. Hoemann CD, Sun J, McKee MD, Chevrier A, Rossomacha E, Rivard GE, Hurtig M, Buschmann MD. Chitosan-glycerol phosphate/blood implants elicit hyaline cartilage repair integrated with porous subchondral bone in microdrilled rabbit defects. Osteoarthritis Cartilage. 2007 Jan;15(1):78-89. Epub 2006 Aug 8.

34. Madihally SV, Matthew HW. Porous chitosan scaffolds for tissue engineering. Biomaterials. 1999 Jun;20(12):1133-42.

35. Khanarian NT, Jiang J, Wan LQ, Mow VC, Lu HH. A Hydrogel-Mineral Composite Scaffold for Osteochondral Interface Tissue Engineering. Tissue Eng Part A. 2012 Mar;18(5-6):533-45. Epub 2011 Nov 8.

36. Dua R, Centeno J, Ramaswamy S. Enhanced Anchorage of Tissue Engineered Cartilage Constructs using Hydoxyapatite nanoparticles. Conference presentation at BMES Annual Meeting in Hartford, CT, October 12-15, 2011. 
37. Ramaswamy S, Gurkan I, Sharma B, Cascio B, Fishbein KW, Spencer RG. Assessment of tissue repair in full thickness chondral defects in the rabbit using magnetic resonance imaging transverse relaxation measurements. J Biomed Mater Res B Appl Biomater. 2008 Aug;86(2):375-80.

38. Toh WS, Lee EH, Guo XM, Chan JK, Yeow CH, Choo AB, Cao T. Cartilage repair using hyaluronan hydrogel-encapsulated human embryonic stem cellderived chondrogenic cells. Biomaterials. 2010 Sep;31(27):6968-80. Epub 2010 Jun 17.

39. Gutowska A, Jeong B, Jasionowski M. Injectable Gels for Tissue Engineering. Anat Rec. 2001 Aug 1;263(4):342-9. 


\section{Chapter 3}

\section{Relative survivability of different human cell types after exposure to photopolymerizable environments}

This chapter presents a study of the cellular cytotoxicity of five different human cell sources at different UV exposure times, with and without a commercially used photoinitiator. The work presented herein formed the foundation for subsequent protocols that were designed in conjunction with in vitro engineered tissue model systems for 
evaluating integration of engineered bone to engineered cartilage. This topic is presented in detail in chapter 4 of this dissertation. In particular, osteoblasts which are very sensitive to photopolymerizable environments were able to remain viable for longer durations under specific incubation temperature and biochemical conditions as described below.

\subsection{Abstract}

Photopolymerizable hydrogels offer great potential in cartilage tissue engineering due to their ability to conform to irregular defect shapes and be applied in a potentially minimally invasive manner. An important process requirement in the use of photopolymerizable hydrogels is the ability of the suspended cells to withstand low intensity ultraviolet light (UV) exposure (4-5 mW/ $\left.\mathrm{cm}^{2}\right)$ and photoinitiator concentrations. For cartilage integration with underlying subchondral bone tissue, robust localized osteoblast activity is necessary. Yet, while it is known that osteoblasts do not respond well to UV light, limited work has been conducted to improve their survivability. In this study, we evaluated the cellular cytotoxicity of five different human cell sources at different UV exposure times, with and without a commercially used photoinitiator. We were able to confirm that human osteoblasts were the least tolerant to varying

UV exposure times in comparison to bone marrow stem cell, periodontal ligament cell, smooth muscle and endothelial cell lineages. Moreover osteoblasts cultured at $39{ }^{\circ} \mathrm{C}$ did not deteriorate in terms of alkaline phosphatase expression or calcium deposition within the extracellular matrix (ECM), but did reduce cell proliferation. We believe however that the lower proliferation diminished osteoblast sensitivity to UV and the photoinitiator. In fact, the relative survivability of osteoblasts was found to be augmented by the combination of a biochemical factor and an elevated incubation temperature; specifically, the use of 50 
$\mathrm{mg} / \mathrm{L}$ of the anti-oxidant, ascorbic acid significantly $(\mathrm{P}<0.05)$ increased the survivability of osteoblasts when cultured at $39{ }^{\circ} \mathrm{C}$. We conclude that ascorbic acid at an incubation temperature of $39{ }^{\circ} \mathrm{C}$ can be included in in vitro protocols used to assess cartilage integration with bone ECM. Such inclusion will enhance conditions of the engineered tissue model system in recapitulating in vivo osteoblast activity.

Keywords: Cytotoxicity, osteoblasts, ascorbic acid, photoinitiator, photopolymerizable hydrogels

\subsection{Introduction}

Tissue engineering has been emerging as the potential approach to restoring and enhancing tissue or organ function in the health care industry $[1,2]$. In the musculoskeletal arena, photopolymerizable hydrogel approaches are thought to offer several advantages, namely that the geometry of defects to be filled with de novo tissue can be arbitrary, delivery may be carried out via injection [3] thus permitting minimal invasiveness and finally, hydrogel 
materials are considerably less expensive than biodegradable fibrous scaffolds thus presenting a more cost effective procedure. In brief, a polymer mixture in monomer form is prepared, with a very low concentration of photoinitiator $(0.02$ to $0.05 \% \mathrm{w} / \mathrm{v})$ [4]; cells are suspended within the solution and the mixture is subsequently injected into the repair site. Next, the monomer solution is exposed to ultraviolet light (UV) at low intensity (4$5 \mathrm{~mW} / \mathrm{cm}^{2}$ ) during which free radicals initiate polymerization [5]. Despite their critical function, the highly mobile free radicals cause a number of adverse effects such as damage to extracellular proteins as well as cell apoptosis and necrosis events $[6,7,8]$.

Our long term goal is to provide better anchorage and fixation between tissue engineered cartilage and the underlying subchondral bone for the treatment of mild to modest osteoarthritis, using a reliable engineered tissue model system for bone and cartilage. This system requires a reasonable degree of survivability of osteoblasts so that integration can occur. Previous experiments including our own experience suggests that osteoblasts ordinarily do not survive well under combined ultraviolet light and photoinitiator environments [90]. This may explain the limited success that has been achieved thus far in co-relation of in vitro to in vivo results and the successful integration of engineered cartilage to bone in vitro [10].

Cartilage integration involves the following two challenges: first, the scaffold that is used initially must be harmonized in the joint; secondly, the ensuing developing tissue must anchor with the underlying bone to provide a strong fixation. We note that none of the existing techniques in cartilage tissue engineering have been able to restore a sustained articular surface because subchondral bone integration to de novo cartilage tissue via osteoblast activity at the interface has to date, not been sufficiently addressed [11]. Thus, 
the main objective of this study was to determine how the detrimental effects of photopolymerization parameters to human osteoblast survivability could be minimized while still permitting sufficient gelation. Primarily, these parameters were ultraviolet light (UV) exposure time and photoinitiator concentration. In addition, we included in this effort, four additional human cell sources as a means of comparison. Since our focus was targeted on osteoblasts which are traditionally known to be cultured at relatively lower temperatures $\left(34^{\circ} \mathrm{C}\right)$ [12], we also examined the role of in vitro temperature incubation on osteoblast viability. Finally, we focused our efforts on the utility of the antioxidant, ascorbic acid on augmenting the survivability of the osteoblasts.

\subsection{Material and Methods}

\subsubsection{Cell Culture}

Five different cell lines were culture expanded and comparatively evaluated as a function of varying UV intensities and photoinitiator concentrations:

\subsubsection{Human Bone marrow derived Mesenchymal Stem Cells (HBMSCs)}

HBMSCs are a well characterized population of adult stem cells that can differentiate into other cell lines to produce cartilage, bone, fat and muscle tissue. HBMSCs (Science cell, Carlsbad, CA, USA) were seeded onto Poly D-lysine coated T-75 flasks (Fisher Scientific, Pittsburg, PA, USA). The cells were cultured until passage 3 (P3) in low glucose media (Dulbecco's modified eagle medium, (DMEM), Invitrogen, Grand Island, NY, USA) supplemented with $10 \%$ fetal bovine serum ((FBS), ATCC, Manassas, VA, USA ) and 1\% penicillin-streptomycin (ATCC). 


\subsubsection{Human Pulmonary Artery Endothelial Cells (HPAEC)}

HPAECs (Fisher Scientific) were seeded in T-75 flasks with proprietary endothelial cell growth medium (Fischer Scientific) and culture expanded to P4.

\subsubsection{Human Pulmonary Artery Smooth Muscle Cells (HPASMC)}

Human Pulmonary Artery Smooth Muscle Cells (HPASMC) (Genlantis, San Diego, CA, USA ) were cultured (up to P4) in T-75 flasks (Fisher Scientific) in proprietary smooth muscle cell growth medium (Genlantis).

\subsubsection{Human Osteoblasts (hFOB)}

Human Osteoblasts (hFOB 1.19) (ATCC) were cultured (passage number was not provided by the depositor) in basal media (Invitrogen) supplemented with 10\% FBS (ATCC), $1 \%$ Penstrep (ATCC) and $0.3 \mathrm{mg} / \mathrm{ml}$ of an aminoglycoside antibiotic (Sigma Aldrich, St Louis, MO, USA)

\subsubsection{Human periodontal ligament cells (HPDLCs)}

HPDLCs (P3) were received as a gift from the University of Miami, FL (Dr. Herman Cheung). The cells were cultured in basal media (up to P3) supplemented with 10\% FBS (ATCC), 1\% Penstrep (ATCC).

\subsubsection{Effect of UV light at different exposure times}

In order to study the effect of UV exposure times on the cells, a cell solution $\left(10^{5}\right.$ cells $\left./ \mathrm{ml}\right)$ was prepared for each cell type; $200 \mu 1$ was subsequently placed in each well of a 96 tissue culture well plate providing a final density of 20,000 cells/ well. Cells ( $\mathrm{N}=4$ /group) were exposed to $4-5 \mathrm{~mW} / \mathrm{cm}^{2}$ of long wave unfiltered UV light $(365 \mathrm{~nm})$ for time durations of 0 , 
$5,10,15$ and 20 minutes. These time intervals were chosen to provide adequate dynamic range of exposure times. After exposing the wells to different time intervals, the plates were incubated at $37{ }^{\circ} \mathrm{C}$ and $5 \% \mathrm{CO}_{2}$ humidified environment for 2 days.

\subsubsection{Effect of Photoinitiator concentration on different cell lines}

We used the commercially available photoinitiator, Irgacure 2959 (BASF Corporation, Florham Park, New Jersey, USA) given its extensive usage in tissue engineering research studies $[13,14]$, and it's relatively less toxic effect on cells. [8,9]. Three concentrations were prepared: $0,0.03 \%$ and $0.05 \mathrm{w} / \mathrm{v}$ ratios. Briefly, $50 \mathrm{mg}$ and $100 \mathrm{mg}$ of Irgacure 2959 were dissolved in $1 \mathrm{ml}$ of $70 \%$ ethanol solution. The contents were sterilized using $0.2 \mu \mathrm{m}$ syringe filters and subsequently, $6 \mu 1 / \mathrm{ml}$ and $5 \mu 1 / \mathrm{ml}$ of the solutions were added into $1 \mathrm{ml}$ of cell solution respectively to give the eventual desired $\mathrm{w} / \mathrm{v}$ ratios of $0.03 \%$ and $0.05 \%$. Cells were seeded in the 96 well plate as described in the UV exposure experiments $(\mathrm{N}=$ 4/group). The two different concentrations of photoinitiator were added in each of the respective groups and placed in an incubator for 2 days. Cells without photoinitiator exposure served as controls.

\subsubsection{Combined effects of UV exposure times and Photoinitiator concentration}

The five different cell lines (BMSCs, HPAEC, HPASMC, hFOB 1.19, PDLCs ) were exposed to combined Photoinitiator $(0.05 \% \mathrm{w} / \mathrm{v}$ ratio) and long wave UV light for different time durations of $0,5,10,15$ and 20 minutes. Well plates were housed in an incubator for 2 days to permit cell growth.

\subsubsection{Effect of incubation Temperature}

We assessed the effect of incubator temperature on osteoblasts owing to the sensitivity of this cell type to this parameter. Osteoblasts were cultured in three 96 well plates. Wells in 
the 96 well plate were grouped into 4 wells and each group was treated with both UV light exposure of 10 minutes and photoinitiator concentration as $0.05 \% \mathrm{w} / \mathrm{v}$ ratio. The wells without any treatment $(\mathrm{N}=4)$ acted as control. All samples were kept at 3 different incubation temperatures of $34^{\circ}, 37^{\circ}$ and $39^{\circ} \mathrm{C}$ for 48 hours and maintained at $5 \% \mathrm{CO}_{2}$ in a humidified environment.

\subsubsection{Effect of temperature on the osteoblast phenotype}

\subsection{Alkaline Phosphatase Activity}

The matrix maturation phase of osteoblasts is characterized by maximal expression of alkaline phosphatase (ALP) and once the mineralization is complete in the matrix, calcium deposits can be visualized in the extracellular matrix (ECM). In order to assess ALP activity ( $\mathrm{n}=3$ samples/group), osteoblasts were plated using the same media conditions as before (section 1.1 ) at $37^{\circ} \mathrm{C}$ and $39^{\circ} \mathrm{C}$, via a colorimetric based assay (Abcam, Cambridge, MA, USA). After 3 days of culture, 20,000 cells were taken for each sample and were lysed in $100 \mu 1$ of assay buffer. Lysed cells were subsequently centrifuged at 13,000 g for 3 minutes to remove the insoluble material. $30 \mu 1$ of sample was taken in replicates of 3 for each sample in 96 well plates. Next, $50 \mu 1$ of sample of assay buffer was added to make a net volume of $80 \mu \mathrm{l}$ in the wells. In addition, background samples were made by taking 30 $\mu 1$ of test samples, and adding $50 \mu 1$ of assay buffer and $20 \mu 1$ of stop solution. Thereafter, $50 \mu$ of $5 \mathrm{mM}$ p-nitrophenyl phosphate solution was added to each well containing the test samples and background samples. The samples were covered to prevent exposure to light and the reaction and held at $25^{\circ} \mathrm{C}$ for $1 \mathrm{hr}$. Next the reaction was halted by the addition of $10 \mu 1$ stop solution (Abcam) to each well (except to the background samples) and gently 
shaken. The optical density was measured per manufacturer instructions using a microplate reader (wavelength of $405 \mathrm{~nm}$; model Synergy HT, Biotek Instruments, Winooski, VT).

\subsection{Calcium Distribution}

As an indicator of the osteoblast maturation process during cell culture, sample calcium mineral distribution was evaluated using von-Kossa histological staining (IHCWORLD, Woodstock, MD, USA). In brief, 20,000 cells/ml were grown on chamber slides (Fisher Scientific) and kept at the two different temperatures $\left(37^{\circ} \mathrm{C}\right.$ and $\left.39^{\circ} \mathrm{C}\right)$ using the same media conditions as before (section 1.1). After 3 days the slides were washed with phosphate buffered solution and were fixed with 10\% formalin (Fisher Scientific). Finally, the von-Kossa stain (IHC world, Woodstock, MD, USA) was applied by treating the slides with silver nitrate solution and exposing them to UV light for 1 hour, which served to highlight spatial locations of calcium deposits in the specimens.

\subsubsection{Effect of using anti-oxidants}

In order to assess the benefits of anti-oxidant incorporation on osteoblast survival rate, we used $50 \mathrm{mg} / \mathrm{ml}$ of ascorbic acid in our cell culture system. Photoinitiator concentrations of $0.05 \% \mathrm{w} / \mathrm{v}$ ratio were added into the selected wells. Ascorbic acid was added to the wells $(\mathrm{N}=4)$ and exposed to long wave UV light for 10 minutes. Plates were incubated at three different temperatures of $34^{\circ} \mathrm{C}, 37^{\circ} \mathrm{C}$ and $39^{\circ} \mathrm{C}$ for 2 days

\subsubsection{Cytotoxicity evaluation using sulforhodamine B (SRB) assay}

At the conclusion of each of the aforementioned experiments, a sulforhodamine B (SRB) assay (Sigma Aldrich) was performed to access cytotoxic effects of UV exposure times and photoinitiator concentrations on the different cells. The SRB assay is a measure of cell 
cytoxicity as a function of proliferation rate of the surviving cells. The assay was performed similar to assays conducted previously [15]. In brief, the assay is based on the measurement of viable cellular protein content in the cells colorimetrically [16]. Cells were first fixed to the bottom of a well plate with $10 \%(\mathrm{wt} / \mathrm{vol})$ trichloroacetic acid. After the cells were fixed, Sulforhoda-mine-B (SRB) dye was added for cell staining at a concentration of $0.4 \%$ $(\mathrm{wt} / \mathrm{vol})$ which bound to viable cellular proteins. Next, $1 \%$ (vol/vol) acetic acid was used to remove the unbound SRB dye. $10 \mathrm{mM}$ Trizma-base was used then to extract the protein bound SRB. The optical density (OD) of the dye was measured [17] at $565 \mathrm{~nm}$ wavelength using a micro plate reader (Biotek, Winooski, VT). Comparisons were made between control and treated samples. A higher OD value would translate to increased cell proliferation. Cell cytotoxicity was reported based on "Relative Survival" which was determined from the absorbance values ( $\mathrm{n}=4$ samples/group) measured. For reporting purposes, a normalization process was carried out similar to previous studies [9]. In brief, results were normalized such that the average absorbance of the control groups was equal to one; first, the average absorbance of the background wells that contained only the specific cell culture medium and the SRB dye were subtracted from each of the individual absorbance values. Next, normalization was performed by dividing each of the absorbance values by the average absorbances of the corresponding control group of cells, without any exposure to UV and photo initiator, but otherwise grown under identical culture conditions.

\subsubsection{Statistical Analysis}

Statistical analysis was performed using commercially available software (SPSS, IBM, version 20, Armonk, New York, USA). A one way ANOVA and post-hoc Tukey test was 
used to determine statistical significance $(\mathrm{P}<0.05)$ between groups in all experiments conducted.

\subsection{Results}

\subsubsection{Effect of UV light at different exposure times}

The human cell sources investigated showed altered viability after exposures to UV light $\left(4-5 \mathrm{~mW} / \mathrm{cm}^{2}\right)$ (Fig. 3.1). The periodontal ligament cells were the most resistant to UV exposure. On the other hand, the Osteoblast survival rate considereably decreased, particularly after $>10$ minutes of UV exposure.

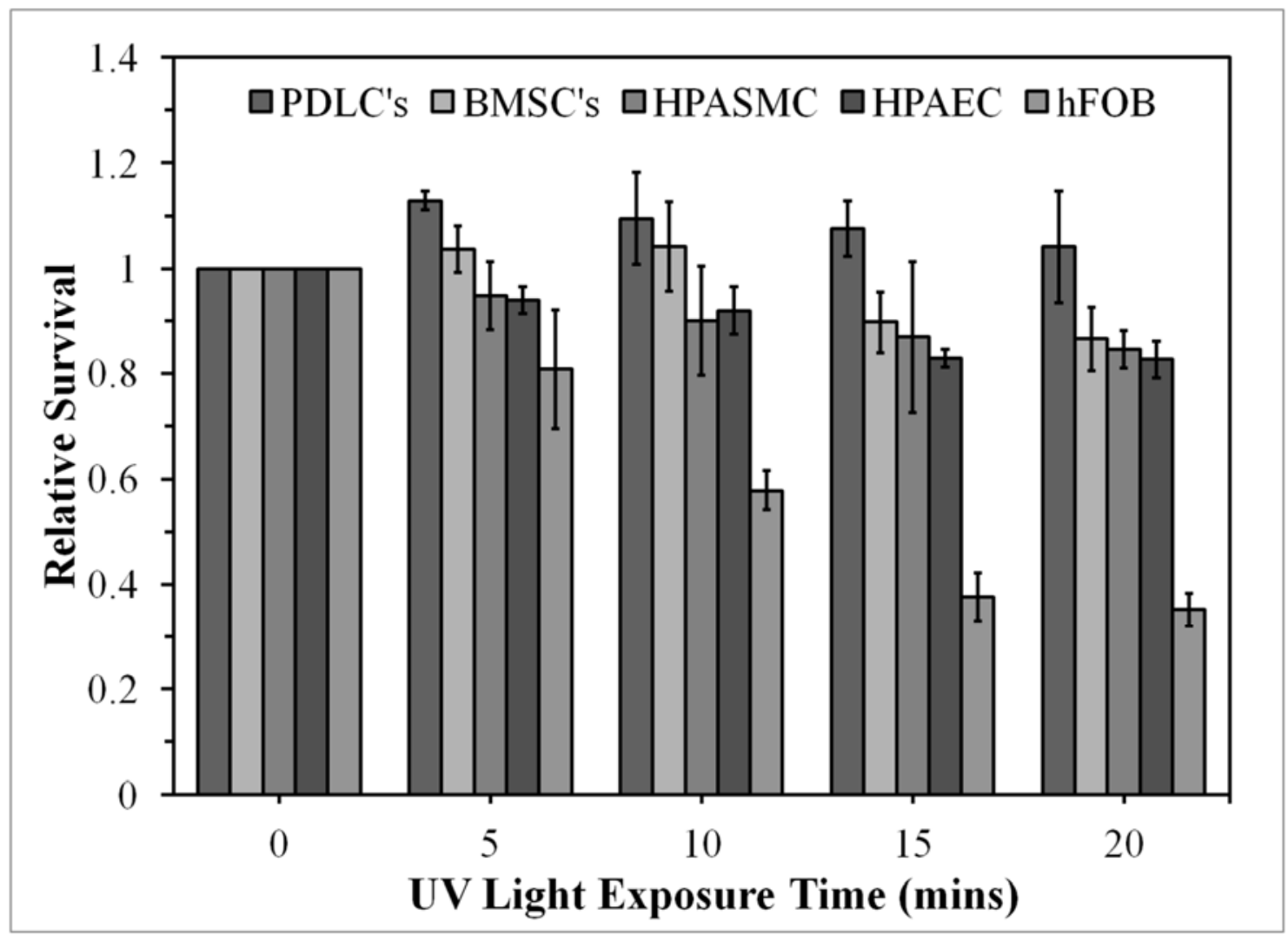


Figure 3.1: Cell toxicity results for different human cell sources after different UV exposure times. Cells were incubated at $37{ }^{\circ} \mathrm{C}$

\subsubsection{Effect of Photoinitiator Concentration}

Fig. 3.2 demonstrates the survival rate of 5 different cell lines with different concentrations of photoinitiator (irgacure 2959; $0,0.03 \%$ and $0.05 \%$ ) and without UV exposure. In general, the effect of photoinitiator alone had little effect on the different cell types.

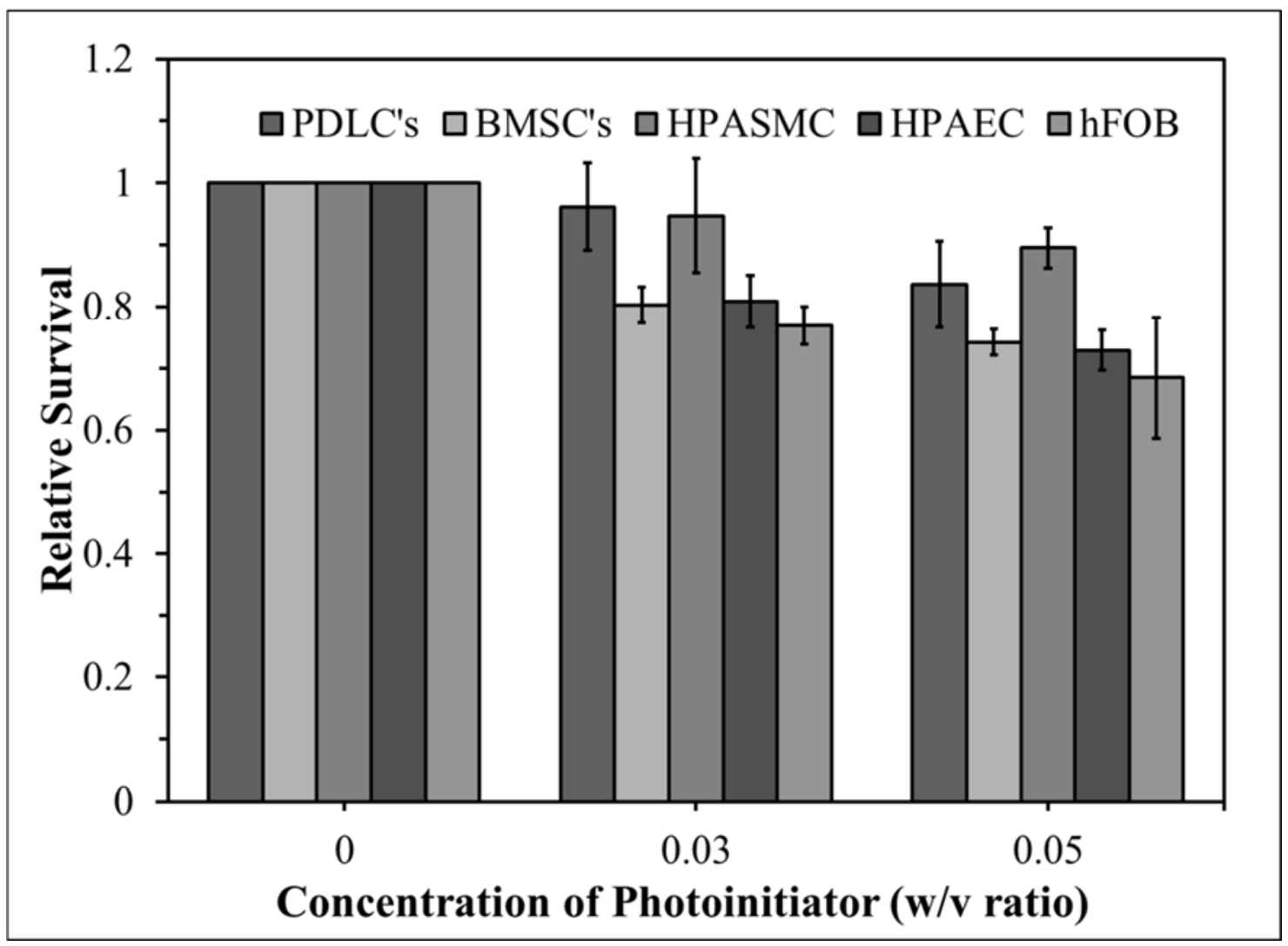

Figure 3.2 Cell toxicity results for different human cell sources incubated at $37^{\circ} \mathrm{C}$ for 48 hours after exposure to different photoinitiator concentrations

\subsubsection{Combined effect of UV exposure and Photoinitiator}

The effect of combined UV exposure and a photoinitiator concentration of $0.05 \%(\mathrm{w} / \mathrm{v})$ were assessed. This amount of photoinitiator concentration was chosen as it is very commonly used and reported in the literature $[13,14,18]$. The general trend was that of 
exaggerated decrease in survivability in all five cell types studied (Fig. 3.3) in comparison to UV exposure alone (Fig. 3.1). Our findings further suggested that osteoblasts cells were the least tolerant to the combined effect of UV light and Photoinitiator, ranging at $\sim 17 \%$ for 10 minutes of UV exposure and only $6 \%$ at 20 minutes.

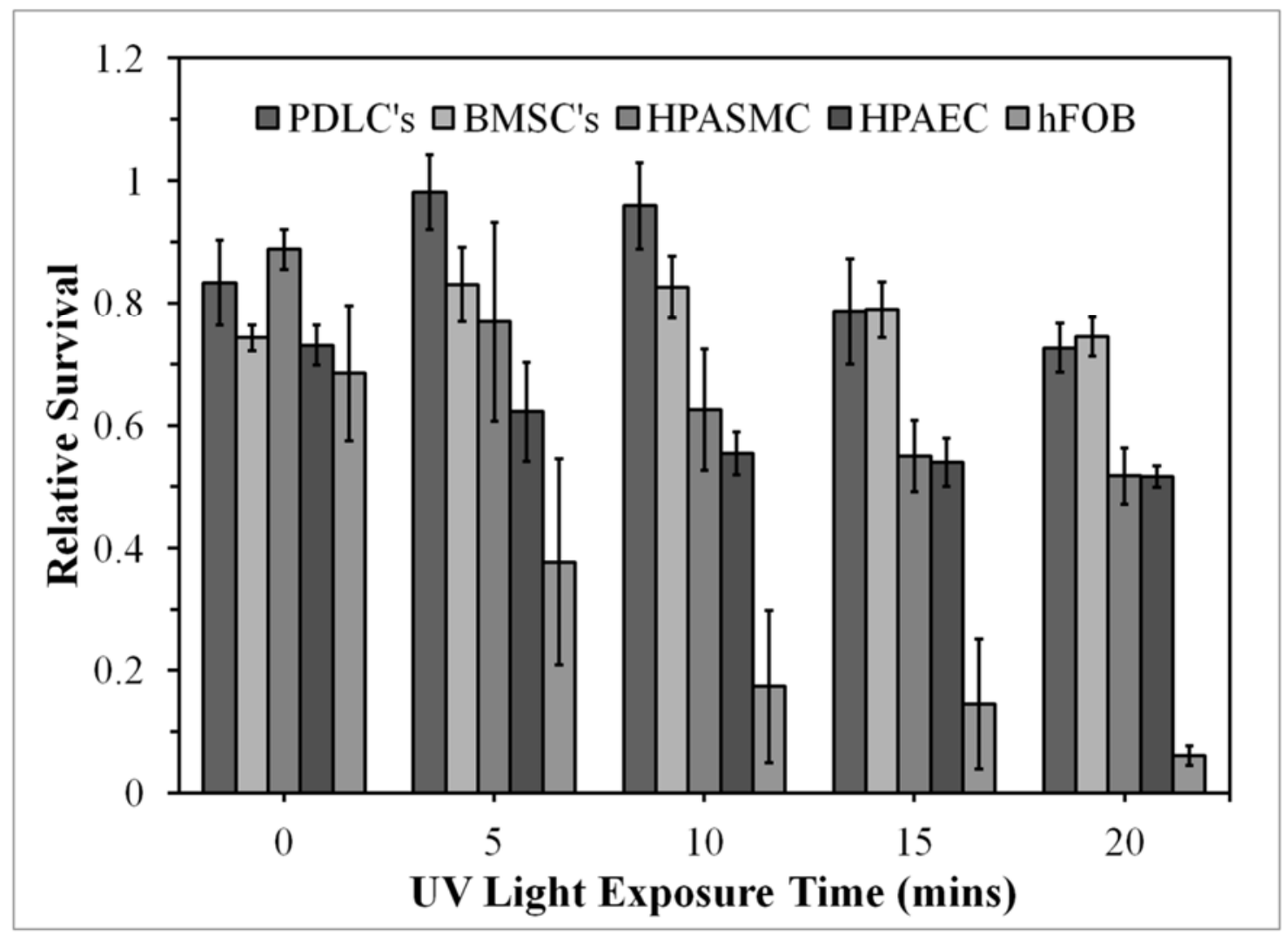

Figure 3.3: Cell toxicity results for different human cell sources after exposure to different UV exposure time concentrations and a fixed photoinitiator concentration of $0.05 \%(\mathrm{w} / \mathrm{v})$.Cells were incubated at $37{ }^{\circ} \mathrm{C}$. Note that osteoblast relative survivability was significantly reduced $(\mathrm{P}<$ $0.05)$ at all UV exposure times shown in comparison with all the other cell types that were investigated

\subsubsection{Effect of incubation temperature}

After obtaining baseline information on the variability of osteoblast viability on UV exposure times and photoinitiator concentrations in comparison to other human cell sources, we proceeded to focus on further improving osteoblast survivability within the 
framework of commonly utilized parameters in injectable photopolymerizable hydrogels. Namely these were UV exposure times of 10 minutes and a photoinitiator concentration of $0.05 \%(\mathrm{w} / \mathrm{v})[14,18,19]$. We speculate that these numbers were chosen not only to ensure sufficient live cell numbers, but also to ensure sufficient gelation of the hydrogels. Human osteoblast survivability under these conditions was approximately $17 \%$. These experiments were conducted at $37 \mathrm{oC}$ and we proceeded to augment it to $39 \mathrm{oC}$. At this higher temperature, a 5\% increase in osteoblast survivability was observed (Fig. 3.4)

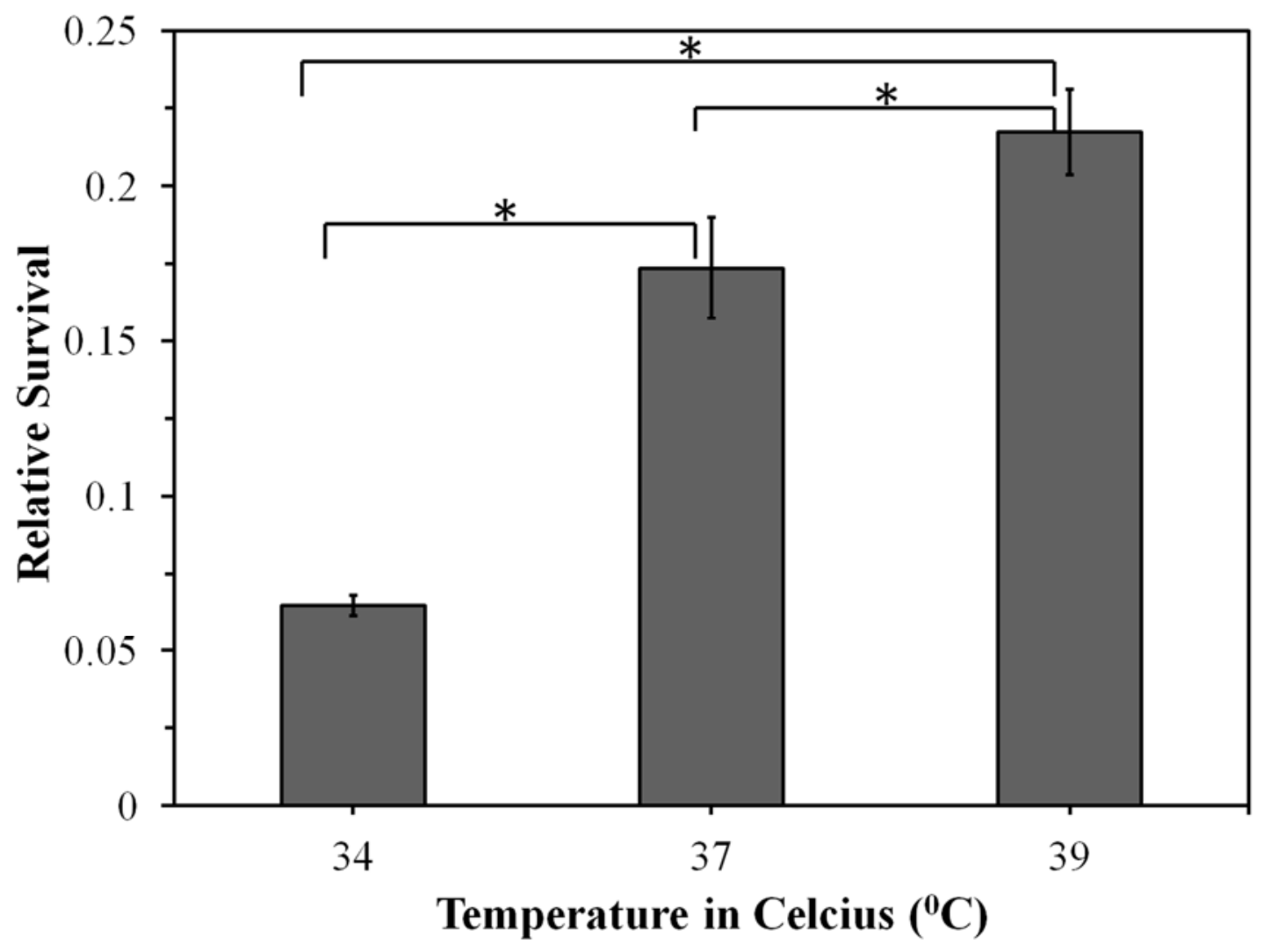

Figure 3.4: Cell toxicity results for human osteoblasts as a function of incubator temperature. Cells were exposed for a total of 10 minutes under UV light and using a fixed photoinitiator concentration of $0.05 \%(\mathrm{w} / \mathrm{v})$. The "**" indicates that the difference between the groups was statistically significant $(\mathrm{P}<0.05)$. 


\subsubsection{Effect of Adding Ascorbic Acid}

When, $50 \mathrm{mg} / \mathrm{L}$ of ascorbic acid was added to the cultured cells, incubated at $39^{\circ} \mathrm{C}$, we found that the osteoblast viability improved to $~ 34 \%$, an increase of $13 \%$ in comparison to cultures grown at identical conditions but without the antioxidant (Fig 3.5). The differences in normalized relative survivability (mean \pm standard deviation) for osteoblasts culture with and without ascorbic acid antioxidant at $39^{\circ} \mathrm{C}$ incubation temperature was found to be significant $(\mathrm{P}<0.05)$ (Table 3.1).

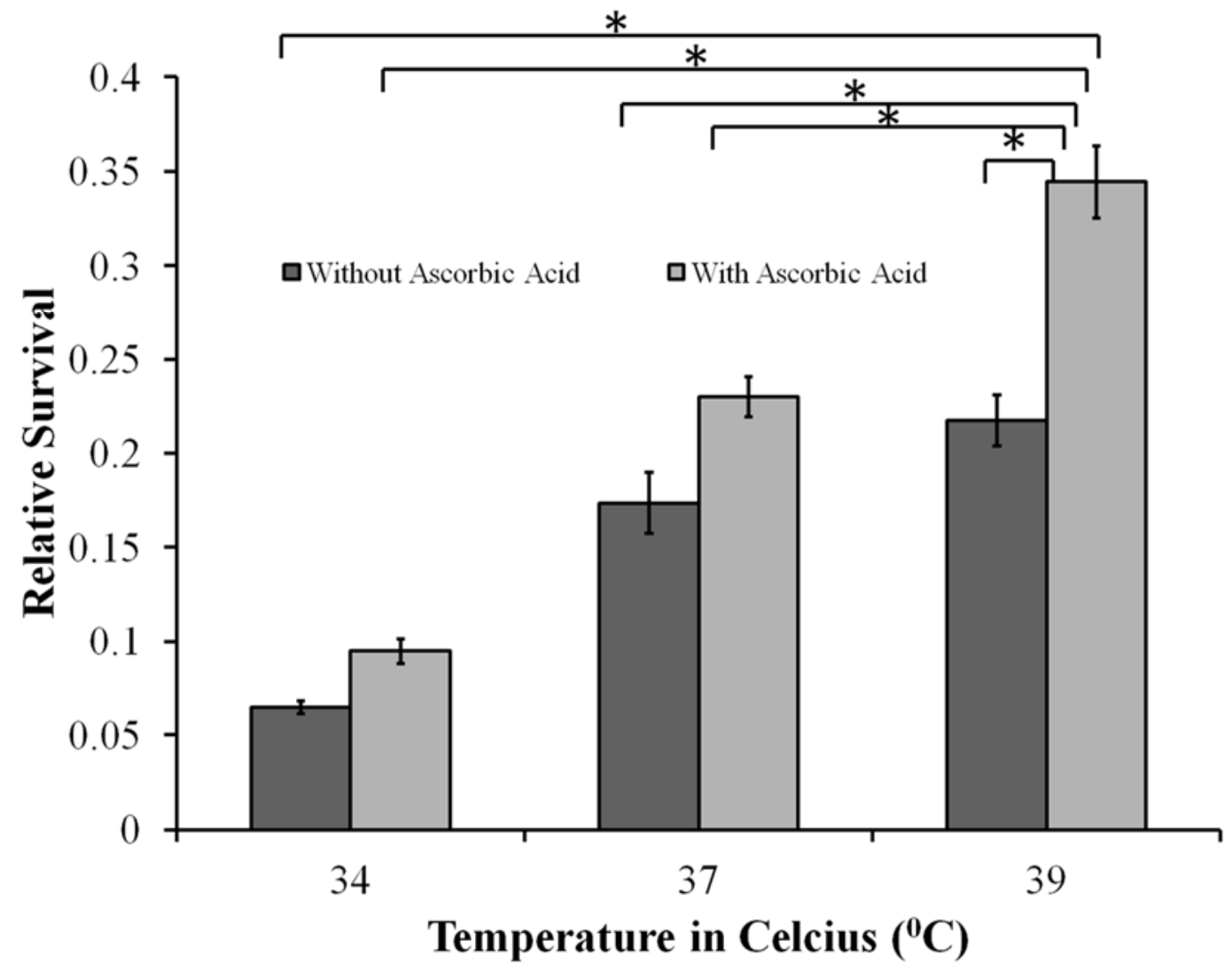

Figure 3.5: Survivability of osteoblasts with and without ascorbic acid. The "*” indicates that the difference between the groups was statistically significant $(\mathrm{P}<0.05)$ 
Table 3.1: Osteoblast Relative Survivability with and without Ascorbic Acid antioxidant at $37^{\circ} \mathrm{C}$ and $39^{\circ} \mathrm{C}$ incubation temperatures

\begin{tabular}{|l|l|l|}
\hline $\begin{array}{c}\text { Groups exposed to } \mathbf{0 . 0 5 \%} \text { w/v photoinitiatior concentration and } \\
\mathbf{1 0} \text { minutes of UV exposure; (n= } \mathbf{4} \text { samples/group) }\end{array}$ & Average & $\begin{array}{l}\text { Standard } \\
\text { deviation }\end{array}$ \\
\hline 37 degrees alone & 0.17 & 0.02 \\
\hline 37 degrees + ascorbic acid & 0.23 & 0.01 \\
\hline 39 degree alone & 0.22 & 0.01 \\
\hline 39 degree + ascorbic acid & 0.34 & 0.02 \\
\hline
\end{tabular}

\subsection{Discussion}

In the past decade considerable efforts have focused on utilizing polymerizable scaffolds for tissue engineering [20, 21, 22, 23, 24]. In this context, the effects of UV exposure and photoinitiator concentrations on cell viability have always been a concern, but none more so than for osteoblasts which are extremely sensitive to ultraviolet light [9]. Accordingly, we attempted to augment the survivability of human osteoblasts in these environments by exploring additional variables, namely, a higher incubation temperature and incorporation of the antioxidant, ascorbic acid. These changes may serve to improve photopolymerizable approaches in bone tissue engineering and outcomes related to nativeengineered tissue integration approaches [24, 25]. In this regard, on-going research efforts in our laboratories are specifically attempting to target an approach to more successfully integrate subchondral bone to tissue engineered cartilage constructs.

Osteoblasts were significantly reduced in survivability $(\mathrm{P}<0.05)$ compared to all the other four human cell types (PDLCs, HPASMCs, HPAECs and BMSCs) investigated at all-time durations of UV exposure $(5,10,15$ and 20 minutes) when in concomitant 0.05 $\% \mathrm{w} / \mathrm{v}$ photoinitiator environments. These results confirmed that human osteoblasts were 
considerably more prone to cell necrosis under combined UV light exposure and photo initiator concentrations. When osteoblasts were exposed to commonly utilized parameters of 10 minutes of UV exposure and a $0.05 \%(\mathrm{w} / \mathrm{v})$ concentration of photoinitiator (Irgacure 2959, BASF Corporation, Florham Park, New Jersey), contrary to reports of using a relatively low incubation temperature of $34{ }^{\circ} \mathrm{C}$ for rapid cell division $[26,27]$ in our case, this lower temperature actually decreased cell viability. In fact, we were able to further ameliorate osteoblast survivability under these environments (combined 10 minutes of UV exposure and $0.05 \%(\mathrm{w} / \mathrm{v})$ photoinitiator concentration) at an elevated temperature of 39 ${ }^{\circ} \mathrm{C}$, suggesting thus, that for photopolymerization studies, osteoblasts require relatively higher, rather than reduced incubation temperatures. We proceeded to conduct statistical analysis on temperature effects of osteoblast survivability and noted that temperature alone at $39^{\circ} \mathrm{C}$ augmented the cellular viability significantly $(\mathrm{P}<0.05)$ in comparison to lower incubation temperatures $\left(34^{\circ} \mathrm{C}\right.$ and $\left.37^{\circ} \mathrm{C}\right)$ (Fig.3.4). This result illustrates the importance of this elevated temperature as a singular independent entity in promoting osteoblast viability. Meanwhile, anti-oxidation effects of ascorbic acid minimized free radical toxicity effects during UV polymerization and was found to be consistent with use of ascorbic acid elsewhere $[28,29,30]$. When ascorbic acid was combined with incubation temperatures at $39^{\circ} \mathrm{C}$, osteoblast survivability was further enhanced significantly $(\mathrm{P}<0.05)$, (Fig. 3.5); (normalized average \pm standard deviation ( $\mathrm{n}=4$ samples/group) osteoblast survivability for: i) $37^{\circ} \mathrm{C}$ without ascorbic acid: $0.17 \pm 0.02$ ii) ascorbic acid at $37^{\circ} \mathrm{C}: 0.23 \pm 0.01$, iii) elevated temperature of $39^{\circ} \mathrm{C}$ without ascorbic acid: $0.22 \pm 0.01$, iv) ascorbic acid at $39^{\circ} \mathrm{C}$ : $0.34 \pm 0.02$ ). We speculate that the increased osteoblast survivability at the higher temperature of $39^{\circ} \mathrm{C}$ can be attributed to a reduction in the proliferation rate of the cells. 
For example, Williams et al [9] showed that higher proliferation rates caused greater cell susceptibility to toxic components in photopolymerization environments (i.e., (UV and photoinitiator) and thereby resulted in decreased cellular viability. Interestingly, use of either ascorbic acid or the $39{ }^{\circ} \mathrm{C}$ incubation temperature promoted roughly the same level of osteoblast survivability. However, we have for the first time demonstrated that the combined effects of ascorbic acid at a concentration of $50 \mathrm{mg} / \mathrm{L}$ and an elevated incubation of $39^{\circ} \mathrm{C}$ significantly improves $(\mathrm{P}<0.05)$ augmentation of osteoblast survival versus using only one of either of these two parameters (Fig. 3.5).

Under these conditions, although the UV and photoinitator environments still considerably reduce human osteoblast survivability (owing to the innate sensitivity of osteoblasts to any changes to in vitro culture parameters) [9] in comparison to controls grown in more standard environments, we note that we still were able to maintain $\sim 34 \%$ survivability; this is considerably greater than other osteoblast groups in our studies, as well as those that have been reported elsewhere [9]. In addition, we note that average osteoblast-like cell densities in osteoinductive environments are in the order of roughly $240,000 \mathrm{cells} / \mathrm{cm}^{2}$ [310] whereas photopolymerizable tissue engineering studies use 850,000 cells $/ \mathrm{cm}^{2}[32,33]$. Even though $850,000 \mathrm{cells} / \mathrm{cm}^{2}$ is closer to the higher end of amounts typically used, the $34 \%$ reduction $\left(290,000\right.$ cells $\left./ \mathrm{cm}^{2}\right)$ is still the same order of magnitude as osteoblast-like cell densities $\left[240,000 \mathrm{cell} / \mathrm{s} / \mathrm{cm}^{2},[31]\right.$ thought to be indicative of heightened osteoblast activity. Thus, in spite of the greater sensitivity of osteoblasts to UV exposure time and photoinitiator concentrations, the addition of ascorbic acid during $\mathrm{UV}$ and photoinitiator exposure at an incubation temperature of $39^{\circ} \mathrm{C}$ would retain sufficient live osteoblast numbers that in turn, would allow for an elevated level of cellular 
activity (e.g. such as osteoinduction). We noted however that an incubation temperature of $39{ }^{\circ} \mathrm{C}$ could potentially aggravate osteoblast ALP-activity and/or ECM-mineral distribution, and thus, we proceeded to look at Alkaline Phosphatase (ALP) expression and the presence of calcium deposits at $37{ }^{\circ} \mathrm{C}$ versus $39{ }^{\circ} \mathrm{C}$. We determined that ALP expression (Average \pm standard deviation; $\mathrm{n}=3$ samples/group) was in the order of $2.26 \pm$ $0.12 \mathrm{U} / \mathrm{ml}$ and $2.00 \pm 0.06 \mathrm{U} / \mathrm{ml}$ for cells cultured at $37{ }^{\circ} \mathrm{C}$ versus $39{ }^{\circ} \mathrm{C}$ for 3 days. We believe that the relatively lower expression at $39^{\circ} \mathrm{C}$ is due to the lower proliferation rate of the osteoblasts that we observed during the cell culture studies at this temperature. However the expression magnitudes at both temperatures are comparable to literature reports for ALP activity from osteoblasts that underwent similar (but not identical) cell culture, and which was found to be in the order of $2.23 \pm 0.14 \mathrm{U} / \mathrm{ml}$ [34]. Overall therefore, we believe our findings for osteoblasts cultured at $39^{\circ} \mathrm{C}$ while relatively lower than that at $37^{\circ} \mathrm{C}$, was due to the slower proliferation rate rather than a result of the cells being adversely affected.

We also assessed elevated temperature effects on the ability of the osteoblasts to synthesize calcium primarily because crystalline salts deposited in the matrix of bone are composed principally of calcium and phosphate, which are combined to form hydroxyapatite crystals and an indicator of healthy cellular activity. We confirmed that as observed during cell culture studies that at $39^{\circ} \mathrm{C}$, proliferation rate was affected and lesser cell numbers were seen after 3 days of cell culture. However calcium mineral deposition was clearly visualized in regions surrounding cells in both the $37{ }^{\circ} \mathrm{C}$ and $39{ }^{\circ} \mathrm{C}$ conditions (Fig. 3.6), thereby providing preliminary evidence that the ability of osteoblasts to produce calcium is not affected at $39^{\circ} \mathrm{C}$. 


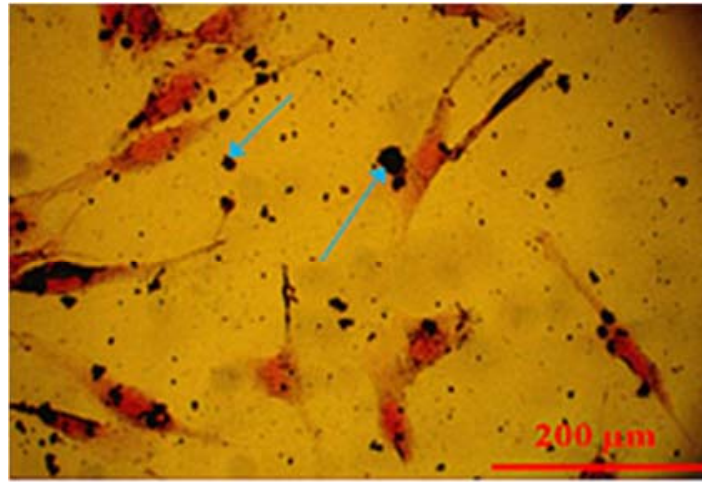

$37^{\circ} \mathrm{C}$

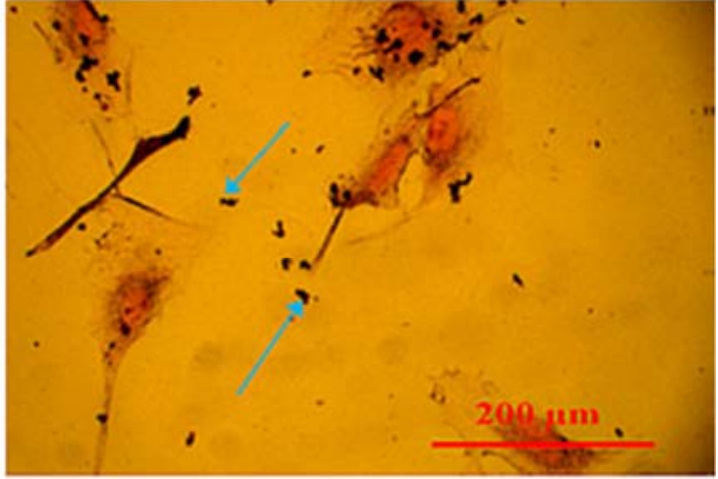

$39^{\circ} \mathrm{C}$

Figure 3.6: Von-Kossa staining conducted at $37{ }^{\circ} \mathrm{C}$ and $39{ }^{\circ} \mathrm{C}$ after 3 days of osteoblast culture. Osteoblasts appear as elongated structures staining red while blue arrows point to examples of calcium deposited by the osteoblasts, which stain black. Osteoblast proliferation rate was observed to be slower at $39{ }^{\circ} \mathrm{C}$. On the other hand, this slower rate improved relative survivability of the cells, because high proliferation rates have shown to make cells more vulnerable to toxic effects (UV and photoinitiator concentrations) present in photopolymerized environments [9]

It is important to point out that the intended application of our findings is not in the clinic as cartilage tissue engineering is still an emerging field as indicated by several leading groups in the area $[35,36,37]$; rather, these conditions can readily be used in in vitro engineered cartilage tissue model systems where injectable hydrogels are being actively experimented with $[38,39,40,41,42]$. The benefit of incorporating our findings is that controlled in vitro experiments to assess integration studies for engineered cartilage to bone extracellular matrix can be achieved without compromising osteoblast activity, a critical component to the integration process, prior to progressing to more variable in vivo models.

\subsection{Conclusions}

In conclusion, for studies involving cellular photopolymerization protocols, we have demonstrated that significant improvement $(\mathrm{P}<0.05)$ of human osteoblasts in situ are possible by combined usage of an increased incubation temperature of $39^{\circ} \mathrm{C}$ and the use 
of ascorbic acid at a concentration of $50 \mathrm{mg} / \mathrm{L}$. We speculate that further improvements to osteoblast survivability may be possible by fine tuning the ascorbic acid concentration further and/or with the use of additional antioxidants such as uric acid and Beta-Carotene. A limitation of our approach was that we conducted our investigations in monolayer culture as opposed to 3-Dimensional (3-D) matrices, such as hydrogels. However, we expect our results to represent a "worst case scenario" since the UV environments which severely diminishes osteoblast viability was introduced by means of direct exposure, while in the case of tissue engineered 3-D constructs, cells remain suspended within a gel or scaffold material, thus offering some level of protection. We therefore recommend the implementation of the enhanced osteoblast culture parameters found herein for cellular experiments that involve photopolymerizable materials. 


\subsection{References}

1. Nerem RM, Sambanis A (1995) Tissue Engineering: From Biology to Biological Substitutes. Tissue Eng 1:3-13

2. Nguyen KT, West JL (2002) Photopolymerizable hydrogels for tissue engineering applications. Biomaterials 23:4307-14

3. Elisseeff J, Anseth K, Sims D, McIntosh W, Randolph M, Yaremchuk M, Langer R (1999) Transdermal photopolymerization of poly(ethylene oxide)-based injectable hydrogels for tissue- engineered cartilage. Plast Reconstr Surg 104:1014-22

4. Elisseeff J, McIntosh W, Anseth K, Riley S, Ragan P, Langer R (2000) Photoencapsulation of chondrocytes in poly(ethylene oxide)-based semiinterpenetrating networks. J Biomed Mater Res 51:164-71

5. Williams CG, Kim TK, Taboas A, Malik A, Manson P, Elisseeff J (2003) In vitro chondrogenesis of bone marrow-derived mesenchymal stem cells in a photopolymerizing hydrogel. Tissue Eng 9:679-88

6. Moan J, Berg K, Kvam E, Western A, Malik Z, Rück A, Schneckenburger H (1989) Intracellular localization of photosensitizers- Ciba Found Symp 146:95-107

7. Terakado M, Yamazaki M, Tsujimoto Y, Kawashima T, Nagashima K, Ogawa J, Fujita Y, Sugiya H, Sakai T, Furuyama S (1984) Lipid peroxidation as a possible cause of benzoyl peroxide toxicity in rabbit dental pulp--a microsomal lipid peroxidation in vitro. J Dent Res 63:901-5

8. Atsumi T, Murata J, Kamiyanagi I, Fujisawa S, Ueha T (1998) Cytotoxicity of photosensitizers camphorquinone and 9-fluorenone with visible light irradiation on a human submandibular-duct cell line in vitro. Arch Oral Biol 43:73-8

9. Williams CG, Malik AN, Kim TK, Manson PN, Elisseeff JH (2005) Variable cytocompatibility of six cell lines with photoinitiators used for polymerizing hydrogels and cell encapsulation. Biomaterials 26: 1211-18

10. Wang DA, Varghese S, Sharma B, Strehin I, Fermanian S, Gorham J, Fairbrother DH, Cascio B, Elisseeff JH (2007) Multifunctional chondroitin sulphate for cartilage tissuebiomaterial integration. Nat Mater 6:385-92

11. Buckwalter AJ, Mankin J (1998) Articular cartilage repair and transplantation. Arthritis Rheum 41:1331-42 
12. Bodine PV, Trailsmith M, Komm BS (1996) Development and characterization of a conditionally transformed adult human osteoblastic cell line. J Bone Miner Res 11:80619

13. Kim J, Hefferan TE, Yaszemski MJ, Lu L (2009) Potential of Hydrogels Based on Poly(Ethylene Glycol) and Sebacic Acid as Orthopedic Tissue Engineering Scaffolds. Tissue Eng Part A 15:2299-07

14. Yang F, Williams CG, Wang DA, Lee H, Manson PN, Elisseeff J (2005) The effect of incorporating RGD adhesive peptide in polyethylene glycol diacrylate hydrogel on osteogenesis of bone marrow stromal cells. Biomaterials 26:5991-98

15. Tang Y, McGoron AJ (2009) Combined effects of laser-ICG photothermotherapy and doxorubicin chemotherapy on ovarian cancer cells. J Photochem Photobiol B 97:13844

16. Vichai V, Kirtikara K (2006) Sulforhodamine B colorimetric assay for cytotoxicity screening. Nat Protoc 1:1112-6

17. Pisco L, Kordian M, Peseke K, Feist H, Michalik D, Estrada E, Carvalho J, Hamilton G, Rando D, Quincoces J (2006) Synthesis of compounds with antiproliferative activity as analogues of prenylated natural products existing in Brazilian propolis. Eur. J. Med. Chem 41:401-07

18. Burdick JA, Anseth KS (2002) Photoencapsulation of osteoblasts in injectable RGDmodified PEG hydrogels for bone tissue engineering. Biomaterials 23:4315-23

19. Namba RM, Cole AA, Bjugstad KB, Mahoney MJ (2009) Development of porous PEG hydrogels that enable efficient, uniform cell-seeding and permit early neural process extension. Acta Biomater 5:1884-97

20. Mann BK, Gobin AS, Tsai AT, Schmedlen RH, West JL (2001) Smooth muscle cell growth in photopolymerized hydrogels with cell adhesive and proteolytically degradable domainssynthetic ECM analogs for tissue engineering. Biomaterials 22:3045-51

21. Paxton JZ, Donnelly K, Keatch RP, Baar K (2009) Engineering the Bone-Ligament Interface Using Polyethylene Glycol Diacrylate Incorporated with Hydroxyapatite. Tissue Eng Part A 15:1201-09

22. Chan-Park MB, Zhu AP, Shen JY, Fan AL (2004) Novel photopolymerizable biodegradable triblock polymers for tissue engineering scaffolds: synthesis and characterization. Macromol Biosci 4:665-73 
23. Beamish JA, Zhu J, Kottke-Marchant K, Marchant RE (2010) The effects of monoacrylated poly(ethylene glycol) on the properties of poly(ethylene glycol) diacrylate hydrogels used for tissue engineering. J Biomed Mater Res A 92:441-50

24. Ramaswamy S, Wang DA, Fishbein KW, Elisseeff JH, Spencer RG (2006) An analysis of the integration between articular cartilage and nondegradable hydrogel using magnetic resonance imaging. J Biomed Mater Res B Appl Biomater 77:144-48

25. Ramaswamy S, Gurkan I, Sharma B, Cascio B, Fishbein KW, Spencer RG (2008) Assessment of tissue repair in full thickness chondral defects in the rabbit using magnetic resonance imaging transverse relaxation measurements. J Biomed Mater Res B Appl Biomater 86:375-80

26. Reinholz GG, Getz B, Pederson L, Sanders ES, Subramaniam M, Ingle JN, Spelsberg TC (2000) Bisphosphonates Directly Regulate Cell Proliferation, Differentiation, and Gene Expression in Human Osteoblasts. Cancer Res 60:6001-07

27. Harris SA, Enger RJ, Riggs BL, Spelsberg TC (1995) Development and characterization of a conditionally immortalized human fetal osteoblastic cell line. $\mathrm{J}$ Bone Miner Res 10:178-86

28. Nojiri H, Saita Y, Morikawa D, Kobayashi K, Tsuda C, Miyazaki T, Saito M, Marumo K, Yonezawa I, Kaneko K, Shirasawa T, Shimizu T (2011) Cytoplasmic superoxide causes bone fragility owing to low-turnover osteoporosis and impaired collagen crosslinking. J Bone Miner Res 26:2682-94

29. Montecinos V, Guzmán P, Barra V, Villagrán M, Muñoz-Montesino C, Sotomayor K, Escobar E, Godoy A, Mardones L, Sotomayor P, Guzmán C, Vásquez O, Gallardo V, van Zundert B, Bono MR, Oñate SA, Bustamante M, Cárcamo JG, Rivas CI, Vera JC (2007) Vitamin $C$ is an essential antioxidant that enhances survival of oxidatively stressed human vascular endothelial cells in the presence of a vast molar excess of glutathione. J Biol Chem 282:15506-15

30. Martinez EC, Wang J, Gan SU, Singh R, Lee CN, Kofidis T (2010) Ascorbic acid improves embryonic cardiomyoblast cell survival and promotes vascularization in potential myocardial grafts in vivo. Tissue Eng Part A 16:1349-61

31. Rajzer I, Menaszek E, Bacakova L, Rom M, Blazewicz M (2010) In vitro and in vivo studies on biocompatibility of carbon fibres. J Mater Sci Mater Med 21:2611-22

32. Ramaswamy S, Greco JB, Uluer MC, Zhang Z, Zhang Z, Fishbein KW, Spencer RG (2009) Magnetic resonance imaging of chondrocytes labeled with superparamagnetic iron oxide nanoparticles in tissue-engineered cartilage. Tissue Eng Part A 15:3899-910

33. Ramaswamy S, Uluer MC, Leen S, Bajaj P, Fishbein KW, Spencer RG (2008) Noninvasive assessment of glycosaminoglycan production in injectable tissue- 
engineered cartilage constructs using magnetic resonance imaging. Tissue Eng Part C Methods 14:243-9

34. Li SH, Guo DZ, Li B, Yin HB, Li JK, Xiang JM, Deng GZ (2009) The stimulatory effect of insulin-like growth factor-1on the proliferation, differentiation, and mineralisation of osteoblastic cells from Holstein cattle. Vet J 179:430-6

35. Prestwich GD (2011) Hyaluronic acid-based clinical biomaterials derived for cell and molecule delivery in regenerative medicine. J Control Release 155:193-9

36. Nöth U, Steinert AF, Tuan RS (2008) Technology insight: adult mesenchymal stem cells for osteoarthritis therapy. Nat Clin Pract Rheumatol 4:371-80

37. Elisseeff J (2004) Injectable cartilage tissue engineering. Expert Opin Biol Ther 4:1849-59

38. Sukarto A, Yu C, Flynn LE, Amsden BG (2012) Co-delivery of Adipose-Derived Stem Cells and Growth Factor-Loaded Microspheres in RGD-Grafted N-Methacrylate Glycol Chitosan Gels for Focal Chondral Repair. Biomacromolecules 13:2490-502

39. Papadopoulos A, Bichara DA, Zhao X, Ibusuki S, Randolph MA, Anseth KS, Yaremchuk MJ (2011) Injectable and photopolymerizable tissue-engineered auricular cartilage using poly(ethylene glycol) dimethacrylate copolymer hydrogels. Tissue Eng Part A 17:161-9

40. Roberts JJ, Nicodemus GD, Greenwald EC, Bryant SJ (2011) Degradation improves tissue formation in (un)loaded chondrocyte-laden hydrogels. Clin Orthop Relat Res 469:2725-34

41. Zhang C, Sangaj N, Hwang Y, Phadke A, Chang CW, Varghese S (2011) Oligo(trimethylene carbonate)-poly(ethylene glycol)-oligo(trimethylene carbonate) triblock-based hydrogels for cartilage tissue engineering. Acta Biomater 7:3362-9

42. Lee HJ, Yu C, Chansakul T, Hwang NS, Varghese S, Yu SM, Elisseeff JH (2008) Enhanced chondrogenesis of mesenchymal stem cells in collagen mimetic peptidemediated microenvironment. Tissue Eng Part A 14:1843-51 
Chapter 4

Improvements in Integration of Engineered Cartilage to Bone Matrix Using

Hydroxyapatite 
This chapter describes the interaction of engineered cartilage to an engineered bone system with and without hydroxyapatite (HA) environments, specifically over the spatial transition zone between the two materials. Through a systematic series of mechanical, biochemical, cellular and histological outcomes, we present compelling evidence here suggesting that HA significantly improves integration of engineered cartilage to a bone matrix.

\subsection{Abstract}

Articular cartilage injuries occur frequently in the knee joint. Photopolymerizable cartilage tissue engineering approaches appear promising; however, fundamentally, forming a stable interface between the subchondral bone and tissue engineered cartilage components remains a major challenge. We investigated the utility of hydroxyapatite (HA) nanoparticles to promote controlled bone-growth across the bone-cartilage interface in an in vitro engineered tissue model system using bone marrow derived stem cells. Samples incorporated with HA demonstrated significantly higher interfacial shear strength (at the junction between engineered cartilage and engineered bone) compared to the constructs without HA ( $<0.05)$, after 28 days of culture. Interestingly, this increased interfacial shear strength due to the presence of HA was observed as early as 7 days and appeared to have sustained itself for an additional three weeks without interacting with strength increases attributable to subsequent secretion of engineered tissue matrix. Histological evidence showed that there was $\sim 7.5 \%$ bone in-growth into the cartilage region from the bone side. The mechanism of enhanced engineered cartilage to bone integration with HA incorporation appeared to be facilitated by the deposition of calcium phosphate in the transition zone. These findings indicate that controlled bone in-growth using HA 
incorporation permits more stable anchorage of the injectable hydrogel-based engineered cartilage construct via augmented integration between bone and cartilage.

\subsection{Introduction}

Articular cartilage defects and lesions are one of the most common injuries that occur in the knee joint[1,2]. Curl et al, [1] demonstrated in their study of consecutive knee arthroscopies that up to $63 \%$ of the patients with knee-related symptoms suffered from chondral or osteochondral defects [3]. These defects may also progress to osteoarthritis if left untreated [4], which further involves degradation of articular cartilage, the subchondral bone, the synovial capsule and membrane as well as the periarticular tissues [5]. Patients suffering from cartilage lesions and other degenerative cartilage diseases currently have limited treatment options available. One technique that is often used clinically to treat these defects is autologous chondrocyte transplantation (ACT); however there is no significant evidence that this approach yields superior results compared to standard treatment of care, such as with physical therapy and anti-inflammatory medication [6,7]. Furthermore, ACT has limited applicability as in some cases, when there is no intact cartilage rim, the covering of the chondrocyte suspension with a periosteal flap or a collagen sheet is often insecure restricting the usage of this technique to only certain types of injuries [2].

A possible solution lies in tissue engineering strategies for cartilage repair. It involves the implantation of a biological scaffold in the defect that would degrade over a period of time and promote tissue repair within the defect space [8]. However, one major problem is the lack of retention of the tissue engineered cartilage. Scaffolds need to be retained during the majority of the regenerative process at their implantation site in order for the treatment strategy to be successful. For this to occur, a stable anchor for the scaffold is required which 
will prevent it from being dislodged. Previous studies have taken approaches based on the principles of mechanical [9-12], chemical [13-15] and biological fixation [16-18] in order to form novel strategies of integration, but have demonstrated limited success in terms of scaffold retention within the defect for the entire duration of the tissue repair process, which can extend up to 4 weeks [19]. Another limitation with the cartilage transplantation is the lack of its integration with the host tissue. Lane et al [20], showed that after a 6 month period there was no integration between the host and osteochondral plug that was inserted into fixed articular cartilage defects. Similarly, there were other studies $[21,22]$ that showed a lack of integration between the engineered cartilage and host tissues.

In cartilage tissue engineering, injectable hydrogels have shown great potential as scaffold support structures. With their similarity to the water content in biological tissues, hydrogels have been used extensively for tissue engineering applications. They can be injected at room temperature and will take the form of the defect during low-intensity ultraviolet (UV) photopolymerization. Thus, they offer a great advantage over fibrous scaffold approaches, particularly for the treatment of small to medium sized focal osteochondral defects arising from injury or mild to moderate osteoarthritis. In the generalized treatment approach, initiation of bleeding through bone microfracture will cause human bone marrow derived stem cells (HBMSCs) to migrate to the defect space. UV-initiated gelation will cause the monomer hydrogel solution, which would have been already pre-treated with chondrogenic factors (e.g. transforming growth factors such as TGF $\beta$ ), to cross link, thereby encapsulating the cells [23]. Very likely, the surgical procedure will be relatively straight forward, short in duration and potentially minimally invasive. However, even though photopolymerizable hydrogel approaches have demonstrated great potential in cartilage 
tissue engineering, there is still a need to tailor enhanced mechanical stability; that would lead to the retention of the engineered tissue construct at the implant location so that de novo cartilage can be formed under optimal conditions, i.e., with the hydrogel scaffold still remaining within the defect space. In order to accomplish this, in this study, we used hydroxyapatite (HA) nanoparticles, to promote controlled bone in-growth from the ventral bone location to the dorsal cell-encapsulated, injectable hydrogel location in an in vitro engineered tissue model system, so that enhanced anchorage of the engineered cartilage could be achieved via a stronger interface.

\subsection{Material and methods}

\subsubsection{Overview}

An in vitro bone and cartilage model was created using osteoblast-seeded Agar scaffolds and HBMSC-seeded photo polymerizable poly (ethylene glycol) diacrylate, respectively. The main focus of the study was to evaluate the effect of HA on augmenting integration between the bone and cartilage layers as a function of time. Experimental time points were: Day 1, Day 7, Day 14 and Day 28. Outcomes were assessed via cell viability, biochemical assays (Sulfated Glycosaminoglycans (sGAGs), DNA, Alkaline Phosphatase), histology and RT-PCR. Finally, direct mechanical testing was performed at the bulk and interface scale using compression and shear tests

\subsubsection{Cell Culture}

\subsubsection{Human Bone marrow derived Mesenchymal Stem Cells (HBMSCs)}

HBMSCs (Science cell, Carlsbad, CA, USA) were seeded onto Poly D-lysine coated T- 75 flasks (Fisher Scientific, Pittsburg, PA, USA). Characterization of HBMSCs was 
confirmed by the supplier via positive immunostaining for CD73, CD105 and particularly, CD 90 (Thy-1) a stem cell marker [24]. After stem cell differentiation, lipid staining was also confirmed. Additional characterization of these HBMSCs showed that they retain their phenotype in cell culture for up to 15 cell doubling cycles and therefore remained stable for the duration of our cell culture experiments in which expansion continued for up to 6 cell doubling periods. The cells were cultured in low glucose media (Dulbecco's modified eagle medium, (DMEM), Life Technologies, Grand Island, NY, USA) supplemented with $10 \%$ fetal bovine serum ((FBS), ATCC, Manassas, VA, USA ) and $1 \%$ penicillinstreptomycin (ATCC), per manufacturer's recommendations [25], until passage 3 (P3).

\subsubsection{Human Osteoblasts (hFOBs)}

The hFOBs (hFOB 1.19,ATCC) were cultured in basal media (Catalog \#: 11039-021; Life Technologies) which consisted of 1:1 mixture of DMEM and Ham's F-12, and included Lglutamine $(2.5 \mathrm{mM})$ and HEPES $(15.01 \mathrm{mM})$. We additionally supplemented the basal media with 10\% FBS (ATCC), 1\% Penstrep (ATCC) and $0.3 \mathrm{mg} / \mathrm{ml}$ of an aminoglycoside antibiotic (Catalog \#: G8168, Sigma Aldrich, St Louis, MO, USA). The hFOBs from the supplier (ATCC) were originally transfected from discarded limb tissue [26] to create an immortalized cell line; upon arrival to our laboratory, the cells were culture expanded until passage 4 (P4).

\subsubsection{Tissue Engineering Experiments}

\subsubsection{Tissue Engineered Bone}

Engineered bone was prepared using 2\% Agar scaffold [27] in which osteoblast cells were encapsulated. Briefly, $2.5 \%$ of Agar solution (Fischer Scientific) was prepared and heated to a temperature of $70^{\circ} \mathrm{C}$. Meanwhile, osteoblasts were trypsinzed and 20 million cells were 
dissolved in $200 \mu 1$ of cell media (Same as media utilized in hFOB cell culture; Catalog \#1039021; Life Technologies). Once the Agar solution started to boil, it was removed from the hot plate and allowed to cool in a room temperature environment. When the temperature reached $40^{\circ} \mathrm{C}, 64 \mu \mathrm{l}$ of Agar solution was mixed with $16 \mu 1$ of cell suspension and were cast for 5 minutes in custom designed molds ( $5 \mathrm{~mm}$ in diameter and $4.1 \mathrm{~mm}$ in length) at room temperature. Each gel construct consisted of a $2 \%$ Agar solution with a suspension of $\sim 1.6$ million osteoblasts and at this juncture, remained immersed in the media used to culture the osteoblasts.

\subsubsection{Tissue Engineered Cartilage}

Engineered Cartilage was prepared using 15\% PEGDA solution with $0.5 \%$ w/v HA. This concentration was chosen after preliminary testing established that it yielded a good compromise between robust cell viability and a strong potential for effective tissue integration through osteoinduction (Data not shown). A 15\% w/v PEGDA solution was prepared by dissolving $150 \mathrm{mg}$ of PEGDA powder (Glycosan Biosystems, Salt Lake City, UT) and $5 \mathrm{mg}$ of HA nanoparticles (Catalog \# 677418, Sigma Aldrich) in Phosphate buffer saline (PBS) (Sigma Aldrich). The protocol for hydrogel preparation with the exception of the incorporation of HA nanoparticles was very similar to that previously reported by Durst et al [28] and Yang et al [29]. Each HA nanoparticle was characterized by a $<200 \mathrm{~nm}$ particle size, a surface area $>9 \mathrm{~m}^{2} / \mathrm{g}$ by the supplier (Sigma-Aldrich) and has been used previously for bone substitute studies [30,31]. Subsequently, $100 \mathrm{mg} / \mathrm{ml}$ of photoinitiator solution (Irgacure 2959, Ciba Specialty Chemicals, Tarytown, NY) in 70\% ethanol was constituted and added to the monomer solution $(5 \mu \mathrm{l} / \mathrm{ml})$, followed by thorough stirring. This resulted in a $0.05 \% \mathrm{w} / \mathrm{v}$ ratio of the photo initiator concentration. HBMSC's at a 
concentration of 20 million cells $/ \mathrm{ml}$ were introduced just prior to UV exposure. Next, the solution was irradiated with UV light at $4-5 \mathrm{~mW} / \mathrm{cm}^{2}$ for 7 minutes to induce polymerization. We previously established that HBMSC viability was unaffected by the UV intensity and exposure timescales utilized here [32].

After the respective engineered cartilage and bone segments were prepared, the former was placed on top of the latter construct. Subsequently, they were both physically held together with a thin stainless steel pin (Fischer Scientific, Catalog \# 26002-10) that was pierced through both the layers. Each of these 2 layer constructs were transferred into a well (in a 24 well plate), with each well containing $1 \mathrm{ml}$ of chondrogenic media (Fisher Scientific, Catalog \# SH3088902); the samples were then incubated in a humidified environment at $37^{\circ} \mathrm{C}$ and $5 \% \mathrm{CO}^{2}$. This chondrogenic media was so-called because it contains proprietary growth factors from the supplier (Fisher Scientific) to direct differentiation of HBMSCs to chondrocytes [33]. Constructs were similarly made with cells but without hydroxyapatite in them i.e., the constructs without HA. In addition, acellular controls with and without hydroxyapatite particles were also made in the similar fashion. In sum, four groups were ultimately prepared: Group 1: PEGDA No HBMSC-No HA; Group 2: PEGDA-HA No HBMSC; Group 3: HBMSC encapsulated in PEGDA No HA and finally Group 4: HBMSC encapsulated in PEGDA-HA. Groups were cultured for 7, 14 and 28 days.

\subsubsection{Cell Viability}

A Live-Dead assay using Calcein AM/Ethidium homodimer (Life Technologies) staining to assess the viability of cells [34] within the constructs was conducted following the manufacturer's protocol on osteoblasts-encapsulated Agar constructs as well as on HBMSC-encapsulated in PEGDA (Group 3) and HBMSC-encapsulated in PEGDA-HA 
(Group 4) samples; Briefly, samples from different group at different time points (Day1, Day 7, Day 14 and Day 28) were cut using a blade to a thickness of $1 \mathrm{~mm}$ and then were stained with Calcein AM and Ethidium homodimer in PBS solution and incubated for 30 minutes. Next, they were washed 3 times with PBS solution to remove the background fluorescence and subsequently visualized under the fluorescent microscope (Olympus IX81, Olympus America Inc., Miami FL) at excitation and emission wavelengths of 468nm and 568nm respectively. Images of the samples were taken with each image encompassing an area of $4.32 \mathrm{~mm}^{2}$. A mean \pm standard deviation (SD) of percentage (\%) cell viability was subsequently computed at the different time points by counting cells on representative images (ImageJ software, NIH, Bethesda, MD) and calculating the ratio of live cells (green dots) to the sum of live and dead cells (red dots) and finally, multiplying by a $100 \%(\mathrm{n}=3$ images/group/time point).

\subsubsection{Glycosaminoglycan and DNA Characterization}

The wet weight of the constructs were initially obtained, and then followed by the dry weight after 48 hours of lyophilization of the constructs [35] for each group ( $\mathrm{n}=3$ samples/group) per time point. The dried constructs were crushed using a tissue grinder and digested in $1 \mathrm{ml}$ of papain digest solution $(0.2 \mathrm{M}$ sodium phosphate buffer $\mathrm{pH} 6.5,0.1 \mathrm{M}$ sodium acetate, $0.01 \mathrm{M}$ EDTA, $0.005 \mathrm{M}$ cysteine $\mathrm{HCl}$, and $2 \mathrm{mg}$ of papain lyophilized crystals $/ 10 \mathrm{ml}$ extraction buffer) for 16 hours at $65^{\circ} \mathrm{C}$. Sulfated Glycosaminoglycan (sGAGs) concentration was determined by using dimethylmethylene blue dye [36] (Biocolor, Blyscan Glycosaminoglycan Assay, County Antrim, UK). Once the samples were digested in papain, $100 \mu 1$ of the sample was taken and mixed with $1 \mathrm{ml}$ of dye in a mechanical shaker for 30 minutes. During this time period, a sulphated 
glycosaminoglycan-dye complex was formed and precipitated out from the soluble unbound dye when centrifuged for 10 minutes. The precipitate was then dissolved in the dissociation agent, and absorbance at $565 \mathrm{~nm}$ was measured using a microplate reader (Biotek) and compared with known, standard solutions of chondroitin 4-sulfate (Biocolor) to calculate the sGAG values. Specifically, dilution of a sterile solution of bovine tracheal chondroitin 4-sulfate (100 $\mu \mathrm{g} / \mathrm{ml}$; Biocolor) with de-ionized water was performed to obtain the following six known standard concentrations of sGAG: $0,0.1,0.2,0.33,4,5 \mu \mathrm{g} / \mathrm{ml}$ chondroitin 4-sulfate. Final presentation of sGAG concentrations were normalized with respect to the sample dry weight ( $\mu \mathrm{g} / \mathrm{mg}$ dry weight).

The papain-based digestion protocol for the DNA assay was identical to the sGAG assay described earlier. The DNA content in the constructs was calculated using the Quant-iT PicoGreen dsDNA kit (Life Technologies) as in previously described studies [37]. Samples were incubated with the Quant-iTTM PicoGreen reagent for 2-5 minutes, and then the fluorescence was measured at an excitation and emission of $485 \mathrm{~nm}$ and $520 \mathrm{~nm}$, respectively, using a microplate reader (Synergy HT, Biotek, Winooski, VT). Fluorescence values measured from the DNA assay were converted to DNA based on fluorescence measured from known standard DNA concentrations. Known standard concentrations were obtained by dilution of a stock DNA solution provided by the manufacturer (Lambda DNA, Biocolor). The stock DNA solution was diluted in a buffer (10 mM Tris-HCl, 1 mM EDTA, $\mathrm{pH}$ 7.5) to obtain the following five concentrations of DNA solution: blank $(0 \mathrm{pg} / \mathrm{ml})$, $25 \mathrm{pg} / \mathrm{ml}, 250 \mathrm{pg} / \mathrm{ml} .2 .5 \mathrm{ng} / \mathrm{ml}$ and $25 \mathrm{ng} / \mathrm{ml}$. A standard curve was plotted after the fluorescence of the known DNA concentrations was measured and subsequently, this curve 
was used to convert the fluorescence-derived signal of the tissue engineered constructs to DNA concentrations.

\subsubsection{Quantitative Real-Time Polymerase Chain Reaction (qRT-PCR)}

To confirm the chondrogenic phenotype of differentiated HBMSCs in PEGDA and to verify the possibility of undesirable expression of bone markers in the tissue engineered cartilage in the presence of HA, quantitative real time-polymerase chain reaction (qRTPCR) was performed on the samples of HBMSC's encapsulated in PEGDA in HBMSC media, HBMSC's encapsulated in PEDGA in chondrogenic media and HBMSC's encapsulated in PEGDA-HA in chondrogenic media, after 4 weeks of culture in their respective media. Total mRNA was extracted for each group using the SV total RNA isolation kit (Promega, Madison, WI). First, 3 samples from each group were crushed and pooled into 1 and subsequently, the RNA isolation procedure was followed as described by the manufacturer (Promega). Next, $5 \mu \mathrm{g}$ of mRNA was used for the reverse transcriptase reaction as previously established $[37,38]$. The mRNA for 3 groups was converted into cDNA using the GoScript_Reverse Transcription kit (Promega). The cDNA was synthesized using an oligo(dT) primer, according to the manufacturer's instructions. The qRT-PCR was performed using the GoTaq qPCR Master Mix (Promega). The PCR tubes contained forward and reverse primers and SYBR green I dye reagent along with the cDNA, which was obtained during reverse transcription. The primers (Table 1) were designed using the Basic Local Alignment Search Tool (BLAST) program, National Center for Biotechnology Information (NCBI) to amplify the target sequences. Step-One RealTime PCR System (Life Technologies) was used to detect the signals when the mixture was followed by thermal cycling conditions per manufacturer's instructions (Promega). 
Finally, the expression of the following markers: GAPDH, SOX9, aggrecan, collagen II, osteocalcin, scleraxis were measured for the different groups. Finally, the change in cycle threshold (Ст) values were averaged and normalized with GAPDH using the $\Delta \Delta \mathrm{C}$ т method [39]. Fold changes were calculated as $2^{-\Delta \mathrm{Cr}}$, and the gene expression ratio of each of the three groups was plotted.

Table 4.1: Quantitative RT-Polymerase Chain Reaction primer sequences used in this study

\begin{tabular}{|l|l|l|}
\hline Genes & \multicolumn{1}{|c|}{ Forward Primer } & \multicolumn{1}{c|}{ Reverse Primer } \\
\hline GAPDH & AATGAAGGGGTCATTGATGG & AAGGTGAAGGTCGGAGTCAA \\
\hline SOX9 & GTAATCCGGGTGGTCCTTCT & GTACCCGCACTTGCACAAC \\
\hline Aggrecan & GCGAGTTGTCATGGTCTGAA & TTCTTGGAGAAGGGAGTCCA \\
\hline Collagen II & AGACTTGCGTCTACCCCAATC & GCAGGCGTAGGAAGGTCATC \\
\hline Osteocalcin & CACTCCTCGCCCTATTGGC & CCCTCCTGCTTGGACACACAAAG \\
\hline
\end{tabular}

\subsubsection{Mineralization Assessment:}

Mineralization of the 2 layer constructs ( $\mathrm{n}=3$ samples/group) at the interface was quantified using a colorimetric based assay qualitatively via an Alkaline Phosphatase (ALP) Assay kit (Abcam, Cambridge, MA, USA). Samples were cut from the interface $1 \mathrm{~mm}$ from each side, and then were homogenized in the assay buffer. The samples were then added to $p$ nitrophenyl phosphate (p-NPP) and incubated for 60 minutes at $25^{\circ} \mathrm{C}$. Next, stop solution from the kit was added to arrest hydrolysis of p-NPP to p-nitrophenol. The optical density was then measured using a microplate reader set to a wavelength at $405 \mathrm{~nm}$ (Synergy HT, BioTek, Winooski, VT) to measure the level of released p-nitrophenol. Results were 
presented as enzyme specific activity per volume of sample solution (enzyme units per liter $(\mathrm{U} / \mathrm{L}))$.

Mineral distribution on the 2 layer constructs was evaluated using the Von-Kossa and Alcian Blue Stain kit (IHC world, Woodstock, MD, USA). Staining was performed such that simultaneous visualization of both bone and cartilage matrix deposition could be observed on the same tissue section. Briefly the sectioned samples were first treated with silver nitrate solution and exposed to UV light for 60 minutes and then with Alcian Blue stain. Sections $(25 \mu \mathrm{m})$ were then washed with distilled water and observed under a microscope.

\section{Tissue fill quantification:}

Representative histological images were analyzed to quantify the \% of engineered tissue in the transition zone, defined as the region between the engineered bone to engineered cartilage layers (ImageJ). First the entire area of the cartilage region was measured and next, the transition zone areas were computed (ImageJ). The transition zone area as a $\%$ of the entire cartilage area was subsequently calculated to reflect the $\%$ filling of tissue within the transition zone. In addition, for the constructs with HA, the calcium deposits as a $\%$ of the transition zone area was also computed. This enabled a determination of the $\%$ tissue in the transition zone that was exclusively filled by engineered bone-derived calcium phosphate matrix, at the conclusion of 4-weeks.

\subsubsection{Mechanical Properties}

\subsubsection{Compression}

Scaffold mechanical properties were determined by performing unconfined static compression testing on the constructs ( $\mathrm{n}=3$ samples/group) using a mechanical testing 
device (Bose, Eden Prairie, MN) with a displacement rate of $0.05 \mathrm{~mm} / \mathrm{sec}$. The experimental group for compression testing consisted of HBMSC-encapsulated in PEGDA (Group 3) and HBMSC encapsulated in PEGDA-HA (Group 4), whereas the control groups included osteoblasts in Agar, as well as corresponding acellular controls for PEGDA (Group 1) and PEGDA-HA (Group 2). Tests were conducted on samples at Day 1, Day 7, Day 14, and Day 28 for all 5 groups. Briefly, the diameter of each tissue engineered construct was initially measured using a vernier caliper. Next, the constructs were placed between the flat metal platens and the load was recorded at $0.05 \mathrm{~mm}$ increments using a displacement rate of $0.05 \mathrm{~mm} / \mathrm{sec}$. Corresponding stress and strain were subsequently computed. The compressive modulus was taken to be the slope in the initial linear region of the stress-strain curve [40].

\subsubsection{Shear}

The interfacial shear stress between the PEGDA-based, tissue engineered cartilage and the Agar-based bone substrate was determined by performing a shear test at the interface location of the 2 layers. For each 2 layer group, Agar with osteoblast-HBMSCencapsulated in PEGDA (Group 5) and Agar with osteoblast-HBMSC-encapsulated in PEGDA-HA (Group 6)), ( $\mathrm{n}=6$ samples/group) samples to be tested for each time point were placed horizontally on the platen on an individual basis. One side of the sample was affixed with super glue to the lower platen. The other side of the sample was similarly glued to the upper platen. Then the upper platen was increased in height with a displacement rate of $0.05 \mathrm{~mm} / \mathrm{sec}$ with load-displacement data recorded simultaneously at every $0.003 \mathrm{~mm}$ displacement. The test was arrested when the 2 layers separated from each other and there was a sudden decrease in the load. 


\subsubsection{Statistics}

Statistical analyses of the results obtained from the biochemical, DNA and ALP assays as well as from the cell viability and mechanical testing experiments were performed using commercially available software (SPSS, IBM, version 20, Armonk, NY, USA). A one way ANOVA and post hoc Tukey test was used to compare means and to determine statistically significant differences $(\mathrm{p}<0.05)$ between groups respectively. In cases where only two groups were compared, the one way ANOVA simply reduced to a t-test for independent groups.

\subsection{Results}

\subsubsection{Cell Viability}

The viability of the cells in the engineered scaffolds was observed over a period of 28 days at 4 time points (Day 1, Day 7, Day 14 and Day 28). At 28 days, Osteoblasts remained very viable in the Agar gel (Fig. 4.1 a and Table 4.2).

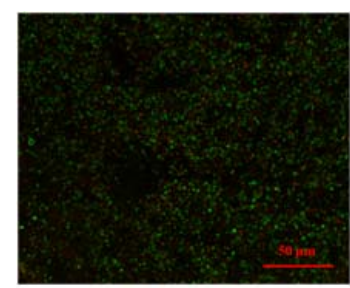

Day 1

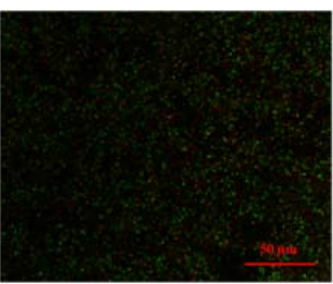

Day 7

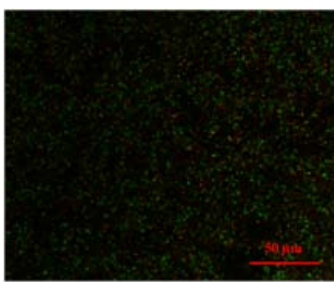

Day 14

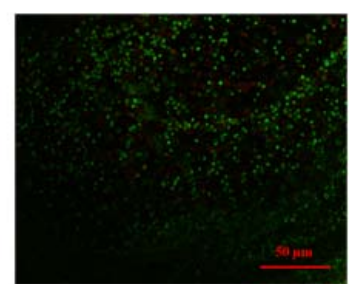

Day 28

Figure 4.1 (a): Live Dead assay over a 4 week period for Osteoblasts in agar scaffold. Images clearly showed that cells remained viable over this time frame with a much larger density of live (green dots) versus dead (red dots) cells.

Similarly, HBMSCs were also found to be very viable within the PEGDA environments without HA (Fig. 4.1 (b) and Table 4.2). 


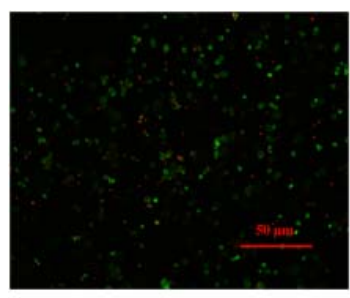

Day 1

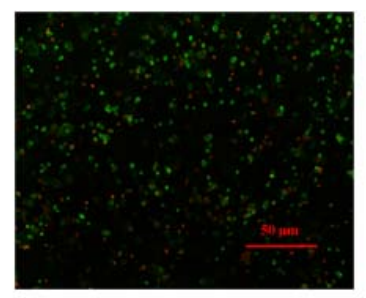

Day 7

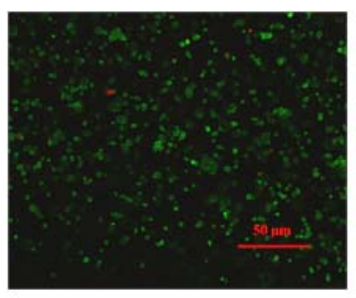

Day 14

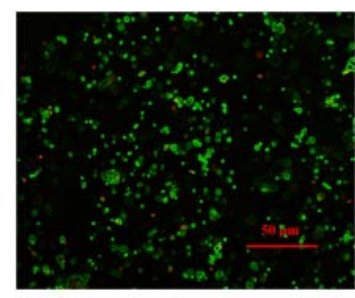

Day 28

Figure 4.1 (b): Live Dead assay over a 4 week period for HBMSCs in PEGDA. Images clearly showed that cells remained viable over this time frame with a much larger density of live (green dots) versus dead (red dots) cells.

The incorporation of HA into the PEGDA hydrogels did produce relatively lower cell counts compared to samples without HA $(\mathrm{p}<0.05)$. However it should be noted that the clustering of cells in the vicinity of HA particles resulted in enlargement of the green intensity regions (Fig. 1c) thereby very likely underestimating the number of live cells in the PEGDA with HA group. In spite of this $\sim 65 \%$ of cells were found to be viable at 28 days (Table 2).

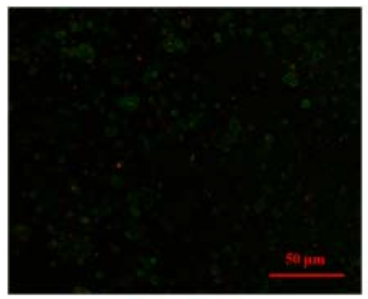

Day 1

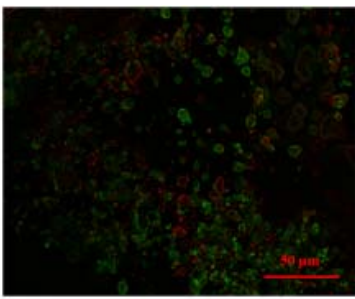

Day 7

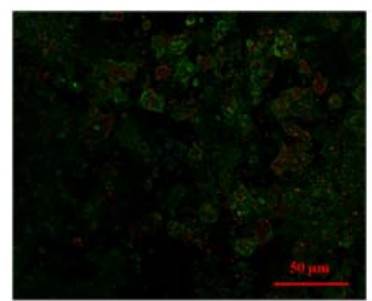

Day 14

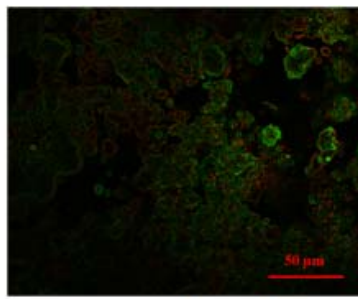

Day 28

Figure 4.1 (c): Live Dead assay over a 4 week period for HBMSCs in PEGDA-HA. Images clearly showed that cells remained viable over this time frame with a much larger density of live (green dots) versus dead (red dots) cells.

Table 4.2: Quantitative assessment of percentage cell viability in samples subjected to the livedead assay

\begin{tabular}{|l|l|l|l|l|}
\hline Sample & Day 1 & Day 7 & Day 14 & Day 28 \\
\hline $\begin{array}{l}\text { Agar } \\
\text { osteoblast }\end{array}$ & $77.96 \pm 1.19$ & $78.72 \pm 0.70$ & $81.86 \pm 0.30$ & $83.42 \pm 0.47$ \\
\hline
\end{tabular}




\begin{tabular}{|l|l|l|l|l|}
\hline $\begin{array}{l}\text { PEGDA with } \\
\text { HBMSC }\end{array}$ & $74.53 \pm 0.90$ & $75.46 \pm 0.50$ & $93.55 \pm 0.95$ & $91.94 \pm 1.02$ \\
\hline $\begin{array}{l}\text { PEGDA HA } \\
\text { with HBMSC }\end{array}$ & $73.47 \pm 0.94$ & $65.83 \pm 0.76$ & $69.97 \pm 0.75$ & $73.84 \pm 0.42$ \\
\hline
\end{tabular}

\subsubsection{Glycosaminoglycan and DNA Characterization}

Proteoglycan deposition in both HBMSC-seeded scaffolds (PEGDA and PEGDA-HA) increased over a period of 4 weeks. At day 1, both scaffolds had similar amounts of sGAGs deposition; at 28 days no statistically significant difference $(\mathrm{p}>0.05)$ in sGAGs could be detected between the cellular scaffolds regardless of whether HA was utilized or not (Fig. 4.2). It was observed however that the sGAG concentration for PEGDA constructs was $5.64 \pm 0.98 \frac{\mu g}{m g \text { dry weight }}$, while for PEGDA-HA constructs the sGAGs concentration was found to be $6.78 \pm 0.15 \frac{\mu g}{m g \text { dry weight }}$ after 4 weeks. 


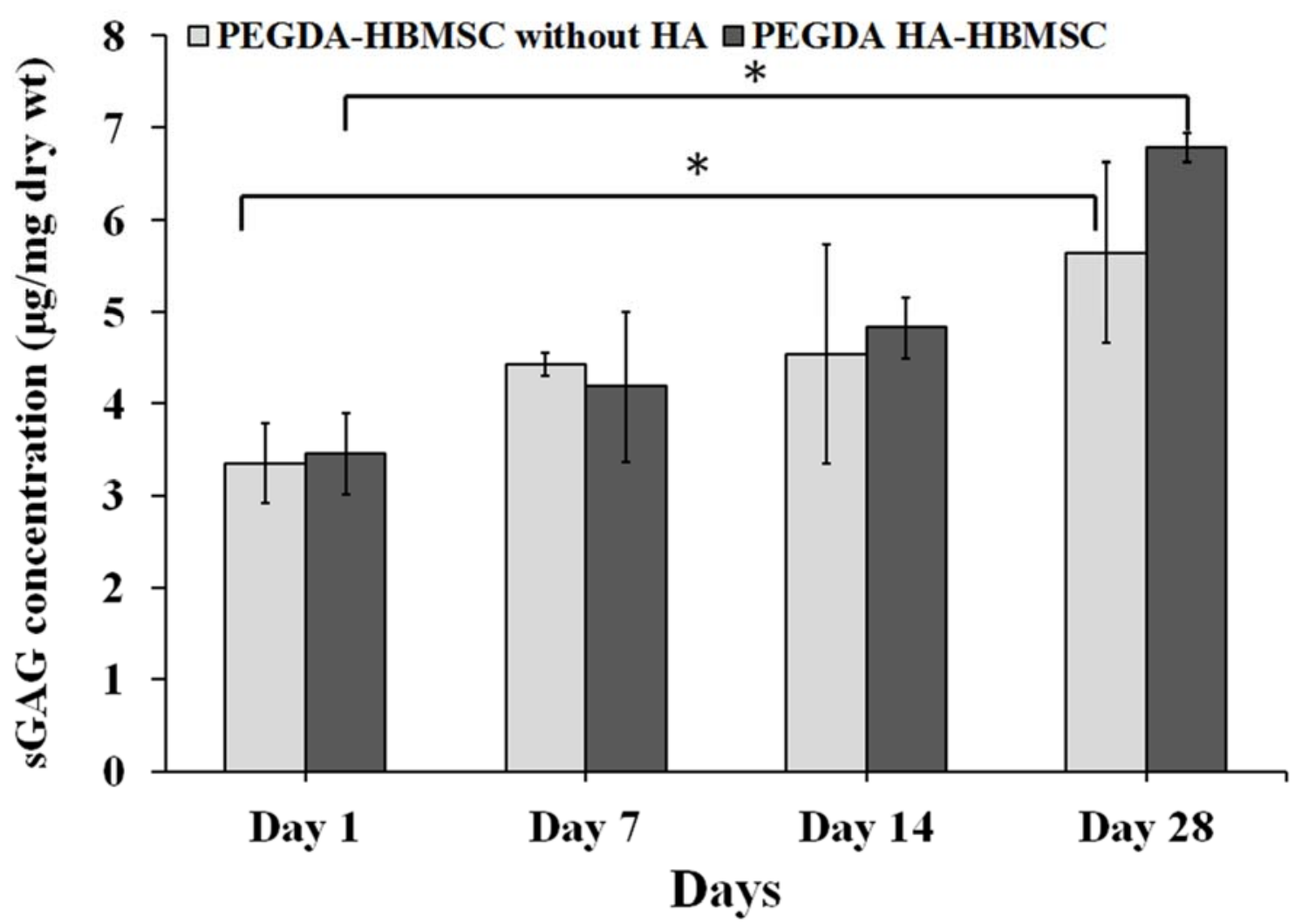

Figure 4.2: S-GAG content in HBMSC seeded-PEGDA and PEGDA-HA constructs. The “*” indicates that the difference between the groups was statistically significant $(p<0.05)$

The DNA content for HBMSC cellular PEGDA constructs remained relatively unchanged temporally. On the other hand, similar samples with the incorporation of HA showed a significant increase $(\mathrm{p}<0.05)$ in DNA content (Fig. 4.3). 


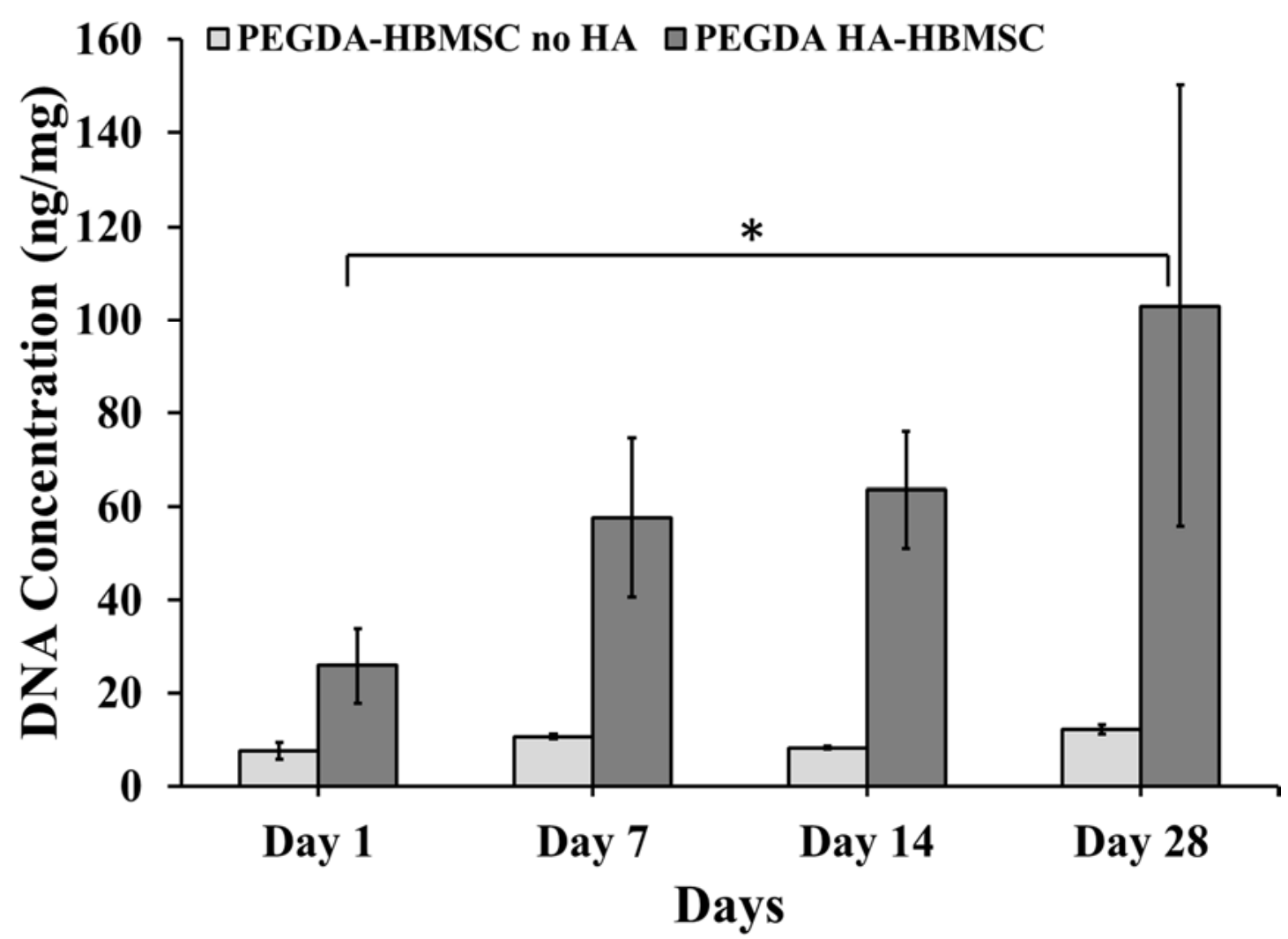

Figure 4.3: DNA concentration of HBMSC encapsulated in PEGDA and PEGDA HA scaffolds. The "*" indicates that the difference between the groups was statistically significant $(p<0.05)$

\subsubsection{Quantitative Real-Time Polymerase Chain Reaction (qRT-PCR)}

It was observed that after culturing the constructs in chondrogenic media for 28 days, there was an increase in the Aggrecan, Sox 9, and Type II collagen gene expression of the BMSCs, indicative of chondrogenic differentiation of the HBMSCs. It was also observed that the HBMSCs encapsulated in PEGDA-HA constructs showed minimal increase in expression of bone marker osteocalcin and minimal decrease in Type II collagen expression (Fig. 4.4). Overall, HBMSCs encapsulated in PEGDA-HA showed similar expression of these genes compared to the non-HA counterparts. 


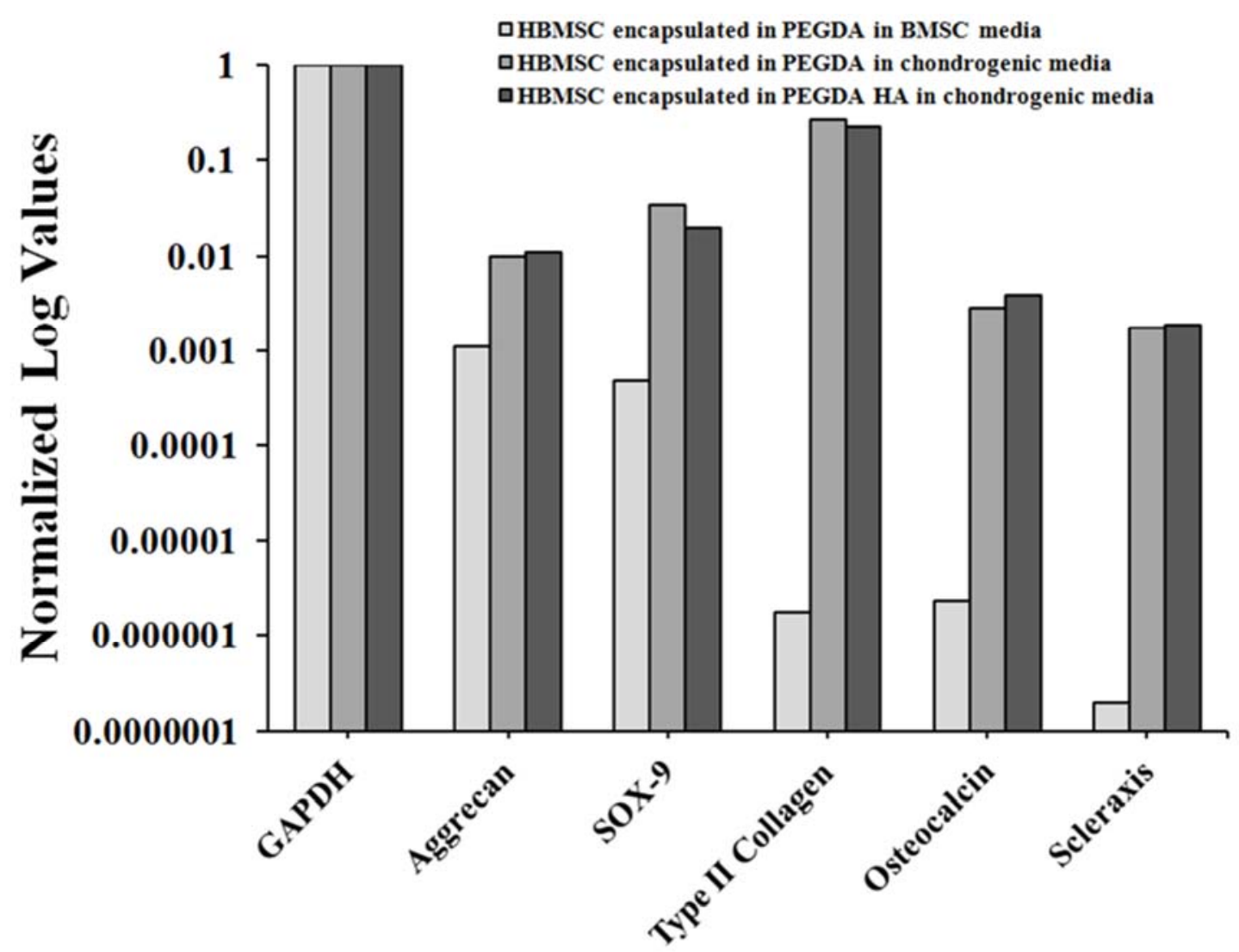

Figure 4.4: qRT-PCR of HBMSC grown over a period of 4 weeks in BMSC media and chondrogenic media. Results indicate that cells exposed to HA underwent similar chondrogenic differentiation to unexposed counterparts

\subsubsection{Mineralization}

The mineralization at the interface of the 2 layer, cellular PEGDA-Agar structures was determined using the ALP assay. The results (Mean $\pm \mathrm{SD}$; U/L) are summarized as follows: Day 1 - PEGDA without HA: $0.2 \pm 0.02$; PEGDA with HA: $0.22 \pm 0.09$; Day 14 - PEGDA without HA: $1.12 \pm 0.29$; PEGDA with HA: $2.2 \pm 0.10$; Day 28 - PEGDA without HA: 2.1 \pm 0.16 ; PEGDA with HA: $5.2 \pm 0.25$. The interface with HA exhibited higher ALP activity $(p<0.05)$ when compared to the constructs without HA at the end of a 4 week duration (Fig. 4.5 a). Confirmation of the enhanced mineralization under HA environments was additionally evidenced by histology using the Von-Kossa staining at the interface, 
specifically in the form of positive staining for calcium phosphate matrix (black staining; Fig. $4.5(b))$.

No evidence of calcium phosphate was evident in the histology of samples without HA (Fig. 4.5 (b)). In addition, without the use of HA, the gap between engineered cartilage and bone decreased only negligibly beyond two-weeks (by an additional $1 \%$ of original gap area). On the other hand, histological image analysis determined that calcium phosphate matrix comprised roughly $7.5 \%$ of the entire cartilage area when HA was incorporated in the engineered constructs. Moreover, when HA was incorporated, the interfacial gap between engineered cartilage to engineered bone was found be filled with tissue with $53 \%$ and $90 \%$ filling at 2 and 4 weeks respectively. Roughly $66 \%$ (area within the white dots; Fig. 4. 5(b)) of the transition zone (sum of areas within the white and yellow dots; Fig. 4.5(b)) comprised of calcium phosphate deposits after 4 weeks.

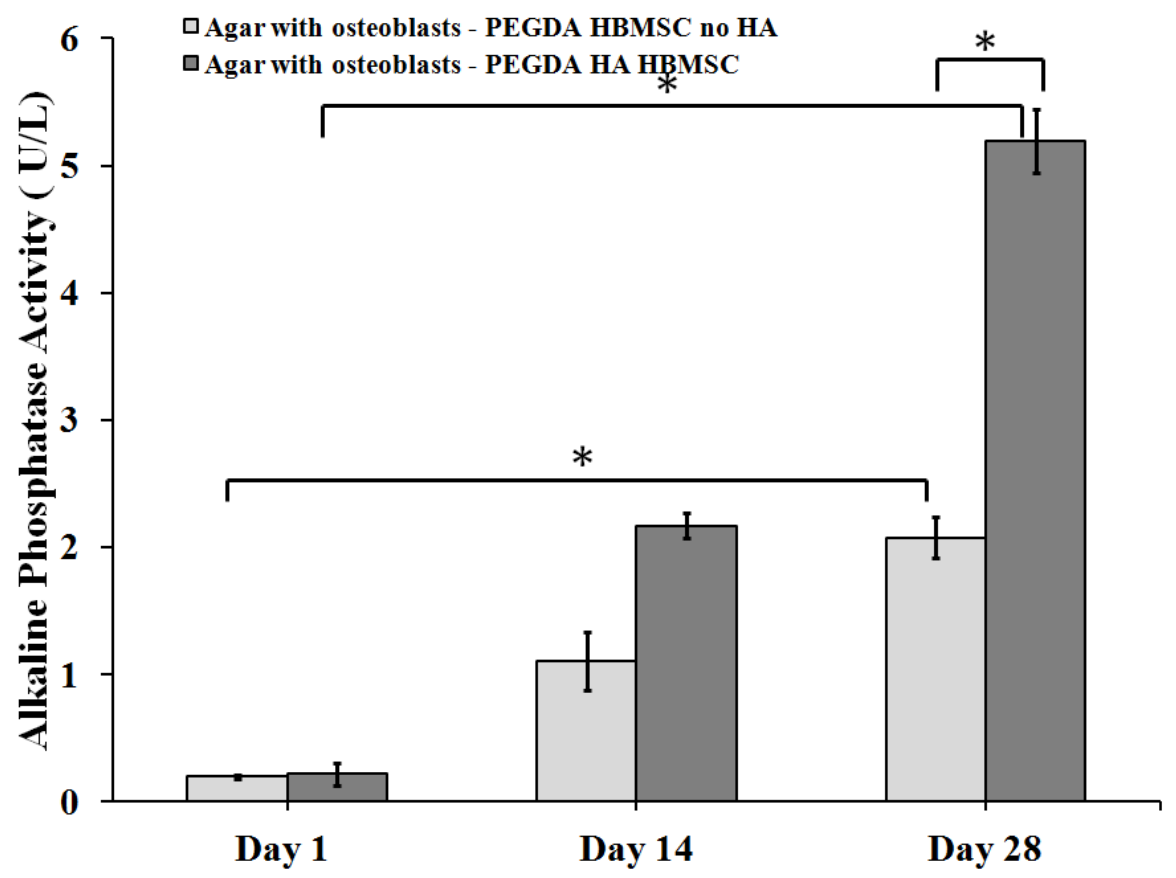

Figure 4.5 (a): ALP Activity using colorimetric method. The "**" indicates that the difference between the groups was statistically significant $(p<0.05)$. 


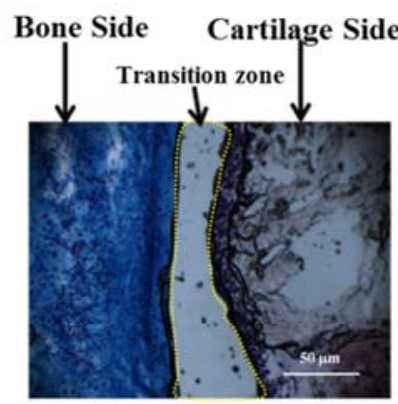

Day 1

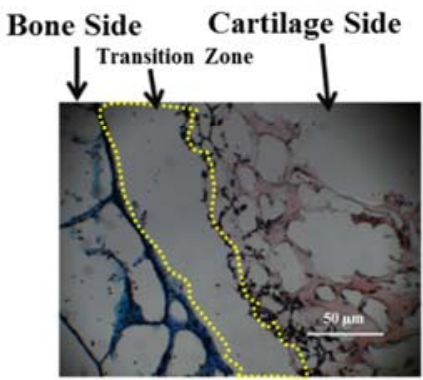

Day 1

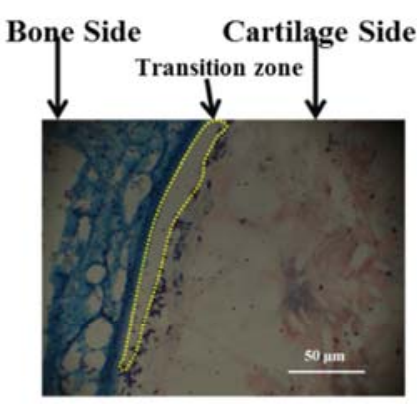

Week 2

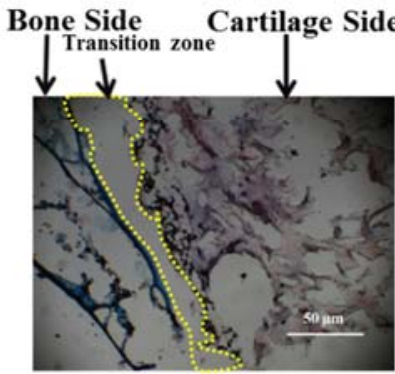

Week 2

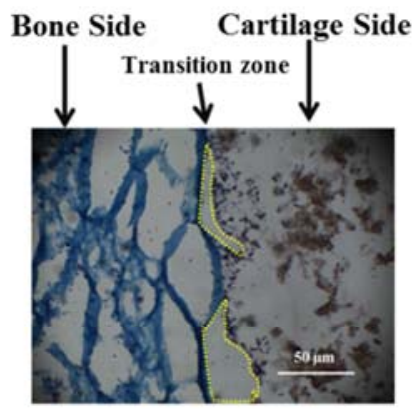

Week 4

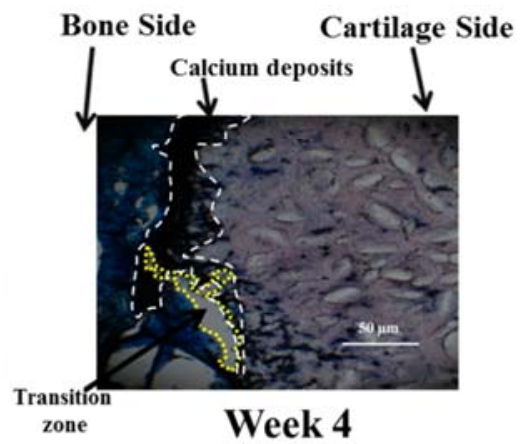

Figure 4.5 (b): Von Kossa - Alcin Blue histology images of 2 layer constructs. Above: Agar osteoblast and PEGDA-HBMSC and Below: Agar osteoblast PEGDA-HA-HBMSC. Results showed that there was an increase in ALP activity at day 28 for the tissue engineered cartilage exposed to HA nanoparticles. The histological findings (Fig. 4.5(b)) confirmed the colorimetric assessment of ALP activity (Fig 4.5(a)). The boundary of the transition zone was traced as indicated by the dotted yellow lines. At Day 1, a clear gap was apparent between the engineered cartilage and bone regions. Progressive filling of the transition zone subsequently occurred with calcium phosphate matrix deposits (black staining). At week 2, roughly $53 \%$ of the initial area of the transition zone was filled by the deposit in constructs with HA. By week 4, 90\% of the transition zone was filled in constructs with HA while it was $\sim 70 \%$ filled in the constructs without HA. White dotted line indicates the bone in growth into the cartilage region. Area measurements were made using Image analysis software (ImageJ, NIH, Bethesda, MD).

\subsubsection{Mechanical Properties}

The Young's modulus of the acellular and cellular scaffolds of all groups (acellular: $\mathrm{PEGDA} \pm \mathrm{HA}$; cellular: HBMSC-seeded PEGDA $\pm \mathrm{HA}$ ) was assessed using unconfined static compression testing. The results revealed no significant differences after 28 days ( $p$ $>0.05$ ) between the acellular groups. Similarly, the cellular groups exhibited comparable 
stiffness properties between each other $(p>0.05)$. However, there was a statistically significant difference $(p<0.05)$ in the temporal evolution of the Young's modulus of cellular samples grown, which increased over the 4 weeks (Fig. 4.6).

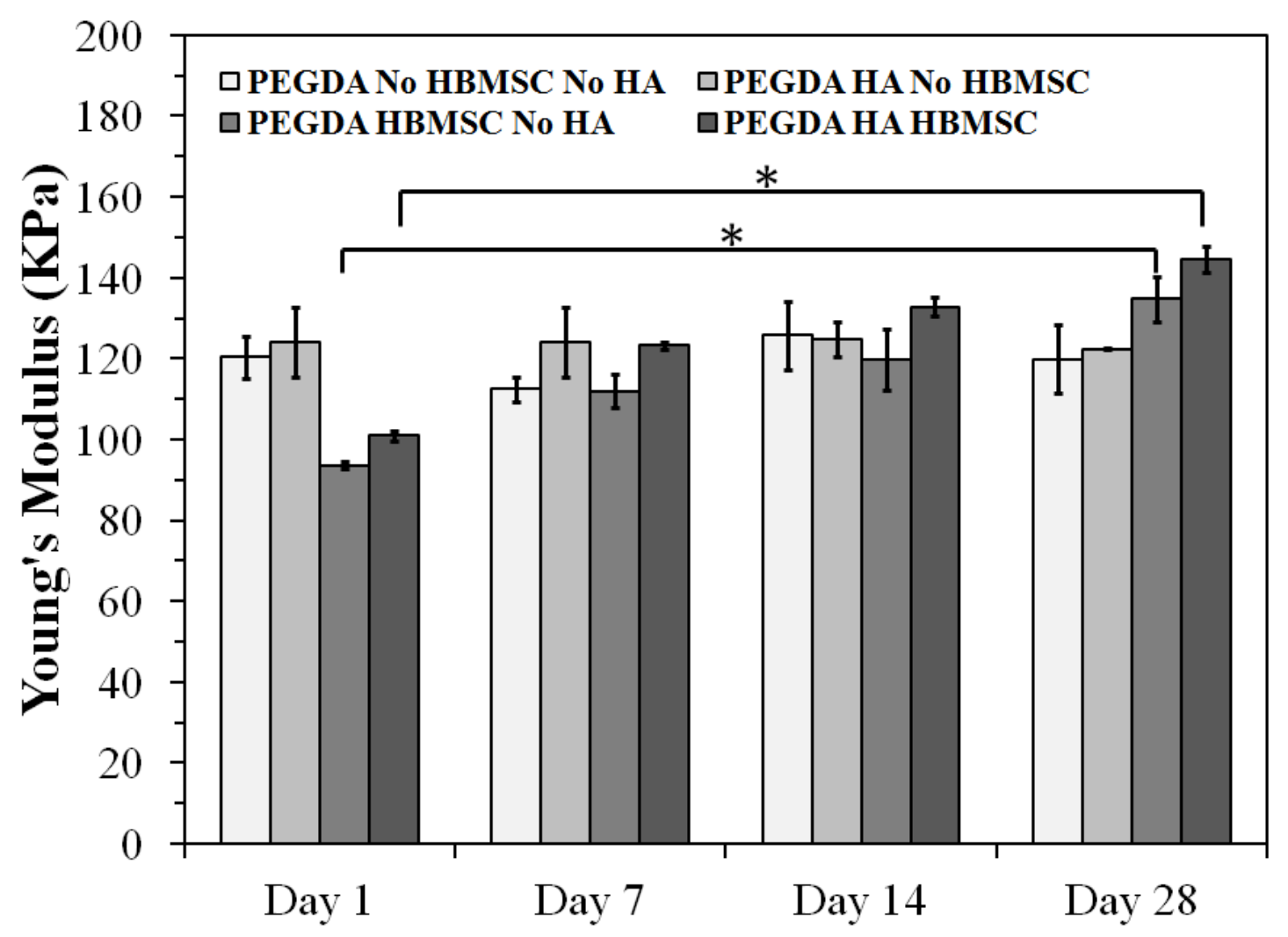

interfacial shear strength after addition of HA at 28 days was found

Figure 4.6: Compression test results. The "*” indicates that the difference between the groups was statistically significant $(p<0.05)$. Results showed that the presence of HA in acellular PEGDA and tissue engineered cartilage did not affect the mechanical integrity of PEGDA as well as that of the tissue engineered cartilage. There was a significant increase $(p<0.05)$ in the Young's modulus in the cellular groups when comparing Day 1 to Day 28. This demonstrated increased engineered tissue formation over 4 weeks resulting in increased stiffness of the cellular constructs.

The integration between engineered bone and cartilage constructs was assessed using mechanical shear loading and it was found that there was a statistically significant $(\mathrm{p}<0.05)$ difference in the integration strength between the groups when compared at both 1 week and at 4 weeks of tissue culture, i.e., Agar with osteoblast-HBMSC-encapsulated in 
PEGDA and Agar with osteoblast-HBMSC-encapsulated in PEGDA-HA. Furthermore, the shear strength of Agar with osteoblast-HBMSC-encapsulated in PEGDA-HA was significantly higher than the Agar with osteoblast-HBMSC-encapsulated in PEGDA-only at 4 weeks $(\mathrm{p}<0.05)$. At 28 days, the mean \pm SD shear strength for the group that incorporated HA exhibited shear strength in the order of: $5.91 \pm 0.59 \mathrm{kPa}$ while in the constructs without $\mathrm{HA}$ it was found to be: $3.60 \pm 0.11 \mathrm{kPa}$ (Fig. 4.7).

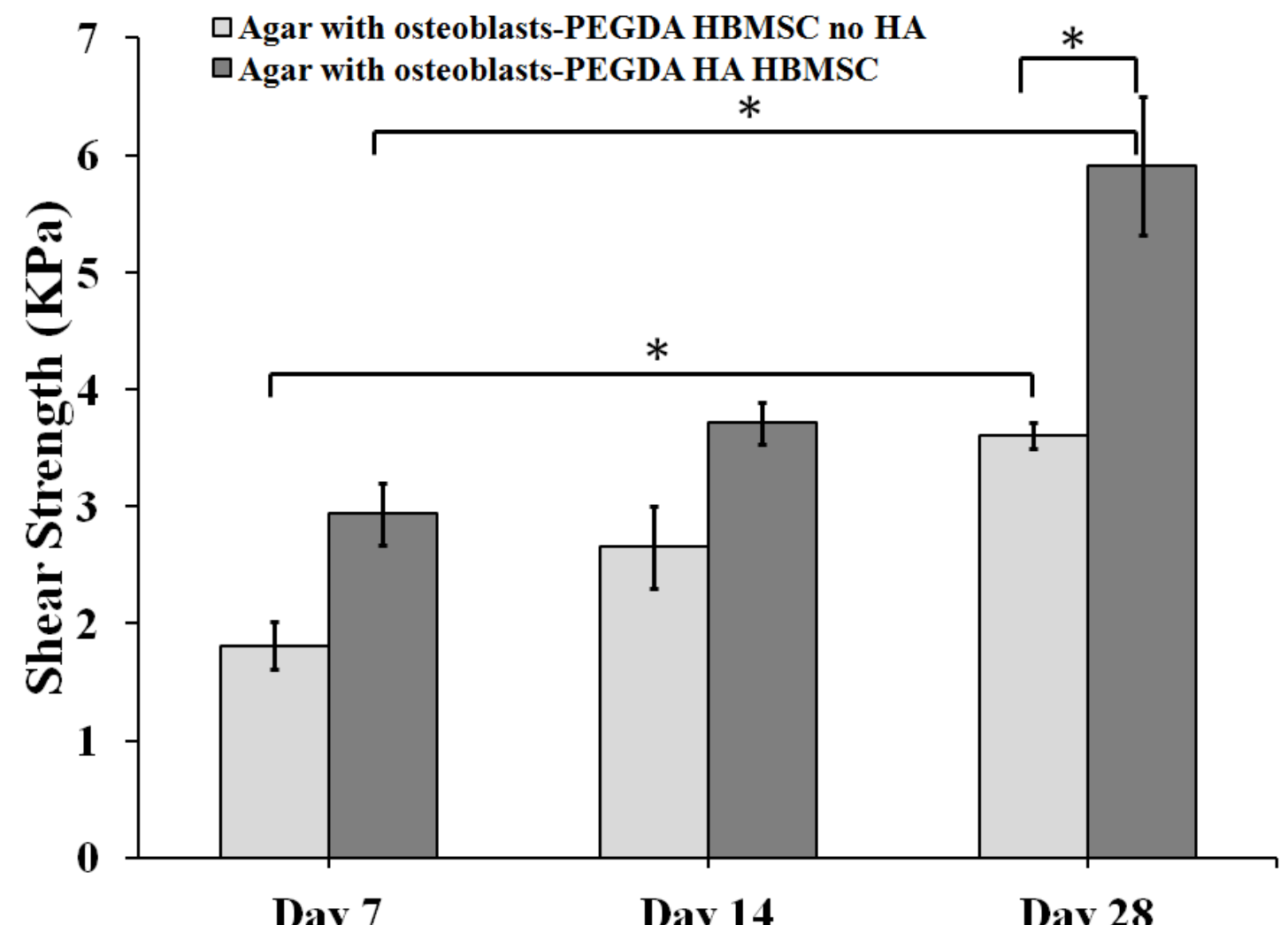

Figure 4.7: Shear Testing Results. The "*” indicates that the difference between the groups was statistically significant $(\mathrm{p}<0.05)$. Results showed that there was enhanced integration with bone at day 28 compared to day 1 in both groups evaluated. However, there was a significant increase in tissue integration at day 28 when HA was present showing its importance in enhancing the anchorage of tissue engineered cartilage to bone 
The $\%$ increase in interfacial shear strength after addition of HA at 28 days was found to be $64 \%$. Meanwhile, the $\%$ temporal increase in interfacial shear strength of samples cultured from 7 to 28 days differed negligibly between the with and without HA groups (over this timeframe, samples without HA increased by $99 \%$ whereas in HA-incorporated samples, it was found to be $101 \%$ ). We note in addition however that there was already a $\sim 62 \%$ increase in the interfacial shear strength of samples with HA inclusion after only 7 days of tissue culture and therefore was comparable to the augmentation in strength that was found after 28 days (64\%).

\subsection{Discussion}

The use of injectable hydrogels to support chondral and osteochondral cartilage filling has been extensively investigated over the past 15 years. Some prominent works are summarized here: Elisseeff et al [41] used an injectable hydrogel approach for the creation of neocartilage in vivo which could be implemented via a transdermal photopolymerization approach. Another study used a new class of injectable hydrogels derived from watersoluble chitosan and oxidized hyaluronic acid [42] which was highly amenable for cartilage tissue engineering applications. Guo et al [43] fabricated an injectable hydrogel bilayered construct in vivo to mimic the osteochondral layer. Another group, Nettles et al [44], suggested the use of another type of injectable elastin like polypeptide for the use of cartilage repair in vivo.

The overall consensus after meticulous in vivo studies was that lack of integration between hydrogel and host tissue yielded inconsistent levels of cartilage filling and repair. Some efforts to ameliorate the integration have been followed by various groups using 
mechanical, chemical or biological fixation [45]. For example, screws [46] and sutures [10] have been utilized previously to mechanical affix engineered cartilage to subchondral bone. Wang et al [16] demonstrated that chondroitin sulphate methacrylate could be used as an engineered cartilage to bone adhesive by demonstrating stable and durable fixation over a period of 5 weeks; however, further investigations were needed to demonstrate a consistently successfully outcome. Elsewhere, Hoemann et al [17] indicated that Chitosan glycerol phosphate when mixed with blood in the cartilage defect space not only formed greatly improved integration with sub-chondral bone, but also resulted in enhanced hyaline cartilage tissue formation. Indeed, in vivo (primarily in the rabbit model) cartilage tissue engineering studies have shown convincing bone marrow stem cell migratory responses towards the ostechondral interface and subsequent tissue remodeling when chitosan was utilized [47,48].

With a persistent lack of conclusive success in effective integration, the objective of this study was to evaluate the use of hydroxyapatite (HA) in nano particulate form, to promote the integration between tissue engineered cartilage grown in an injectable hydrogel substrate, to bone extracellular matrix (ECM). HA nanoparticles were found to settle at the inferior end of the cylindrical hydrogel specimens. Under these HA-rich environments, we determined first that the HBMSC viability and proliferation remained stable. Further, the cells exhibited chondrogenic differentiation in PEGDA+ HA environments through robust expression of articular cartilage genes, Aggrecan, Sox-9 and type II collagen (Fig. 4). Upon verification that HA was safe to incorporate within the PEGDA hydrogels, we proceeded with investigations on mechanical properties and integration effectiveness of PEGDA+ HA based engineered cartilage to bone ECM. Interfacial shear stress was significantly 
increased when HA was used $(\mathrm{p}<0.05$; Fig. 8). Histological findings demonstrated traversing of the PEGDA to Bone interface with the creation and a distinct presence of a calcium phosphate-rich transition zone (Fig. 5b).

The incorporation of HA in an injectable photopolymerizable system was able to provide an enhanced anchorage of engineered cartilage to bone ECM; to our knowledge we are the first to demonstrate this finding in photopolymerizable hydrogels. However, other laboratories have attempted to augment the interfacial mechanical properties of engineered cartilage and subchondral bone using biomaterials such as chitosan particles [48], porous calcium polyphosphate [49], chitosan-chondroitin sulfate [50]. One group even used HA in conjunction with non-photopolymerizable alginate hydrogels and reported on its shear mechanical properties [18,51]. As data was reported as shear moduli [18], we first computed the shear moduli of our PEGDA-HA constructs at 14 and 28 days in the linear region of the mean stress-strain curve ( $n=6$ samples; curve not shown), which persisted up to $\sim 5 \%$ strain. The computed shear moduli from Khanarian et al [18] was $\sim 1.8$ and 3.5 $\mathrm{kPa}$ at 14 and 28 days respectively, whereas we found the shear moduli for the PEGDAHA samples to be in the order of $33.6 \pm 1.9 \mathrm{kPa}$ at 14 days and $40.2 \pm 3.7 \mathrm{kPA}$ at 28 days $(\mathrm{n}=6$ samples/group). This evaluation indicates that the shear moduli determined here is an order of magnitude large than other reports in the literature on osteochondral scaffold shear properties which incorporated HA. However, it should be noted that this is not a direct comparison because shear properties were measured using a rheometer [18], whereas we assessed shearing properties at the interface of engineered cartilage and engineered bone. Interestingly, we found that the benefit of HA incorporation was seen as early as after 7 days of culture at which point there was already a substantial increase in interfacial 
shear strength (by $\sim 62 \%$ ) in comparison to corresponding samples without HA (Fig. 7). The presence of HA had a negligible effect on the subsequent \% temporal increase in interfacial shear strength between 7 and 28 days of tissue culture (\% increase in samples with HA: $101 \%$ and in samples without HA: $99 \%$ ). As a result, at 28 days, there was similar $\%$ interfacial shear strength improvement in the samples with HA versus the samples without HA (by $\sim 64 \%$ ) in comparison to the corresponding $\%$ increase observed at 7 days (by 62\%). This finding suggests that HA augments the interfacial shear strength of engineered cartilage to engineered bone constructs during the early, i.e., the first week of tissue development, and this benefit carries forward beyond this period in a relatively unaffected manner. From a translational standpoint, the incorporation of HA for osteochondral repair will thus have a pronounced effect in terms of the interfacial shear strength of the tissue engineered cartilage construct to the subchondral bone during the early stages (first 7 days) following treatment, after which standard tissue integration process will continue, likely unaltered. Thus, future in vivo studies in cartilage tissue engineering that will incorporate HA into their development protocol could likely assess maximum interfacial shear strength improvement of engineered cartilage to host bone tissue that is directly attributable to HA, as early as 1 week following implantation.

Alkaline phosphatase activity was found to be higher in the groups when HA was used. Histological studies also demonstrated controlled growth of calcium phosphate deposits at the interface. We interpret that the augmented calcium phosphate deposits were due to migration of osteoblasts from the bone ECM to the inferior region of the tissue engineered cartilage layer that ultimately led to the creation of a transition zone; again this was directly attributable to the presence of HA particles at the interface. However it is important to note 
that the transition zone characterized by calcium phosphate, i.e., bone-related ECM occupied $\sim 7.5 \%$ of the total cartilage region, whereas the rest of this area was rich in engineered cartilage tissue. Thus, in the context of osteochondral defects we anticipate that the majority of the space would still be filled by cartilaginous tissue, except for an ingrowth of calcium phosphate from subchondral bone (promoted by HA nanoparticles), which would thereby assist in securing the engineered cartilage construct in-place. Indeed, histological evidence suggested that a temporal narrowing of the interfacial gap between engineered cartilage to bone progressively occurred over 4 weeks when HA was used ( $53 \%$ and $90 \%$ filling at 2 and 4 weeks respectively), via the creation of a transition zone, primarily characterized by calcium phosphate ECM deposits (Fig. 6b). The incorporation of $\mathrm{HA}$ in the engineered constructs permitted $\sim 66 \%$ of the transition zone to be comprised of calcium phosphate deposits after 4 weeks. Conversely a calcium phosphate-rich transition zone was absent when HA was not utilized. In addition, in the constructs without HA, the gap between engineered cartilage and bone decreased only negligibly beyond twoweeks (by an additional $1 \%$ of original gap area) demonstrating that in an in vitro framework, tissue filling of the transition zone can be enhanced during extended culture periods ( $>2$ weeks) using HA nanoparticles. Recently St. Pierre et al [49], reported that the presence of a calcified zone at the osteochondral junction augmented the interfacial shear strength by $\sim 3.3$ times in comparison to when a calcified matrix was absent. Taking this finding in the context of our study, HA may have initiated sparse calcium phosphate deposition in the transition zone during the early stages of tissue culture (1 week) which contributed to the increase in interfacial shear strength. 
Even though our results with HA appear promising, our model was restricted to in vitro, static processes and did not mimic in vivo physiological loading states or interactions from surrounding such as the synovial fluid. Secondly, the cells utilized were from healthy sources, yet very frequently osteochondral and chondral defects are common in individuals who have mild to moderate disease states such as osteoarthritis. We are currently examining the effect of disease on our proposed approaches of integration effectiveness utilizing HA. Finally, even though significant improvement in integration strength with HA was observed $(\mathrm{p}<0.05)$, the critical strength needed for effective cartilage tissue repair and regeneration outcomes clinically has not been identified. In addition native human cartilage to bone failure shear strength has been reported to be at least three orders of magnitudes higher ( 7.25 MPa) [52]. Thus, whether or not the improvements found in the constructs with HA will translate into enhanced cartilage repair in vivo still remains to be proven.

Nonetheless, we in summary demonstrated that the significant improvement $(p<0.05)$ in the integration strength of tissue engineered cartilage with underlying engineered bone can be obtained with the use of hydroxyapatite nanoparticles, which aggregate at the inferior end of the injectable photopolymerizable hydrogels. The process of interfacial shear strength improvement between engineered cartilage to engineered bone constructs seems to have occurred during the early tissue culture period (first 7 days), and this increase carried forward to extended durations (up to 28 days) without interaction with the subsequent intrinsic augmentation in strength due to de novo tissue formation processes. The mechanism of improved integration and as a consequence, enhanced anchorage of the 
engineered cartilage constructs appeared to be due to the osteoblast secretion of calcium phosphate deposits, induced by the presence of HA.

Meanwhile, the bulk of the engineered cartilage region still consisted of de novo tissue formation rich in cartilage ECM. We therefore propose the incorporation of HA nanoparticles as a means to enhance the integration of engineered cartilage to subchondral bone in future photopolymerizable hydrogel-based cartilage tissue engineering studies.

\subsection{References}

1. Curl WW, Krome J, Gordon ES, Rushing J, Smith BP, Poehling GG. Cartilage injuries: a review of 31,516 knee arthroscopies. Arthroscopy 1997;13(4):456-60 
2. Kreuz PC, Muller S, Ossendorf C, Kaps C, Erggelet C. Treatment of focal degenerative cartilage defects with polymer-based autologous chondrocyte grafts: four-year clinical results. Arthritis Res Ther 2009;11(2):R33.

3. Hjelle K, Solheim E, Strand T, Muri R, Brittberg M. Articular cartilage defects in 1,000 knee arthroscopies. Arthroscopy 2002;18(7):730-4.

4. Wang Y, Ding C, Wluka AE, Davis S, Ebeling PR, Jones G, Cicuttini FM. Factors affecting progression of knee cartilage defects in normal subjects over 2 years. Rheumatology (Oxford) 2006;45(1):79-84.

5. Henrotin Y, Kurz B, Aigner T. Oxygen and reactive oxygen species in cartilage degradation: friends or foes? Osteoarthritis Cartilage 2005;13(8):643-54.

6. Magnussen RA, Dunn WR, Carey JL, Spindler KP. Treatment of focal articular cartilage defects in the knee: a systematic review. Clin Orthop Relat Res 2008;466(4):952-62.

7. Wasiak J, Clar C, Villanueva E. Autologous cartilage implantation for full thickness articular cartilage defects of the knee. Cochrane Database Syst Rev 2006;(3):CD003323.

8. Ramaswamy S, Uluer MC, Leen S, Bajaj P, Fishbein KW, Spencer RG. Noninvasive assessment of glycosaminoglycan production in injectable tissueengineered cartilage constructs using magnetic resonance imaging. Tissue Engineering Part C-Methods 2008;14(3):243-249.

9. Robertson DB, Daniel DM, Biden E. Soft tissue fixation to bone. Am J Sports Med 1986;14(5):398-403.

10. Stengel D, Casper D, Bauwens K, Ekkernkamp A, Wich M. Bioresorbable pins and interference screws for fixation of hamstring tendon grafts in anterior cruciate ligament reconstruction surgery: a randomized controlled trial. Am J Sports Med 2009;37(9):1692- 8 .

11. Herrmann JB, Kelly RJ, Higgins GA. Polyglycolic acid sutures: Laboratory and clinical evaluation of a new absorbable suture material. Archives of Surgery 1970;100(4):486- 490.

12. Zantop T, Welbers B, Weimann A, Rummler M, Hedderich J, Musahl V, Petersen W. Biomechanical evaluation of a new cross-pin technique for the fixation of different sized bone-patellar tendon-bone grafts. Knee Surg Sports Traumatol Arthrosc 2004;12(6):520-7. 
13. Bruns TB, Worthington JM. Using tissue adhesive for wound repair: a practical guide to dermabond. Am Fam Physician 2000;61(5):1383-8.

14. Hunziker EB, Kapfinger E. Removal of proteoglycans from the surface of defects in articular cartilage transiently enhances coverage by repair cells. J Bone Joint Surg Br 1998;80(1):144-50.

15. Djouad F, Rackwitz L, Song Y, Janjanin S, Tuan RS. ERK1/2 activation induced by inflammatory cytokines compromises effective host tissue integration of engineered cartilage. Tissue Eng Part A 2009;15(10):2825-35.

16. Wang DA, Varghese S, Sharma B, Strehin I, Fermanian S, Gorham J, Fairbrother DH, Cascio B, Elisseeff JH. Multifunctional chondroitin sulphate for cartilage tissuebiomaterial integration. Nat Mater 2007;6(5):385-92.

17. Hoemann CD, Sun J, McKee MD, Chevrier A, Rossomacha E, Rivard GE, Hurtig M, Buschmann MD. Chitosan-glycerol phosphate/blood implants elicit hyaline cartilage repair integrated with porous subchondral bone in microdrilled rabbit defects. Osteoarthritis Cartilage 2007;15(1):78-89.

18. Khanarian NT, Jiang J, Wan LQ, Mow VC, Lu HH. A hydrogel-mineral composite scaffold for osteochondral interface tissue engineering. Tissue Eng Part A 2012;18(5- 6):533-45.

19. Ramaswamy S, Gurkan I, Sharma B, Cascio B, Fishbein KW, Spencer RG. Assessment of tissue repair in full thickness chondral defects in the rabbit using magnetic resonance imaging transverse relaxation measurements. J Biomed Mater Res B Appl Biomater 2008;86(2):375-80.

20. Lane JG, Massie JB, Ball ST, Amiel ME, Chen AC, Bae WC, Sah RL, Amiel D. Followup of osteochondral plug transfers in a goat model: a 6-month study. Am J Sports Med 2004;32(6):1440-50.

21. Horas U, Pelinkovic D, Herr G, Aigner T, Schnettler R. Autologous chondrocyte implantation and osteochondral cylinder transplantation in cartilage repair of the knee joint. A prospective, comparative trial. J Bone Joint Surg Am 2003;85$\mathrm{A}(2): 185-92$.

22. Hunziker EB. Articular cartilage repair: are the intrinsic biological constraints undermining this process insuperable? Osteoarthritis Cartilage 1999;7(1):15-28.

23. Wang DA, Williams CG, Li Q, Sharma B, Elisseeff JH. Synthesis and characterization of a novel degradable phosphate-containing hydrogel. Biomaterials 2003;24(22):3969-80. 
24. Dominici M, Le Blanc K, Mueller I, Slaper-Cortenbach I, Marini F, Krause D, Deans R, Keating A, Prockop D, Horwitz E. Minimal criteria for defining multipotent mesenchymal stromal cells. The International Society for Cellular Therapy position statement. Cytotherapy 2006;8(4):315-7.

25. Zhang Y, Wang C, Liao W, Li Z, Guo X, Zhao Q, Duan C, Xia R. In vitro chondrogenic phenotype differentiation of bone marrow-derived mesenchymal stem cells. J Huazhong Univ Sci Technolog Med Sci 2004;24(3):275-8.

26. Harris SA, Enger RJ, Riggs BL, Spelsberg TC. Development and characterization of a conditionally immortalized human fetal osteoblastic cell line. J Bone Miner Res 1995;10(2):178-86.

27. Huang CY, Reuben PM, D'Ippolito G, Schiller PC, Cheung HS. Chondrogenesis of human bone marrow-derived mesenchymal stem cells in agarose culture. Anat Rec A Discov Mol Cell Evol Biol 2004;278(1):428-36.

28. Durst CA, Cuchiara MP, Mansfield EG, West JL, Grande-Allen KJ. Flexural characterization of cell encapsulated PEGDA hydrogels with applications for tissue engineered heart valves. Acta Biomater 2011;7(6):2467-76.

29. Yang F, Williams CG, Wang DA, Lee H, Manson PN, Elisseeff J. The effect of incorporating RGD adhesive peptide in polyethylene glycol diacrylate hydrogel on osteogenesis of bone marrow stromal cells. Biomaterials 2005;26(30):5991-8.

30. Kim SS, Sun Park M, Jeon O, Yong Choi C, Kim BS. Poly(lactide-coglycolide)/ hydroxyapatite composite scaffolds for bone tissue engineering. Biomaterials 2006;27(8):1399-409.

31. Sato M, Sambito MA, Aslani A, Kalkhoran NM, Slamovich EB, Webster TJ. Increased osteoblast functions on undoped and yttrium-doped nanocrystalline hydroxyapatite coatings on titanium. Biomaterials 2006;27(11):2358-69.

32. Dua R, Ramaswamy S. Relative survivability of human osteoblasts is enhanced by 39 degrees $\mathrm{C}$ and ascorbic acid after exposure to photopolymerization ingredients. Cytotechnology 2012;65(4):587-96.

33. Jeon O, Alsberg E. Regulation of Stem Cell Fate in a Three-Dimensional Micropatterned Dual-Crosslinked Hydrogel System. Advanced Functional Materials 2013;23(38):4765- 75.

34. Hwang NS, Kim MS, Sampattavanich S, Baek JH, Zhang Z, Elisseeff J. Effects of threedimensional culture and growth factors on the chondrogenic differentiation of murine embryonic stem cells. Stem Cells 2006;24(2):284-91. 
35. Williams CG, Kim TK, Taboas A, Malik A, Manson P, Elisseeff J. In vitro chondrogenesis of bone marrow-derived mesenchymal stem cells in a photopolymerizing hydrogel. Tissue Eng 2003;9(4):679-88.

36. Farndale RW, Buttle DJ, Barrett AJ. Improved quantitation and discrimination of sulphated glycosaminoglycans by use of dimethylmethylene blue. Biochim Biophys Acta 1986;883(2):173-7.

37. Betz MW, Modi PC, Caccamese JF, Coletti DP, Sauk JJ, Fisher JP. Cyclic acetal hydrogel system for bone marrow stromal cell encapsulation and osteodifferentiation. J Biomed Mater Res A 2008;86(3):662-70.

38. Myers TW, Gelfand DH. Reverse transcription and DNA amplification by a Thermus thermophilus DNA polymerase. Biochemistry 1991;30(31):7661-6.

39. Vandesompele J, De Preter K, Pattyn F, Poppe B, Van Roy N, De Paepe A, Speleman F. Accurate normalization of real-time quantitative RT-PCR data by geometric averaging of multiple internal control genes. Genome Biol 2002;3(7); Epublication.

40. Chang C-W, van Spreeuwel A, Zhang C, Varghese S. PEG/clay nanocomposite hydrogel: a mechanically robust tissue engineering scaffold. Soft Matter 2010;6(20):5157-5164.

41. Elisseeff J, Anseth K, Sims D, McIntosh W, Randolph M, Yaremchuk M, Langer R. Transdermal photopolymerization of poly(ethylene oxide)-based injectable hydrogels for tissue-engineered cartilage. Plast Reconstr Surg 1999;104(4):101422.

42. Tan H, Chu CR, Payne KA, Marra KG. Injectable in situ forming biodegradable chitosan-hyaluronic acid based hydrogels for cartilage tissue engineering. Biomaterials 2009;30(13):2499-506.

43. Guo X, Park H, Liu G, Liu W, Cao Y, Tabata Y, Kasper FK, Mikos AG. In vitro generation of an osteochondral construct using injectable hydrogel composites encapsulating rabbit marrow mesenchymal stem cells. Biomaterials 2009;30(14):2741- 52.

44. Nettles DL, Kitaoka K, Hanson NA, Flahiff CM, Mata BA, Hsu EW, Chilkoti A, Setton LA. In situ crosslinking elastin-like polypeptide gels for application to articular cartilage repair in a goat osteochondral defect model. Tissue Eng Part A 2008;14(7):1133-40.

45. Dua R, Ramaswamy S. Strategies for integration of tissue engineered constructs to native cartilage and bone, In: Tissue Engineering: Fundamentals, Techniques and 
Applications, Ishikawa T. and Yamamoto M. Eds, Nova Publishers, Hauppauge, NY; 2012; 75-87.

46. Matthews LS, Lawrence SJ, Yahiro MA, Sinclair MR. Fixation strengths of patellar tendon-bone grafts. Arthroscopy 1993;9(1):76-81.

47. Siu RK, Zara JN, Hou Y, James AW, Kwak J, Zhang X, Ting K, Wu BM, Soo C, Lee M. NELL-1 promotes cartilage regeneration in an in vivo rabbit model. Tissue Eng Part A 2012;18(3-4):252-61.

48. Lafantaisie-Favreau CH, Guzman-Morales J, Sun J, Chen G, Harris A, Smith TD, Carli A, Henderson J, Stanish WD, Hoemann CD. Subchondral pre-solidified chitosan/blood implants elicit reproducible early osteochondral wound-repair responses including neutrophil and stromal cell chemotaxis, bone resorption and repair, enhanced repair tissue integration and delayed matrix deposition. BMC Musculoskelet Disord 2013;14:27.

49. St-Pierre JP, Gan L, Wang J, Pilliar RM, Grynpas MD, Kandel RA. The incorporation of a zone of calcified cartilage improves the interfacial shear strength between in vitro-formed cartilage and the underlying substrate. Acta Biomater 2012;8(4):1603-15.

50. Silva JM, Georgi N, Costa R, Sher P, Reis RL, Van Blitterswijk CA, Karperien M, Mano JF. Nanostructured 3D constructs based on chitosan and chondroitin sulphate multilayers for cartilage tissue engineering. PLoS One 2013;8(2):e55451.

51. Khanarian NT, Haney NM, Burga RA, Lu HH. A functional agarosehydroxyapatite scaffold for osteochondral interface regeneration. Biomaterials 2012;33(21):5247-58.

52. Kumar P, Oka M, Nakamura T, Yamamuro T, Delecrin J. Mechanical strength of osteochondral junction. Nihon Seikeigeka Gakkai Zasshi 1991;65(11):1070-7. 


\section{Chapter 5}

Improvement in integration of engineered cartilage with native cartilage matrix in healthy and diseased state

This chapter describes the interaction of engineered cartilage to a healthy and diseased mimics of cartilage in HA rich environments. This chapter provides evidence that the incorporation of HA can be beneficial for enhancing the integration of a tissue engineered scaffold to a defect space even if the native cartilage has become diseased. 


\subsection{Abstract}

We previously reported that Hydroxyapatite (HA) nanoparticles promote engineered cartilage to bone matrix integration. In the present study, using a similar approach, we investigated the effectiveness of integrating tissue engineered cartilage derived from human bone marrow derived stem cells (HBMSCs) to healthy as well as osteoarthritic cartilage mimics in an in vitro engineered tissue model system. We found that there was a statistically significant $(p<0.05)$ higher shear strength in the tissue engineered cartilage from HBMSCs without HA particles which was integrated with healthy chondrocytederived cartilage matrix as compared to the corresponding counterparts with HA. However we found the opposite effect in osteoarthritic environments, wherein the HBMSC-derived cartilage integrated with cartilage matrix with HA particles exhibited a significantly higher $(p<0.05)$ interfacial shear strength as compared to when HA was not incorporated; histological evidence subsequently confirmed that a distinct spatial transition zone, rich in calcium phosphate deposits, is likely to have attributed to this higher interfacial strength. These findings collectively point towards an important role for HA nanoparticles in treating osteochondral defects when osteoarthritis is a co-morbidity. We speculate that the calcified layer formation at the interface in the osteoarthritic environment in the presence of HA is due to similarities in gene expression in this diseased state in comparison to bone matrix.

\subsection{Introduction}

Articular cartilage lesions in the knee frequently occur following an injury. Curl et al [1] demonstrated that up to $63 \%$ out of a total of 31514 knee arthroscopies suffered from chondral lesions. Another study by Hjelle et al [2], found that $61 \%$ out of 1000 knee 
arthroscopies had chondral or osteochondral lesions. Ultimately, an absence of an intrinsic healing capacity in chondrocytes prevents it from permitting complete restoration of the lost tissue. With limited treatment options, the sustained presence of cartilage defects may lead to the onset of osteoarthritis [3-5], which will accelerate the tissue loss. Numerous studies have been done $[6,7]$ to treat articular cartilage defects in the knee but none of them have been able to provide consistently favorable outcomes.

Tissue engineering approaches have been shown to hold great promise for treating cartilage defects. Tissue engineering generally involves the implantation of a biodegradable scaffold within the defect space that will degrade over time and concomitantly, it will support tissue repair/regeneration processes, initiated by cells present within the defect space [8]. Since the knee is highly mobile, an added prerequisite for cartilage tissue engineering is the retention of new cartilage within the defect, i.e., the scaffold would need to be retained in the defect site during the early phases of the regenerative process to promote sufficient tissue filling. We note that such retention would not only require effective integration of de novo cartilage with the underlying subchondral bone (in the case of osteochondral defects), but in addition, would also need to integrate well with surrounding native cartilage tissues. To permit such integration, previous studies have utilized approaches based on the principles of mechanical [9-12], chemical [13-15] and biological fixation [16-18]. While these investigations were promising, consistent success was again lacking.

Recently, injectable hydrogels incorporating hydroxyapatite (HA) nanoparticles have shown great potential in enhancing the integration of engineered cartilage to bone matrix $[18,19]$. The targeted treatment was intended for small to medium sized 
osteochondral defects $\left(<50 \mathrm{~mm}^{2}\right)$ that could arise either from an injury and/or from mild to moderate levels of osteoarthritis [20]. In addition, our recent experience suggested that HA directly promoted enhanced integration of the engineered cartilage to the bone matrix by the creation of an intermediate calcium phosphate rich transition zone, thereby permitting greater stability of the implant [19]. We note that previous studies have described that a graded transition in material properties between two different tissue matrices is an indicator of integration effectiveness [21]. However, as described earlier, complete spatial integration must require fusion of the engineered cartilage to the surrounding native cartilage as well, and not only to bone. This is particularly the case in chondral defects where the surrounding native tissue is characterized completely by articular cartilage. In this context, here, we report on the utility of HA nanoparticles in promoting the integration between engineered cartilage derived from human bone marrow mesenchymal stem cells (HBMSCs) with the chondral matrix secreted by healthy (HCs) human chondrocytes (HCs). The experiments were subsequently repeated with human osteoarthritic chondrocytes (HCOAs) in place of the HCs, so as to understand the impact of this diseased state on cartilage-cartilage integration processes, in considering that some level of osteoarthritis is usually present in knee articular cartilage, containing injuryinduced defects [22].

\subsection{Material and methods}

\subsubsection{Overview}

An in vitro healthy and diseased engineered cartilage model system originating from human chondrocytes was integrated with HBMSC-derived cartilaginous engineered 
matrix and evaluated after 28 days of growth. The cartilage matrix from the chondrocytes was prepared using agar scaffolds that encapsulated in a segregated manner, the healthy and osteoarthritic chondrocytes populations. Meanwhile the HBMSCs were seeded onto photopolymerizable poly (ethylene glycol) diacrylate (PEGDA). Assessment was conducted in terms of viability, mechanical testing, histological and gene expression at the following time points: Day 1, Day 7, Day 14 and Day 28.

\subsubsection{Cell Culture}

\subsubsection{Human Bone marrow derived Mesenchymal Stem Cells (HBMSCs)}

HBMSCs (Science cell, Carlsbad, CA, USA) were seeded onto Poly D-lysine coated T-75 flasks (Fisher Scientific, Pittsburg, PA, USA). The cells were cultured in manufacturer supplied proprietary medium (AdvanceSTEM Mesenchymal Stem Cell Expansion Kit (Thermo Scientific, Waltham, WA) until passage three (P3).

\subsubsection{Healthy Human Chondrocytes (HC)}

HCs (Cell Applications Inc., San Diego, CA, USA) were sourced from nonpathologic articular cartilage. They were cryopreserved at passage 2 (P2) when shipped by the manufacturer. When the cells were received, they were plated in T-75 flasks (Fisher Scientific, Pittsburgh, PA, USA) and allowed to proliferate. The cells were cultured in the Human Chondrocyte Media (Cell Applications, San Deigo, CA) until P4 and were subsequently used for the experiments. 


\subsubsection{Human Chondrocytes-Osteoarthritis (HCOA)}

HCOA (Cell Applications) were isolated from the articular cartilage from patients with Osteoarthritis. They were received from the manufacturer at P1 and prior to usage in the experiments, they were cultured, and propagated in the human chondrocyte media (Cell Applications) until P4.

\subsubsection{Tissue Engineered Healthy Cartilage}

Engineered healthy cartilage was prepared using 2\% Agar scaffold [23] in which adult chondrocytes were encapsulated. $2.5 \%$ of Agar solution (Fischer Scientific) was prepared and heated to a temperature of $70^{\circ} \mathrm{C}$. Meanwhile, chondrocytes were trypsinzed and 20 million cells were dissolved in $200 \mu 1$ of cell media. Once the Agar solution started to boil, it was removed from the hot plate and allowed to cool in a room temperature environment. When the temperature reached $40^{\circ} \mathrm{C}, 64 \mu \mathrm{l}$ of Agar solution was mixed with $16 \mu 1$ of cell suspension and casted for 5 minutes in custom designed molds $(5 \mathrm{~mm}$ in diameter and $4.1 \mathrm{~mm}$ in length) at the room temperature. Each gel construct consisted of a $2 \%$ Agar solution with a cellular suspension consisting of $\sim 1.6$ million chondrocytes.

\subsubsection{Tissue Engineered Diseased Cartilage}

Tissue engineered osteoarthritic cartilage was prepared in the same manner as tissue engineered healthy cartilage except for the use of HCOAs instead of HCs.

\subsubsection{Stem-Cell derived Tissue Engineered Cartilage}

BMSC derived engineered cartilage was prepared using our previously established protocols [19]. Briefly, the constructs were fabricated using 15\% PEGDA solution with a $0.5 \% \mathrm{w} / \mathrm{v}$ HA. $15 \%$ PEGDA solution was prepared by dissolving $150 \mathrm{mg}$ of PEGDA 
powder obtained from Glycosan Biosystems ( Salt Lake city, UT) and $5 \mathrm{mg}$ of HA nanoparticles (Catalog \# 677418, Sigma Aldrich) in $1 \mathrm{ml}$ Phosphate buffer saline (PBS) (Sigma Aldrich). Subsequently, $100 \mathrm{mg} / \mathrm{ml}$ of photoinitiator solution (Irgacure 2959, Ciba Specialty Chemicals, Tarrytown, NY) in 70\% ethanol was added to the monomer solution in a concentration of $(5 \mu \mathrm{l} / \mathrm{ml})$ to get a final concentration of $0.05 \% \mathrm{w} / \mathrm{v}$ of photo initiator. HBMSCs were introduced just prior to UV exposure at a concentration of 20 million cells $/ \mathrm{ml}$. Next, to induce polymerization, the solution was irradiated with UV light at 4-5 $\mathrm{mW} / \mathrm{cm}^{2}$ for 7 minutes that we previously demonstrated did not antagonize the viability of the cells [24].

Once the chondrocyte-derived $\mathrm{HC}$ and $\mathrm{HCOA}$ engineered cartilage segments were prepared, samples of engineered cartilage matrix secreted from HBMSCs were positioned on top of the chondrocyte-based constructs, i.e., either healthy or osteoarthritic, to mimic adjacent healthy and diseased native articular cartilage environments respectively. The two-layered constructs were subsequently physically held together with a thin stainless steel pin (Fischer Scientific, Catalog \# 26002-10) that was pierced through both the layers. The two layer constructs were transferred to 24-well plates, and supplied with $1 \mathrm{ml}$ of chondrogenic media per sample (Fisher Scientific, Catalog \# SH3088902) that were then incubated in a standard cell culture incubator operating under $95 \%$ air, $5 \% \mathrm{CO}_{2}, 37^{\circ} \mathrm{C}$ and humidified conditions.

Cellular constructs were similarly made without HA. In sum, four groups of 2 layers specimens were ultimately prepared as follows: 1) HCs encapsulated in Agar-HBMSCs encapsulated in PEGDA without HA 2) HCs encapsulated in Agar-HBMSCs encapsulated in PEGDA with HA, 3) HCOAs encapsulated in Agar-HBMSCs encapsulated in PEGDA 
without HA, and 4) HCOAs encapsulated in Agar-HBMSCs encapsulated in PEGDA with HA.

\subsubsection{Cell Viability}

To assess the viability of HCs and HCOAs encapsulated in Agar constructs as well the HBMSCs encapsulated in PEGDA constructs with and without HA, a Live-Dead assay was conducted using Calcein AM/Ethidium homodimer (Life Technologies, Carlsbad, CA) staining following the manufacturer's protocol.

In brief, $1 \mathrm{~mm}$ sections from the different groups were grown to different time points (Day1, Day 7, Day 14 and Day 28) and were cut using a blade and subsequently stained with Calcein AM and Ethidium homodimer in PBS solution and incubated for 30 minutes. Next, to remove the background fluorescence they were washed 3 times with PBS solution and then visualized under a fluorescent microscope (Olympus IX81, Olympus America Inc., Miami, FL) at excitation and emission wavelengths of 495/515 nm and 495/635 nm for Calcein AM and Ethidium homodimer respectively. Viability of HBMSCs in PEGDA environment with and without the incorporation of HA was previously reported by our research group [19].

\subsubsection{Mechanical Testing}

The interfacial shear strength between the PEGDA-based tissue engineered cartilage and the agar based healthy (or alternatively, diseased) engineered cartilage substrates were determined by performing shear testing at the interface of the 2 layers. Samples to be tested ( $n=6 /$ group) were placed horizontally on the platens. One side of the sample was adhered to the upper platen while the other end was secured to the lower platen, 
both using super glue. The upper platen was subsequently displaced at a rate of 0.05 $\mathrm{mm} / \mathrm{sec}$ with data logging conducted at every $0.03 \mathrm{~mm}$ of displacement. The test was ended when the 2 layers were observed to separate from each other that were also accompanied with a sudden rapid decrease in the loads recorded.

\subsubsection{Histology}

Calcium and GAG matrix distribution at the interface of two layer constructs for Group 1-4 specifically 1) HCs encapsulated in Agar-HBMSCs encapsulated in PEGDA without HA 2) HCs encapsulated in Agar-HBMSCs encapsulated in PEGDA with HA, 3) HCOAs encapsulated in Agar-HBMSCs encapsulated in PEGDA without HA, and 4) HCOAs encapsulated in Agar-HBMSCs encapsulated in PEGDA with HA was evaluated using the Von-Kossa and Alcian Blue Stain kit (IHC world, Woodstock, MD, USA). Briefly the samples from each group were first fixed in $10 \%$ formalin. They were then embedded in molds using OCT. Sections were cut using cryostat (25 micron thickness) and were stained using the manufacturer's protocols. In short, sectioned samples were first washed with PBS three times to remove the OCT. Then they were treated with silver nitrate solution and exposed to UV light for 60 minutes. Next, they were stained with Alcian Blue Stain, washed with distilled water and observed under a microscope to visualize both the calcium and cartilage matrix deposition at the same time on the same tissue section.

\subsubsection{Energy-Dispersive X-ray Spectroscopy}

To quantify the composition of elements found within the transition zone of two distinct engineered tissue matrices treated with HA, energy-dispersive x-ray spectroscopy (EDS) was performed (JEOL 6330F Field Emission Scanning Electron Microscopy (FEG- 
SEM), (JEOL Ltd, Akishima-Shi, Tokyo). Specifically in an effort to obtain unambiguous spectra, because the transition zone between engineered cartilage and bone possessed a relatively large spatial region for assessment. For continuity in the text, the EDS results are presented directly in the "Discussion" section since they were obtained to primarily corroborate our histological findings,

\subsubsection{Quantitative Real Time-Polymerase Chain Reaction q(RT-PCR)}

To assess the gene expression of the stem cell-generated de novo cartilage tissue, quantitative real time-polymerase chain reaction (qRT-PCR) analysis was conducted, both at the interface and at the spatial location $4 \mathrm{~cm}$ from the interface, well within the stem-cell derived engineered tissues. First, engineered cartilage derived from HBMSC's after 28 days of culture was extracted from each group (1. HCs encapsulated in Agar-HBMSCs encapsulated in PEGDA without HA 2. HCs encapsulated in Agar-HBMSCs encapsulated in PEGDA with HA, 3. HCOAs encapsulated in Agar-HBMSCs encapsulated in PEGDA without HA, and 4. HCOAs encapsulated in Agar-HBMSCs encapsulated in PEGDA with HA.).

Each sample was subsequently cut into 2 parts. One part comprised of the transition region of $1 \mathrm{~cm}$ and the remaining part of the spatial region of the engineered cartilage from HBMSCs. Three samples from each group were cut in the similar fashion and, crushed and pooled together for analysis. This was repeated for another 2 samples from each group that generated a total number of pooled samples as $n=3$ for each of the interfacial and distal cartilage locations for $\mathrm{q}(\mathrm{RT}-\mathrm{PCR})$ assessment. Total mRNA was extracted from each group

three times using the SV total RNA isolation kit (Promega, Madison, WI). Subsequently, 
the RNA isolation procedure was followed as described by the manufacturer (Promega). Next, $5 \mu \mathrm{g}$ of mRNA was used for the reverse transcriptase reaction as previously reported $[25,26]$. GoScript Reverse Transcription kit (Promega) was used for converting the mRNA for the four groups into cDNA using an oligo(dT) primer, according to the manufacturer's instructions.

The qRT-PCR was performed using the GoTaq_qPCR Master Mix (Promega). The forward and reverse primers and SYBR green I dye reagent along with the cDNA, which was obtained during reverse transcription were mixed in PCR tubes. The primers (Table 1) were designed using the Basic Local Alignment Search Tool (BLAST) program, National Center for Biotechnology Information (NCBI) to amplify the target sequences. Step-One Real-Time PCR System (Life Technologies) was used to detect the signals when the mixture was followed by thermal cycling conditions as per manufacturer's instructions (Promega). Finally, the expression of the following markers: GAPDH, Aggrecan, SOX9, Collagen II, MMP13, Runx2, Collagen X, Collagen I, Osteocalcin were measured for the different groups. The choice of these markers was made mainly to access the quality of formed de novo cartilage. Aggrecan, Sox9 and Collagen II were selected as they were healthy cartilage specific markers [27, 28]. High expression of MMP13, Runx2, Collagen I were the indication of the deep zone calcified cartilage or hypertrophic cartilage [29, 30]. High expression of Collagen I and osteocalcin indicated the formation of oteoarthritic cartilage [31]. Finally, to interpret the results, the change in cycle threshold (Ст) values were averaged and normalized with GAPDH using the $\Delta \Delta \mathrm{C}$ т method [32]. Fold changes were calculated as $2^{-\Delta \mathrm{Cr}}$, and the gene expression ratio of each of the four groups was plotted. 


\subsubsection{Statistics}

Statistical analysis was performed for the results obtained from cell viability, shear testing and $\mathrm{q}(\mathrm{Rt}-\mathrm{PCR})$. The results obtained were reported as means \pm standard deviation. Commercially available software (SPSS, IBM, version 20, Armonk, NY, USA) was used to perform the statistics. To compare means and to determine statistically significant differences $(p<0.05)$ between groups respectively for shear testing a one way ANOVA and post hoc Tukey test was used. In cases where only two groups were compared, t-test for independent groups was utilized.

Table 5.1: Quantitative RT-Polymerase Chain Reaction Primer Sequences 


\begin{tabular}{|l|l|l|}
\hline Genes & \multicolumn{1}{|c|}{ Forward Primer } & \multicolumn{1}{c|}{ Reverse Primer } \\
\hline GAPDH & AATGAAGGGGTCATTGATGG & AAGGTGAAGGTCGGAGTCAA \\
\hline Aggrecan & GCGAGTTGTCATGGTCTGAA & TTCTTGGAGAAGGGAGTCCA \\
\hline SOX9 & GTAATCCGGGTGGTCCTTCT & GTACCCGCACTTGCACAAC \\
\hline Collagen II & AGACTTGCGTCTACCCCAATC & GCAGGCGTAGGAAGGTCATC \\
\hline MMP 13 & ACATCCCAAAACGCCAGACAA & GATGCAGCCGCCAGAAGAAT \\
\hline Runx2 & AATCCTCCCCAAGTTGCCA & TTCTGTCTGTCCTTCTGGGT \\
\hline Type X Collagen & TGGATCCAAAGGCGATGTG & GCCCAGTAGGTCCATTAAGGC \\
\hline Collagen I & TGAGAGACCAAGAACTG & CCATCCAAACCACTGAAACC \\
\hline Osteocalcin & CACTCCTCGCCCTATTGGC & CCCTCCTGCTTGGACACACAAAG \\
\hline
\end{tabular}

\subsection{Results}

\subsubsection{Cell Viability}

The viability of the cells in the engineered scaffolds was observed over a period of 28 days at 4 time points (Day 1, Day 7, Day 14 and Day 28). We found that the HCs (Fig. 5.1 (a)) and HCOAs (Fig. 5.1 (b)) were both viable more than $85 \%$ in the Agar gel at 28 days of growth (Table 5.2).

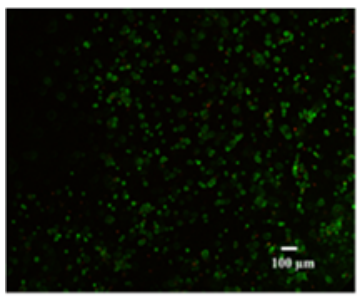

Day 1

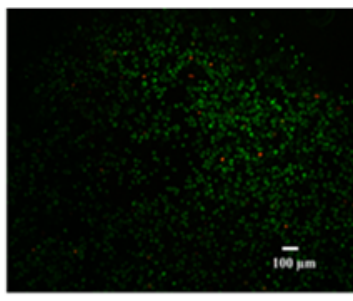

Day 7

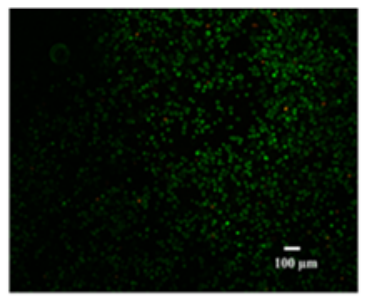

Day 14

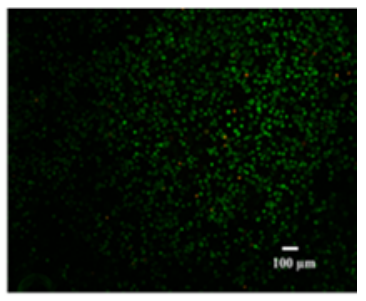

Day 28

Figure 5.1 (a): Live Dead assay over a period of 28 days for HCs encapsulated in agar scaffold. The images clearly showed that cells remained viable over this time frame with a much larger density of live (green dots) versus dead (red dots) cells 


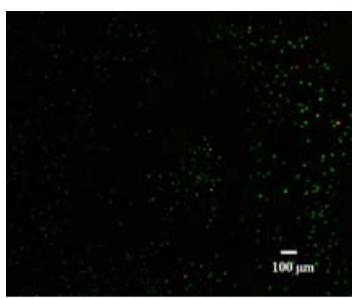

Day 1

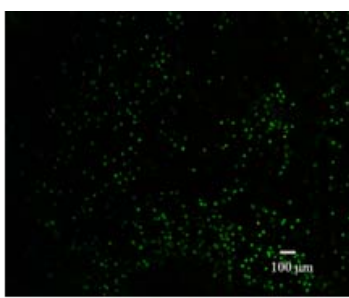

Day 7

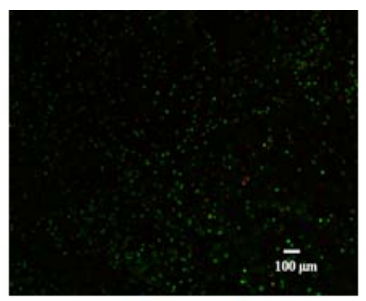

Day 14

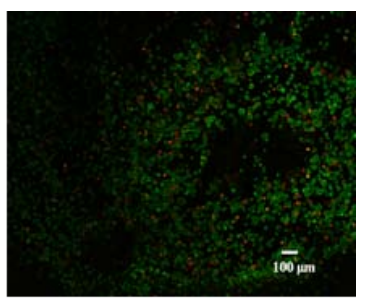

Day 28

Figure 5.1 (b): Live Dead assay over a period of 28 days for HCOAs encapsulated in agar scaffold. The images clearly showed that cells remained viable over this time frame with a much larger density of live (green dots) versus dead (red dots) cells

Table 5.2 Quantitative assessment of percentage cell viability in samples subjected to the livedead assay

\begin{tabular}{|c|c|c|c|c|}
\hline Sample & Day 1 & Day 7 & Day 14 & Day 28 \\
\hline $\begin{array}{c}\text { HCs } \\
\text { encapsulated in } \\
\text { agar scaffold }\end{array}$ & $83.41 \pm 1.99$ & $97.55 \pm 0.39$ & $97.50 \pm 0.08$ & $96.87 \pm 0.13$ \\
\hline $\begin{array}{c}\text { HCOAs } \\
\text { encapsulated in } \\
\text { Agar Scaffold }\end{array}$ & $87.50 \pm 0.41$ & $96.96 \pm 0.10$ & $89.63 \pm 0.24$ & $85.72 \pm 1.10$ \\
\hline
\end{tabular}

\subsubsection{Mechanical Testing}

The integration of tissue engineered cartilage derived from HBMSC's (with and without HA nanoparticles) with healthy and diseased cartilage matrix mimics was assessed. We found a statistically significant $(\mathrm{p}<0.05)$ difference in the shear strength between HCs encapsulated in Agar - HBMSCs encapsulated in PEGDA without HA and HCs encapsulated in Agar - HBMSCs encapsulated in PEGDA with HA after both 7 days and 28 days of tissue culture (Fig. 2). Furthermore the integration strength of HCs encapsulated in Agar - HBMSCs encapsulated in PEGDA without HA was significantly higher $(\mathrm{p}<0.05)$ than the integration strength of HCs encapsulated in Agar - HBMSCs encapsulated in PEGDA with HA group after 28 days of tissue culture. It was in the order of $6.87 \pm 0.74$ 
$\mathrm{KPa}$ for HCs encapsulated in Agar - HBMSCs encapsulated in PEGDA without HA. Meanwhile the corresponding group with HA demonstrated shear strength of $5.55 \pm 0.36$ KPa. (Fig. 5.2)

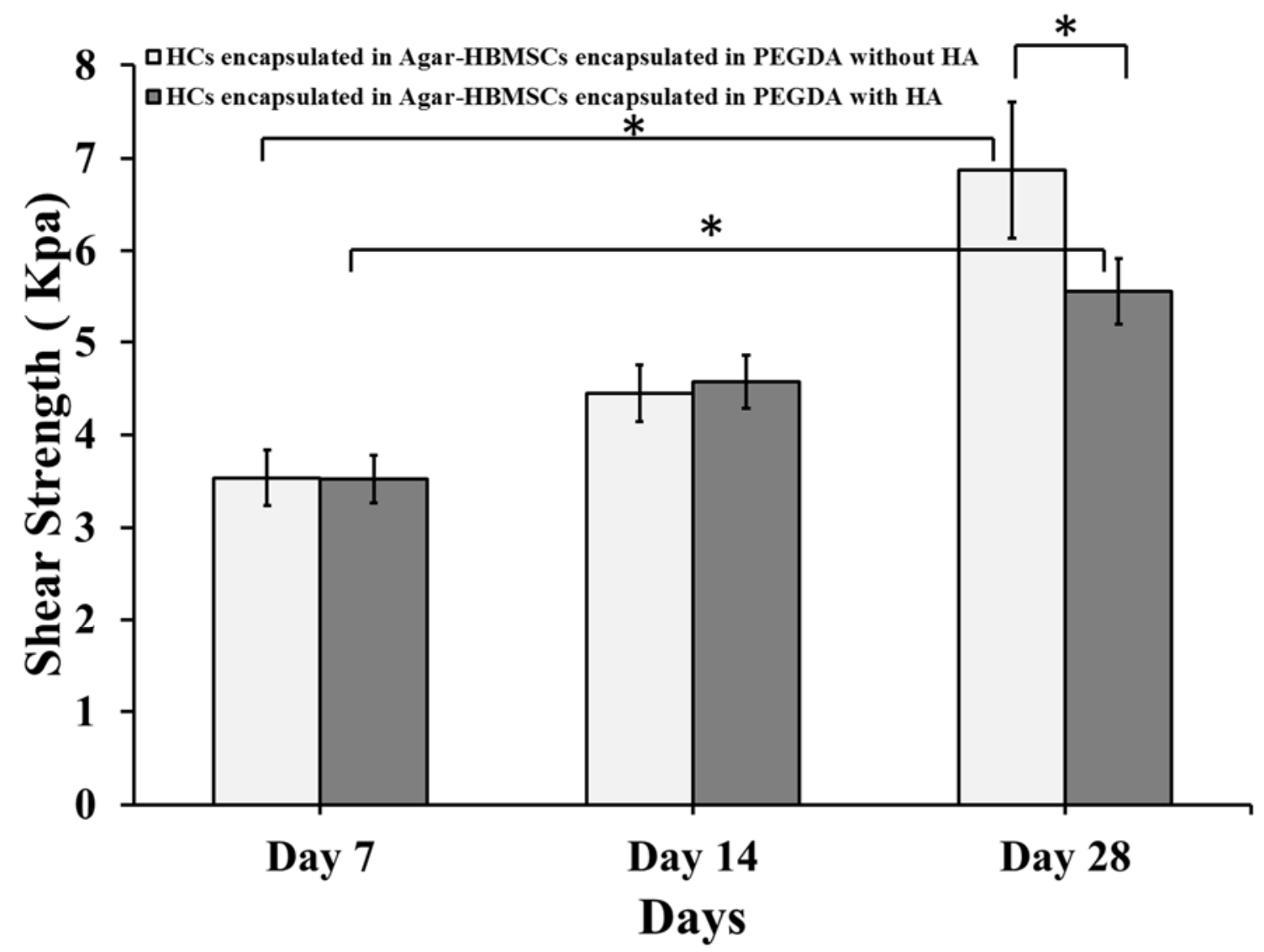

Figure 5.2: Interfacial shear test results of tissue engineered cartilage joined with healthy cartilage mimics with and without the presence of HA. The "*" indicates that the difference between the groups was statistically significant $(p<0.05)$. Enhanced integration of tissue engineered cartilage with healthy cartilage at day 28 compared to day 1 was found in both groups. However, there was a significant increase $(\mathrm{p}<0.05)$ in interfacial shear strength at day 28 when HA was not present.

This finding demonstrated that the presence of HA did not promote integration in healthy cartilage environments

When comparing the shear strength of engineered cartilage with diseased cartilage mimics with and without the inclusion of HA nanoparticles, we found that there was a statistically significant difference in shear strength at all-time points (Day 7, Day 14 and 
Day 28) between HCOAs encapsulated in Agar - HBMSCs encapsulated in PEGDA without HA and HCOAs encapsulated in Agar - HBMSCs encapsulated in PEGDA with HA. We also found that the HCOAs-based samples which included HA nanoparticles exhibited statistically significant $(\mathrm{p}<0.05)$ higher shear strength when compared with the group without the HA nanoparticles. The value of shear strength after 28 days of tissue culture was found to be $5.39 \pm 0.25 \mathrm{KPa}$ while for the corresponding group without $\mathrm{HA}$, it was in the order of $4.16 \pm 0.8 \mathrm{KPa}$ (Fig. 5.3).

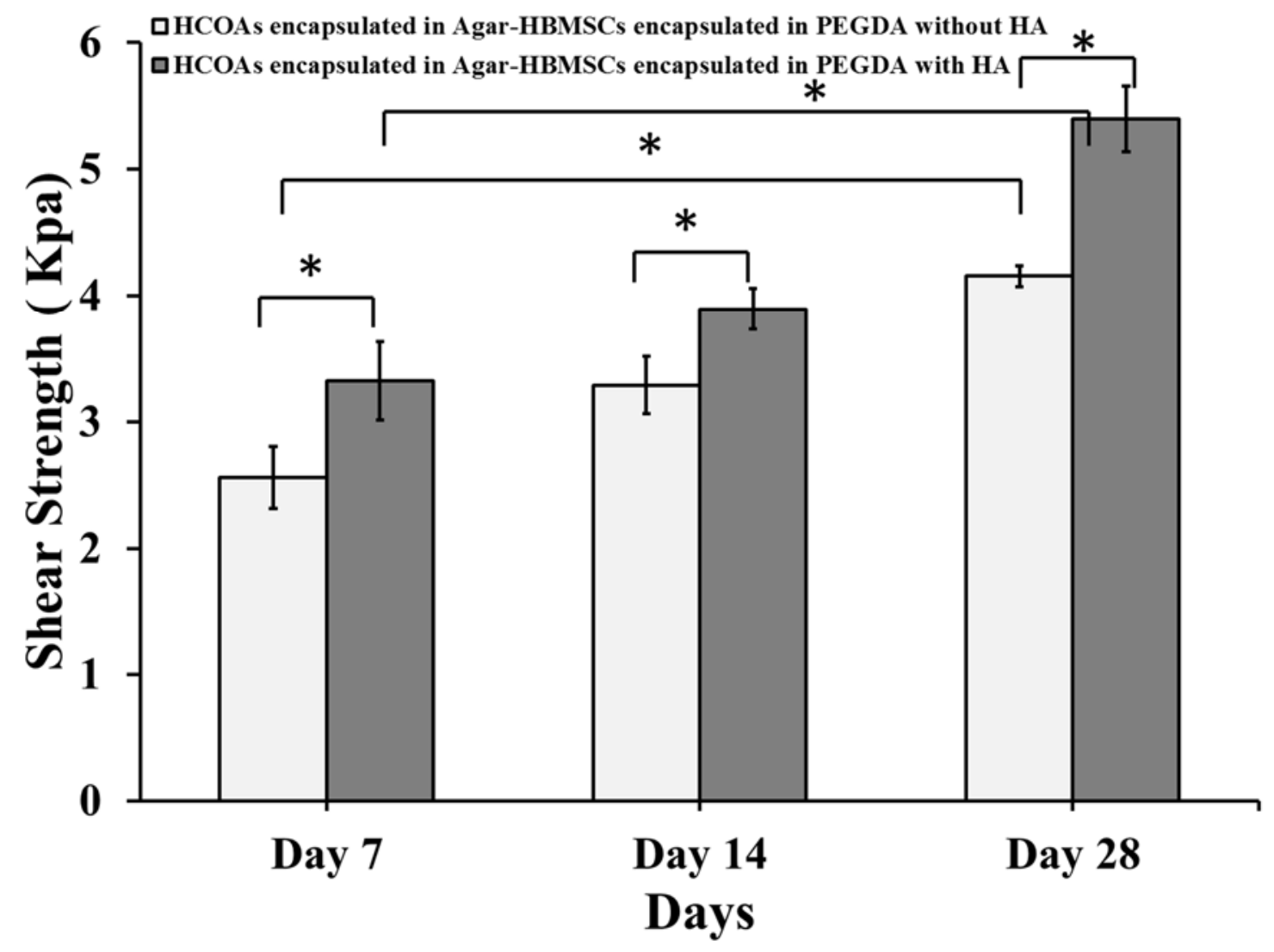

Figure 5.3: Interfacial shear test results of tissue engineered cartilage joined with osteoarthritic cartilage mimics with and without presence of HA. The "*" indicates that the difference between the groups was statistically significant $(\mathrm{p}<0.05)$. Enhanced integration of tissue engineered cartilage with osteoarthritic cartilage at day 28 compared to day 1 was found in both groups. However, there was a substantial increase in interfacial shear strength at day 28 when HA was present. This finding demonstrated that the presence of HA significantly $(\mathrm{p}<0.05)$ promoted integration in osteoarthritic cartilage environments. 


\subsubsection{Histology}

Histological sections revealed that HCs encapsulated in Agar-HBMSCs encapsulated in PEGDA with HA did not form a transition zone, but instead presented with a physical spacing or gap between the two engineered constructs (Fig. 5.4). By transition zone, we refer to a defined spatial region located between the tissue engineered two-layer constructs (e.g. between HBMSCs engineered cartilage and HCs / HCOAs engineered cartilage), that is made up of heterogeneous components derived from the two layers and is relatively much larger than the size of the actual interface. However regardless of whether or not HA was present, a narrowing of the gap was observed to have occurred in the constructs at 28 days in comparison to samples evaluated after 1 day of tissue culture (Fig. 5.4).

After 28 days of tissue culture, in HCOAs encapsulated in Agar-HBMSCs encapsulated in PEGDA with HA, a thin transition zone was formed between HBMSCderived engineered cartilage and HCOA-derived cartilage; on the other hand, when HA was not utilized, only a narrowing of the gap between the two layers was observed as was previously seen in the HC groups (Fig 5.5). 


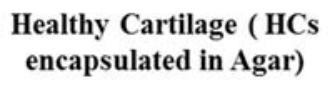

Engineered Cartilage ( HBMSCs encapsulated in PEGDA without HA

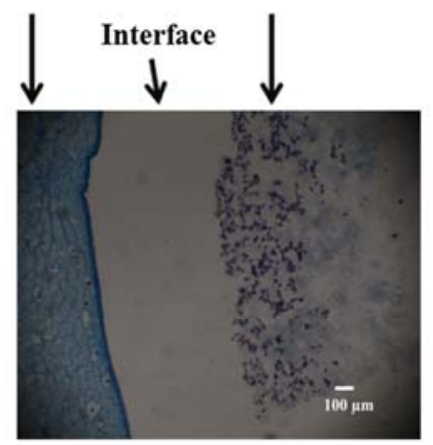

Day 1

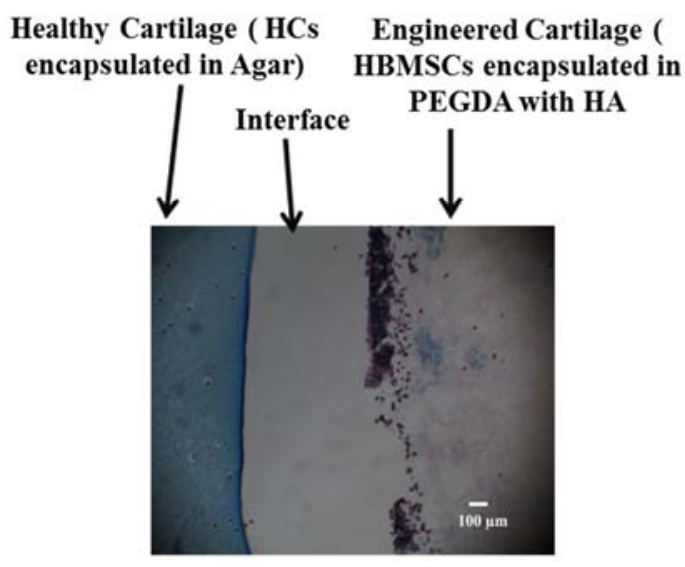

Day 1

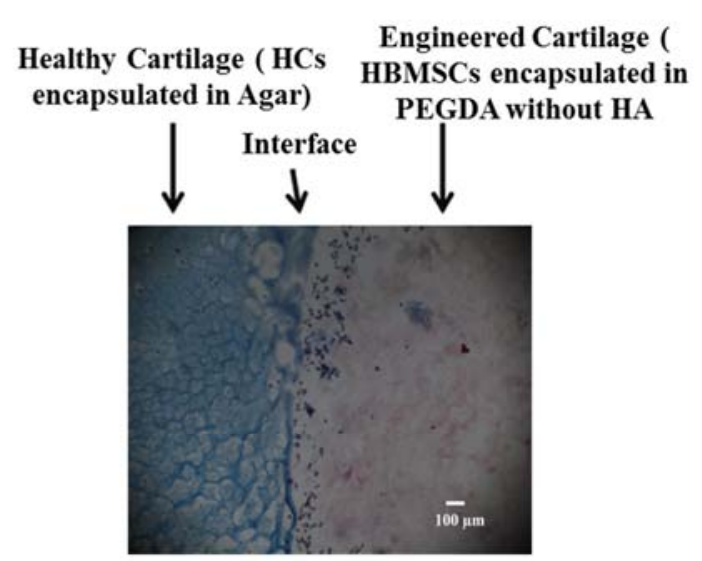

Day 28

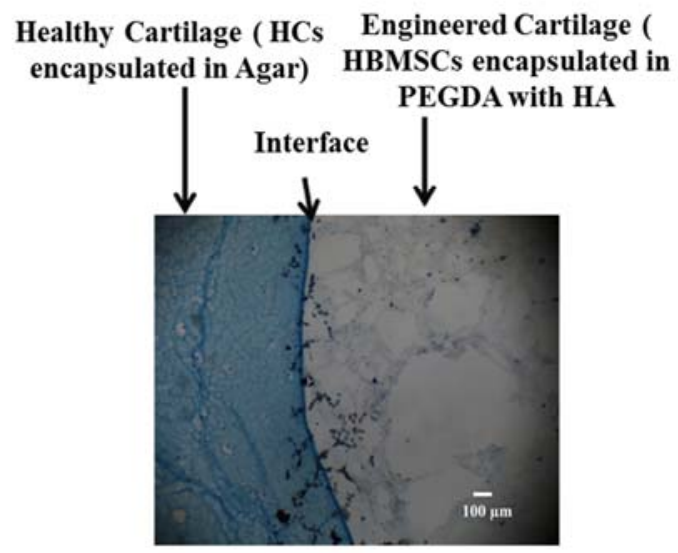

Day 28

Figure 5.4: Von Kossa - Alcian Blue histology of tissue engineered cartilage derived from HBMSCs integrated to HC-secreted cartilage matrix with and without HA incorporation. At Day 1 , a clear gap was apparent between the engineered cartilage and healthy cartilage regions for both groups. Progressive narrowing and filling of tissue subsequently occurred. 


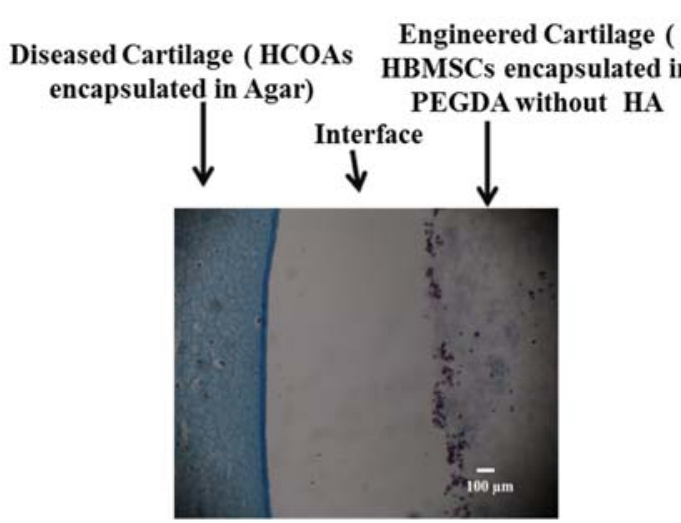

Day 1
Engineered Cartilage (

Diseased Cartilage ( HCOAs HBMSCs encapsulated in encapsulated in Agar) PEGDA without HA

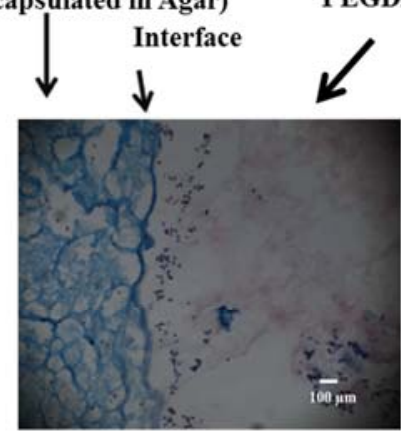

Day 28

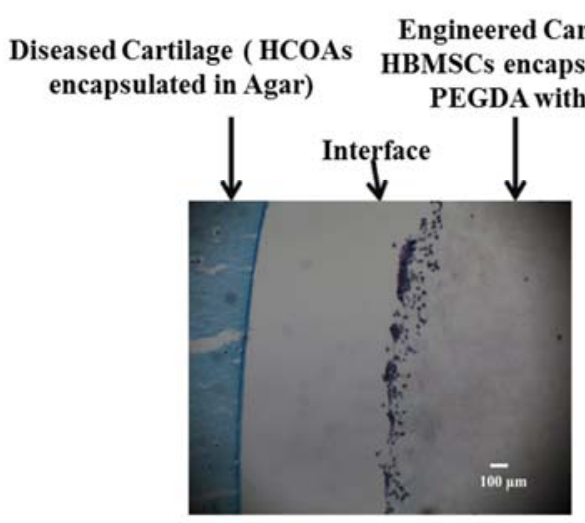

Day 1

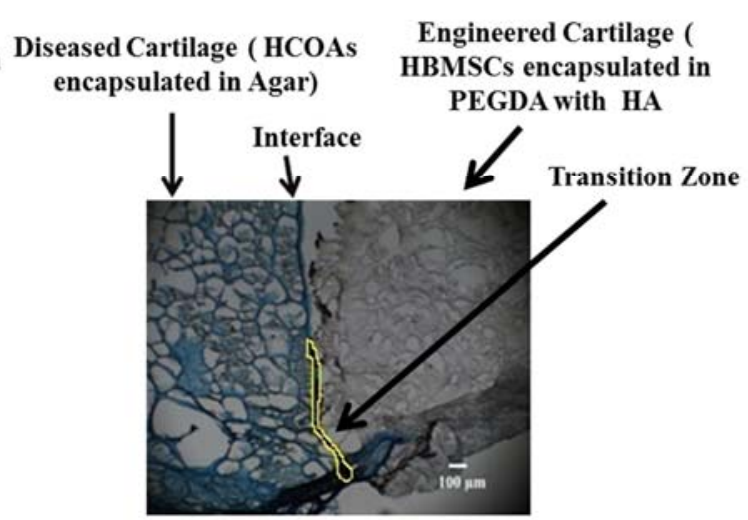

Day 28

Figure 5.5: Von Kossa - Alcian Blue histology of tissue engineered cartilage derived from HBMSCs integrated to HCOA-secreted cartilage matrix with and without HA incorporation. At Day 1, a clear gap was apparent between the engineered cartilage and diseased cartilage regions for both groups. Progressive filling of the transition zone with calcium phosphate deposits (indicated by dotted yellow lines) in the group with HA was found to occur.

\subsubsection{Quantitative Real-Time Polymerase Chain Reaction (qRT-PCR)}

After 28 days of culture in chondrogenic media, it was observed that HBMSCs derived tissue engineered cartilage within HCs encapsulated in Agar-HBMSCs encapsulated in PEGDA without HA exhibited relatively high expression of Aggrecan, SOX9 and Collagen II genes in both the proximal and distal regions (relative to the interface with HCs-derived engineered cartilage). In addition, there was a higher gene expression of MMP13, Runx2 and collagen $\mathrm{X}$ at proximal to the interface but not at the 
distal region in HBMSCs derived tissue engineered cartilage within HCs encapsulated in Agar-HBMSCs encapsulated in PEGDA with HA (Fig. 5.6).

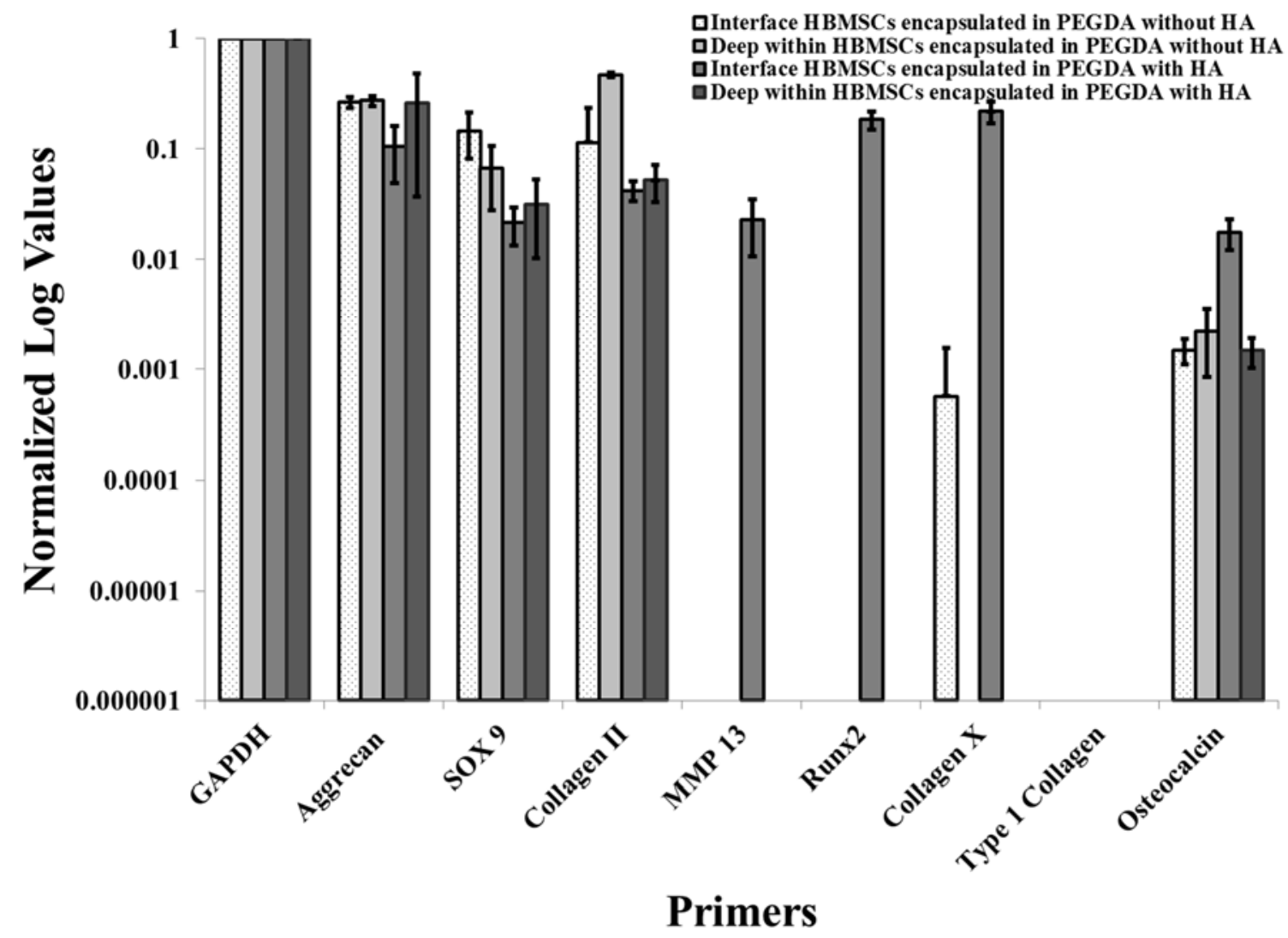

Figure 5.6: q(RT-PCR) of HBMSCs derived engineered cartilage integrated to HC-secreted cartilage matrix at a region of $1 \mathrm{~cm}$ (proximal) and $4 \mathrm{~cm}$ (distal) from the interface within the HBMSC portion. In samples with and without HA, the results indicated a high expression of Aggrecan, SOX9 and Collagen II genes at both the proximal and distal positions, indicating the formation of healthy cartilage. In addition, in the samples with HA, high gene expression of MMP13, Runx2 and collagen $\mathrm{X}$ at the proximal location was found, indicating the presence of a calcified cartilage matrix at the interface.

Similarly, for HBMSCs derived cartilage within HCOAs encapsulated in AgarHBMSCs encapsulated in PEGDA without HA, it was found that there was a relatively higher gene expression of Sox9, Collagen II, MMP13, Runx2, Collagen X, osteocalcein at the interface as well as to the regions deep within the HBMSCs-secreted engineered matrix. 
Gene expression of Type I collagen was nonetheless high at both the interface and deep in the HBMSCs derived engineered cartilage within HCOAs encapsulated in Agar-HBMSCs encapsulated in PEGDA without HA sample. However, when HA was incorporated, there was no gene expression of Type 1 collagen at the distal region and minimal expression of this gene at the interface (Fig. 5.7).

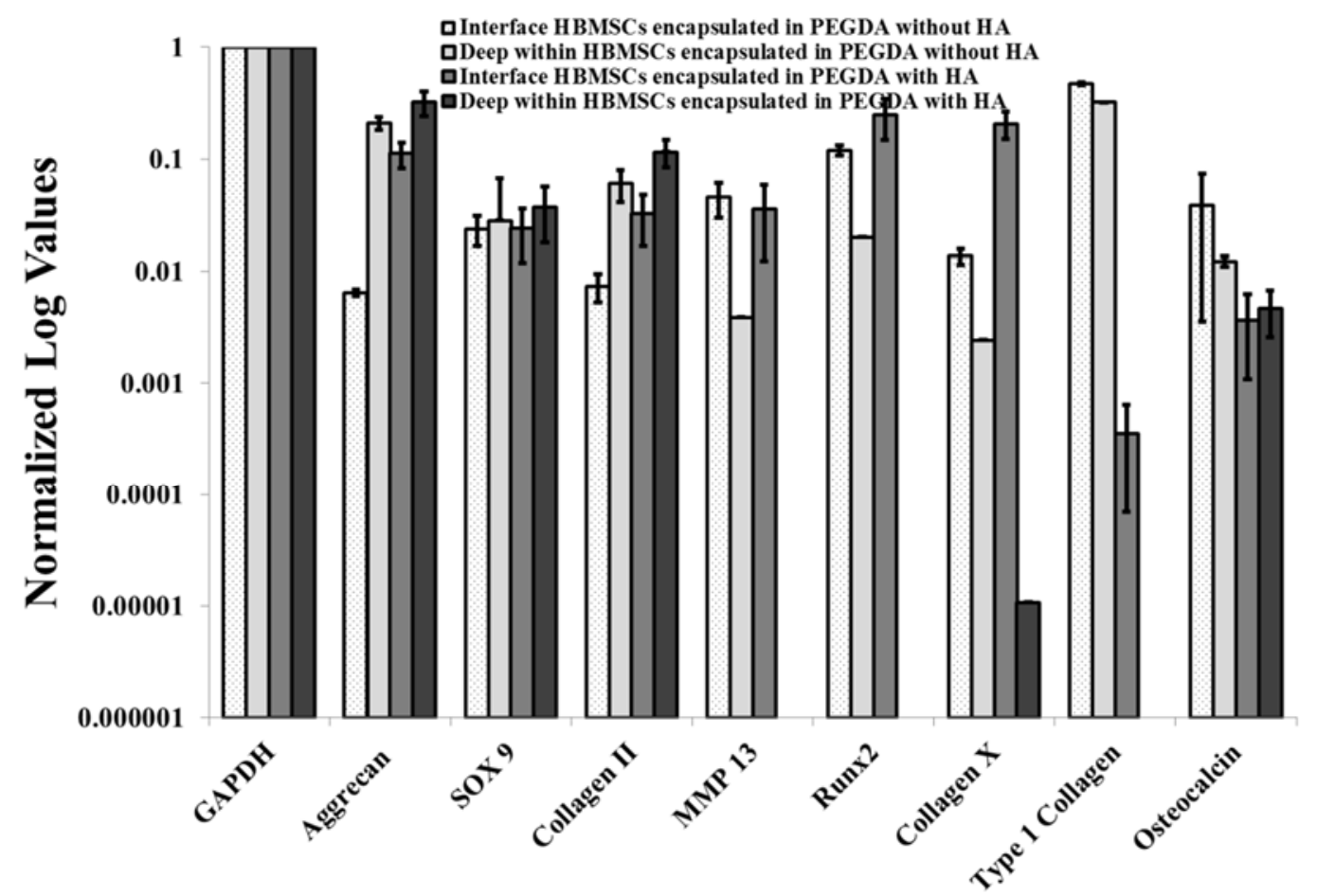

Primers

Figure 5.7: q(RT-PCR) of HBMSCs derived engineered cartilage integrated to HCOA-secreted cartilage matrix at a region of $1 \mathrm{~cm}$ (proximal) and $4 \mathrm{~cm}$ (distal) from the interface within the HBMSC portion. In samples without HA, the results indicated a high expression of Type 1 collagen at both the proximal and distal positions, indicating a loss of the articular cartilage phenotype in the presence of osteoarthritic environments. On the other hand, Type 1 collagen expression was found to be minimal in the samples with HA; in addition high gene expression of MMP13, Runx2 and collagen X at the proximal interface location was observed, indicating the presence of a calcified cartilage matrix at the interface. Meanwhile these genes were minimally

expressed at locations deep within the BMSC-derived engineered tissues and yet, strong expression of Aggrecan, SOX9, and Collagen II was maintained, indicative of a robust articular cartilage phenotype, when HA was incorporated. 


\subsection{Discussion}

Over the past decade, extensive research has been conducted in the area of tissue engineered cartilage integration with native tissues [33-35]. However most if not all of the previous studies focused on integration between engineered cartilage to bone $[35,36]$; yet of equal importance is the need for effective integration of the engineered cartilage with surrounding native articular cartilage, especially in the case of focal chondral defects. We thus sought to build on our previous work [19] on enhanced integration between cartilage and bone matrix using HA in a similar manner in this study, except to examine the utility of HA nanoparticles to promote the anchorage and integration of engineered cartilage to healthy as well as osteoarthritic cartilage extracellular matrix.

We found a significantly higher shear strength ( $p<0.05$; Fig. 5.2) after 28 days of tissue culture in HCs encapsulated in Agar-HBMSCs encapsulated in PEGDA without HA constructs in comparison to equivalent constructs with HA. From this observation, we interpret that matrix produced by HCs, that incorporates HA does not promote chondralchondral integration but rather, that the HA particles aggregate as non-heterogonous components along the interface of the two materials which ultimately results in reduction of shear strength. In contrast however, after 28 days of culture, we found a significantly higher shear strength $(\mathrm{p}<0.05$; Fig. 5.3) in HCOAs encapsulated in Agar-HBMSCs encapsulated in PEGDA with HA in comparison to its without HA counterpart. Interestingly thus, an opposing effect was observed (compared to HC-derived matrix) in the presence of osteoarthritis wherein the HA did support significant improvement in interfacial strength, and hence more effective integration between the two tissue matrices. 
These findings under a diseased state were consistent with our earlier work on HA-interface promotion at the engineered cartilage to engineered bone interface [19].

Following Von Kossa staining of the samples with and without HA in healthy and osteoarthritic-chondrogenic environments, a narrowing of the gap for both HCs encapsulated in Agar-HBMSCs encapsulated in PEGDA with and without HA was observed after 28 days of tissue culture (Fig. 5.4). In both cases, an intermediate transition zone between the HBMSC and chondrocyte-derived engineered cartilage matrices was absent. This corroborated with the decrease in the interfacial strength of the tissue engineered cartilage with the healthy cartilage when HA was present and in-line with the observation that a sharper or more abrupt transition between the two matrices, i.e., a smaller spatial transition zone is indicative of less effective integration [21].

On the other hand, after 28 days of culture in HCOAs encapsulated in AgarHBMSCs encapsulated in PEGDA with HA, we observed the formation of a thin transition zone (Fig. 5.5). This transition zone was largely occupied by calcium phosphate deposits. Notably similar presence of calcium phosphate but in larger quantities was observed in our previous studies, examining tissue engineered cartilage with HA integrated with an osteoblast-derived bone matrix [19]. Subsequent EDS analysis in the transition zone between these tissues confirmed a quantity of elemental Calcium in the order of $\sim 6.41 \%$ (Fig. 5.8). This finding provided conclusive evidence that the transition zone that was created was due to the presence of calcium phosphate deposits, which was likely attributable to the presence of the HA nanoparticles that had settled solely along the interface location. 


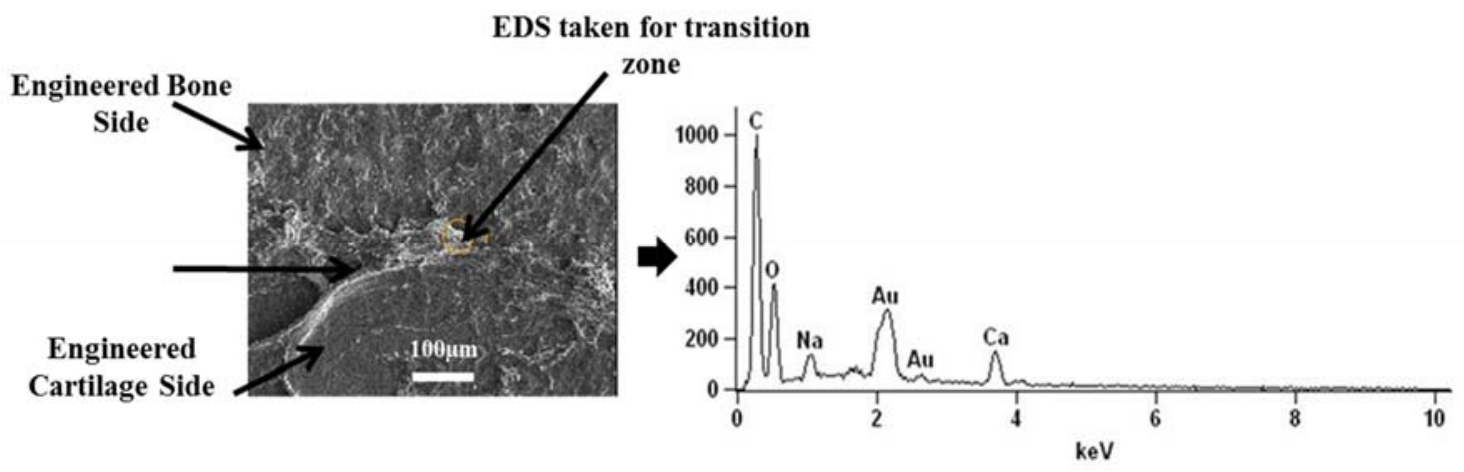

Figure 5.8: Elementary composition of the transition zone using Energy-Dispersive X-ray Spectroscopy. A large transition region between engineered cartilage and engineered bone treated with HA was analyzed after 28 days of culture. Elemental Calcium in the order of $\sim 6.41$ $\%$ was found to be present in the transition zone.

Further, we observed that in samples without HA, the BMSC-portion of HCs encapsulated in Agar-HBMSCs encapsulated in PEGDA exhibited a healthy cartilage phenotype after 28 days of culture (Fig. 5.6). However, when HA was incorporated there was a high expression of the genes, MMP13, Runx2 and Type 2 Collagen at the proximal region. This confirmed the presence of a calcified articular cartilage matrix at the interface, even though a larger spatial transition zone was absent. We note that this calcified matrix is likely to be similar in biochemical composition to the calcified matrix found in the deep zone of normal healthy articular cartilage [37]. Corresponding HBMSC regions integrated with HCOA-derived cartilage matrix without HA, revealed a high expression of Type 1 Collagen in both proximal and distal regions to the interface, i.e., indicative of a loss of articular cartilage phenotype in osteoarthritic environments. On the other hand, Type 1 Collagen expression was found to be minimal at proximal locations to the interface when HA was incorporated (Fig. 5.7). Finally, distal locations deep within the HBMSC-derived engineered tissue did not express MMP13, runx2 and Type X Collagen; instead, a high level of expression of the healthy articular cartilage genes, Sox9, aggrecan and Type II 
Collagen was observed demonstrating that the HBMSC-derived engineered tissues preserved a healthy cartilage phenotype despite its integration with extracellular matrix secreted by HCOAs. As previously stated, Type 1 collagen is a phenotypic indicator of the arthritic-state in articular cartilage [38]. We speculate that the presence of HA at the interface and the subsequent creation of a calcium phosphate-rich transition zone served to reduce the spread of osteoarthritic conditions to the de novo cartilage formed by the HBMSCs. Ironically however, the osteoarthritic state of adjacent cartilage matrix is a necessary precursor to initiate calcium phosphate generation at the interface location because calcium phosphate was found to be absent when the adjacent environment comprised of engineered cartilage derived from healthy chondrocytes. From a clinical perspective, we note that following cartilage injury, osteoarthritis rapidly develops [39-41] and is usually a co-morbidity when small to medium size cartilage defects [42] are present.

Even though our results appear promising and our HA-based protocol could potentially be transferred directly to clinical photopolymerizable tissue engineered cartilage strategies currently being investigated $[16,43]$, we note that all our findings were obtained from in vitro experiments. Specifically, we observed an increase in integration shear strength of engineered cartilage with the osteoarthritic cartilage when HA particles were incorporated. However, the critical strength that would be needed clinically for effective engineered cartilage retention in order to permit an adequate amount of time for subsequent tissue regeneration within the defect space has not been identified to date.

In summary, we were able to demonstrate substantial improvement in the integration of engineered cartilage to an underlying layer of osteoarthritic cartilage matrix in the presence of HA nanoparticles. The interfacial strength and histology results 
suggested that the utility of HA particles is only beneficial to the chondral-chondral integration when the chondrocyte-derived cartilage matrix is osteoarthritic. In such as state, a calcified cartilage matrix manifests itself between HBMSC and HCOA derived engineered cartilage tissues in the form of a larger, spatial transition zone region, thereby forming a stronger and a more stable interface. The calcium-phosphate deposits formed via incorporation of HA in the photopolymerizable gel also served to act as a physical barrier that reduced or at least delayed the onset of osteoarthritis progression from the surrounding environment to the HBMSC-derived de novo cartilage matrix.

\subsection{References}

1. Curl WW, Krome J, Gordon ES, Rushing J, Smith BP, Poehling GG. Cartilage injuries: a review of 31,516 knee arthroscopies. Arthroscopy : the journal of arthroscopic \& related surgery : official publication of the Arthroscopy Association of North America and the International Arthroscopy Association 1997;13:456-60. 
2. Hjelle K, Solheim E, Strand T, Muri R, Brittberg M. Articular cartilage defects in 1,000 knee arthroscopies. Arthroscopy : the journal of arthroscopic \& related surgery : official publication of the Arthroscopy Association of North America and the International Arthroscopy Association 2002;18:730-4.

3. Buckwalter JA, Mankin HJ. Articular cartilage: degeneration and osteoarthritis, repair, regeneration, and transplantation. Instructional course lectures 1998;47:487504.

4. Gilbert JE. Current treatment options for the restoration of articular cartilage. The American journal of knee surgery 1998;11:42-6.

5. Messner K, Gillquist J. Cartilage repair. A critical review. Acta orthopaedica Scandinavica 1996;67:523-9.

6. Aroen A, Loken S, Heir S, Alvik E, Ekeland A, Granlund OG, et al. Articular cartilage lesions in 993 consecutive knee arthroscopies. The American journal of sports medicine 2004;32:211-5.

7. Shelbourne KD, Jari S, Gray T. Outcome of untreated traumatic articular cartilage defects of the knee: a natural history study. The Journal of bone and joint surgery American volume 2003;85-A Suppl 2:8-16.

8. Ramaswamy S, Uluer MC, Leen S, Bajaj P, Fishbein KW, Spencer RG. Noninvasive assessment of glycosaminoglycan production in injectable tissueengineered cartilage constructs using magnetic resonance imaging. Tissue engineering Part C, Methods 2008;14:243-9.

9. Robertson DB, Daniel DM, Biden E. Soft tissue fixation to bone. The American journal of sports medicine 1986;14:398-403.

10. Stengel D, Casper D, Bauwens K, Ekkernkamp A, Wich M. Bioresorbable pins and interference screws for fixation of hamstring tendon grafts in anterior cruciate ligament reconstruction surgery: a randomized controlled trial. The American journal of sports medicine 2009;37:1692-8.

11. Herrmann Jb KRJHGA. Polyglycolic acid sutures: Laboratory and clinical evaluation of a new absorbable suture material. Archives of Surgery 1970;100:48690.

12. Zantop T, Welbers B, Weimann A, Rummler M, Hedderich J, Musahl V, et al. Biomechanical evaluation of a new cross-pin technique for the fixation of different sized bone-patellar tendon-bone grafts. Knee surgery, sports traumatology, arthroscopy : official journal of the ESSKA 2004;12:520-7. 
13. Bruns TB, Worthington JM. Using tissue adhesive for wound repair: a practical guide to dermabond. American family physician 2000;61:1383-8.

14. Hunziker EB, Kapfinger E. Removal of proteoglycans from the surface of defects in articular cartilage transiently enhances coverage by repair cells. The Journal of bone and joint surgery British volume 1998;80:144-50.

15. Djouad F, Rackwitz L, Song Y, Janjanin S, Tuan RS. ERK1/2 activation induced by inflammatory cytokines compromises effective host tissue integration of engineered cartilage. Tissue engineering Part A 2009;15:2825-35.

16. Wang DA, Varghese S, Sharma B, Strehin I, Fermanian S, Gorham J, et al. Multifunctional chondroitin sulphate for cartilage tissue-biomaterial integration. Nat Mater 2007;6:385-92.

17. Hoemann CD, Sun J, McKee MD, Chevrier A, Rossomacha E, Rivard GE, et al. Chitosan-glycerol phosphate/blood implants elicit hyaline cartilage repair integrated with porous subchondral bone in microdrilled rabbit defects. Osteoarthritis and cartilage / OARS, Osteoarthritis Research Society 2007;15:7889.

18. Khanarian NT, Jiang J, Wan LQ, Mow VC, Lu HH. A hydrogel-mineral composite scaffold for osteochondral interface tissue engineering. Tissue engineering Part A 2012;18:533-45.

19. Dua R, Centeno J, Ramaswamy S. Augmentation of engineered cartilage to bone integration using hydroxyapatite. Journal of biomedical materials research Part B, Applied biomaterials 2013.

20. Kim YS, Park EH, Lee HJ, Koh YG, Lee JW. Clinical comparison of the osteochondral autograft transfer system and subchondral drilling in osteochondral defects of the first metatarsal head. The American journal of sports medicine 2012;40:1824-33.

21. Ramaswamy S, Gurkan I, Sharma B, Cascio B, Fishbein KW, Spencer RG. Assessment of tissue repair in full thickness chondral defects in the rabbit using magnetic resonance imaging transverse relaxation measurements. Journal of biomedical materials research Part B, Applied biomaterials 2008;86:375-80.

22. Buckwalter JA, Mankin HJ, Grodzinsky AJ. Articular cartilage and osteoarthritis. Instructional course lectures 2005;54:465-80.

23. Huang CY, Reuben PM, D'Ippolito G, Schiller PC, Cheung HS. Chondrogenesis of human bone marrow-derived mesenchymal stem cells in agarose culture. The 
anatomical record Part A, Discoveries in molecular, cellular, and evolutionary biology 2004;278:428-36.

24. Dua R, Ramaswamy S. Relative survivability of human osteoblasts is enhanced by $39^{\circ} \mathrm{C}$ and ascorbic acid after exposure to photopolymerization ingredients. Cytotechnology 2012:1-10.

25. Betz MW, Modi PC, Caccamese JF, Coletti DP, Sauk JJ, Fisher JP. Cyclic acetal hydrogel system for bone marrow stromal cell encapsulation and osteodifferentiation. Journal of biomedical materials research Part A 2008;86:66270.

26. Myers TW, Gelfand DH. Reverse transcription and DNA amplification by a Thermus thermophilus DNA polymerase. Biochemistry 1991;30:7661-6.

27. Munirah S, Samsudin OC, Aminuddin BS, Ruszymah BH. Expansion of human articular chondrocytes and formation of tissue-engineered cartilage: a step towards exploring a potential use of matrix-induced cell therapy. Tissue \& cell 2010;42:282-92.

28. Perkins GL, Derfoul A, Ast A, Hall DJ. An inhibitor of the stretch-activated cation receptor exerts a potent effect on chondrocyte phenotype. Differentiation; research in biological diversity 2005;73:199-211.

29. Goldring MB. Chondrogenesis, chondrocyte differentiation, and articular cartilage metabolism in health and osteoarthritis. Therapeutic advances in musculoskeletal disease 2012;4:269-85.

30. Martinez-Sanchez A, Dudek KA, Murphy CL. Regulation of human chondrocyte function through direct inhibition of cartilage master regulator SOX9 by microRNA-145 (miRNA-145). The Journal of biological chemistry 2012;287:91624.

31. Gebhard PM, Gehrsitz A, Bau B, Soder S, Eger W, Aigner T. Quantification of expression levels of cellular differentiation markers does not support a general shift in the cellular phenotype of osteoarthritic chondrocytes. Journal of orthopaedic research : official publication of the Orthopaedic Research Society 2003;21:96-101.

32. Vandesompele J, De Preter K, Pattyn F, Poppe B, Van Roy N, De Paepe A, et al. Accurate normalization of real-time quantitative RT-PCR data by geometric averaging of multiple internal control genes. Genome biology 2002;3:RESEARCH0034.

33. Tognana E, Chen F, Padera RF, Leddy HA, Christensen SE, Guilak F, et al. Adjacent tissues (cartilage, bone) affect the functional integration of engineered 
calf cartilage in vitro. Osteoarthritis and cartilage / OARS, Osteoarthritis Research Society 2005;13:129-38.

34. Schaefer D, Martin I, Jundt G, Seidel J, Heberer M, Grodzinsky A, et al. Tissueengineered composites for the repair of large osteochondral defects. Arthritis \& Rheumatism 2002;46:2524-34.

35. Lopa S, Madry H. Bioinspired Scaffolds for Osteochondral Regeneration. Tissue engineering Part A 2014.

36. Smyth NA, Haleem AM, Murawski CD, Do HT, Deland JT, Kennedy JG. The effect of platelet-rich plasma on autologous osteochondral transplantation: an in vivo rabbit model. The Journal of bone and joint surgery American volume 2013;95:2185-93.

37. Davies DV, Barnett CH, Cochrane W, Palfrey AJ. Electron microscopy of articular cartilage in the young adult rabbit. Annals of the rheumatic diseases 1962;21:1122.

38. Sandell LJ, Aigner T. Articular cartilage and changes in arthritis. An introduction: cell biology of osteoarthritis. Arthritis research 2001;3:107-13.

39. Vijayan S, Bentley G, Briggs T, Skinner J, Carrington R, Pollock R, et al. Cartilage repair: A review of Stanmore experience in the treatment of osteochondral defects in the knee with various surgical techniques. Indian journal of orthopaedics 2010;44:238-45.

40. Furman BD, Olson SA, Guilak F. The development of posttraumatic arthritis after articular fracture. Journal of orthopaedic trauma 2006;20:719-25.

41. Fleming BC, Hulstyn MJ, Oksendahl HL, Fadale PD. Ligament Injury, Reconstruction and Osteoarthritis. Current opinion in orthopaedics 2005;16:35462 .

42. Khashan M, Chechik O, Arbel R, Morag G. [The treatment of focal chondral lesions of the knee]. Harefuah 2010;149:542-6, 9.

43. Nettles DL, Kitaoka K, Hanson NA, Flahiff CM, Mata BA, Hsu EW, et al. In situ crosslinking elastin-like polypeptide gels for application to articular cartilage repair in a goat osteochondral defect model. Tissue engineering Part A 2008;14:1133-40. 


\section{Chapter 6}

\section{Conclusions and Future work}

\subsection{Conclusions, limitations and future work}

This study presented an overall approach to integration of tissue engineered cartilage with bone, healthy and diseased cartilage matrices in an in-vitro environment. We anticipate this protocol can be utilized for treatment of small to modest sized osteochondral defects so as to prevent or at minimum, delay the onset of Osteoarthritis. The novelty of this project was the use of HA nanoparticulate usage in HBMSC-seeded, 
photopolymerizable injectable hydrogels, to promote biological integration of engineered cartilage to adjacent bone and cartilage matrices.

HA is a bioactive form of calcium phosphate $\mathrm{Ca} 10\left(\mathrm{PO}_{4}\right)_{6}(\mathrm{OH}) 2$, has a $\mathrm{Ca} / \mathrm{P}$ molar ratio of 1.67 [2], and is considered osteoinductive [1]. For example, HA coatings in implants have shown to promote bone in growth $[3,4,5]$. With a similar approach, here, we proposed the use of HA nanoparticles for enhancing the anchorage and hence retention of tissue engineered cartilage with surrounding native tissues (subchondral bone and articular cartilage). For the studies conducted, in theory, we could have used any form of calcium phosphate in nanoparticulate form with a molar ratio of $\mathrm{Ca} / \mathrm{P}$ as 1.67 . We selected HA because it is the most predominant material in bone [6].

In this dissertation: Chapter 1 explained the area of tissue engineered cartilage and the need to augment retention and integration properties of engineered cartilage within a osteochondral or chondral defect space. Chapter 2 provided a critical review of previous research that was done in this field and helped us to determine and frame our objectives which were to: (i) promote the integration between engineered cartilage to subchondral bone using HA nanoparticles in an optimized photopolymerizable hydrogel environment. (ii) To enhance the integration between tissue engineered cartilage and surrounding native cartilage, again with HA nanoparticle incorporation in photopolymerizable hydrogel environments. (iii) To identify the impact of osteoarthritic diseased states, in photopolymerizable hydrogel environments in conjunction with HA particles.

In chapter 3, we presented a toxicity study of different cell sources to different levels of UV exposure and photoinitiator concentrations. This chapter formed the 
foundation for subsequent protocols that were designed in conjunction with in vitro engineered tissue model systems for evaluating integration of engineered cartilage to bone, healthy cartilage and diseased cartilage. From this investigation, we were able to select the ideal UV exposure time and establish cellular response to UV exposure for subsequent PEGDA-based experiments. Chapter 4 focused on the utility of HA nanoparticles for integration of engineered cartilage to bone matrix. We were able to show a significant improvement in the interfacial strength between engineered cartilage and subchondral bone matrix when HA was used, via the formation of a calcium phosphate-rich transition zone between the two materials.

We then subsequently tested the incorporation of HA particles for improving the integration strength of engineered cartilage with underlying healthy and diseased cartilage, the focus of Chapter 5. Surprisingly, Osteoarthritic cartilage yielded more effective integration with HBMSC-originating engineered cartilage, in comparison to healthy cartilage matrix derived from chondrocytes. We interpret the similarities in gene expression between bone and Osteoarthritic cartilage to have enhanced HA activity, thereby resulting in the greater integration observed.

Even though our results appear promising, we were limited in our scope and restricted to in-vitro environments. Our model while exhibiting enhanced integration properties would need to be able to withstand in vivo physiological loading conditions. Tissue remodeling and growth would likely be very different from the observations of this study, which therefore needs to be evaluated in our future work. In our laboratories, in conjunction with our collaborators at Mississippi State University, we have already undertaken the first steps 
in this direction by utilizing the rabbit model. The specific protocol follows a similar paradigm to the studies reported by Ramaswamy et al [7], and is likely to also at some point involve noninvasive longitudinal assessment of engineered cartilage tissue integration and repair using magnetic resonance imaging. At the time of submission of this dissertation, surgically created chondral defects in osteoarthritic rabbit knees were treated following a similar protocol developed from the current work on HBMSC-PEGDA-HA constructs. Over the next calendar year, following animal sacrifice and knee explant, we anticipate that a greater understanding and identification of in vivo integration processes will be uncovered. Pending completion of the in vivo phase with a successful outcome, we anticipate that our HA-based protocol can be directly assimilated into existing clinical studies that are utilizing injectable hydrogel approaches for cartilage repair and regeneration $[8,9]$.

\section{2 References}

1. Park J-H, Lee Y-K, Kim K-M, Kim K-N. Bioactive calcium phosphate coating prepared on $\mathrm{H} 2 \mathrm{O} 2$-treated titanium substrate by electrodeposition. Surface and Coatings Technology 2005;195:252-7.

2. Benaqqa C, Chevalier J, Saadaoui M, Fantozzi G. Slow crack growth behaviour of hydroxyapatite ceramics. Biomaterials 2005;26:6106-12.

3. L H, O A. An Introduction to Bioceramics1993. 
4. Cook SD, Thomas KA, Kay JF, Jarcho M. Hydroxyapatite-coated titanium for orthopedic implant applications. Clinical orthopaedics and related research 1988:225-43.

5. Ducheyne P, Hench LL, Kagan A, 2nd, Martens M, Bursens A, Mulier JC. Effect of hydroxyapatite impregnation on skeletal bonding of porous coated implants. Journal of biomedical materials research 1980;14:225-37.

6. Stanciu GA, I.Sandulescu, Savu B, Stanciu SG, Paraskevopoulos KM, Chatzistavrou X, et al. Investigation of the Hydroxyapatite Growth on Bioactive Glass Surface. Journal of Biomedical \& Pharmaceutical Engineering 2007;1:34-9.

7. Ramaswamy S, Gurkan I, Sharma B, Cascio B, Fishbein KW, Spencer RG. Assessment of Tissue Repair in Full Thickness Chondral Defects in the Rabbit Using Magnetic Resonance Imaging Transverse Relaxation measurements. Journal of Biomedical Materials Research- Part B: Applied Biomaterials, 2008; 86B:2:375-380.

8. Elisseeff J, Anseth K, Sims D, McIntosh W, Randolph M, Yaremchuk M, et al. Transdermal photopolymerization of poly(ethylene oxide)-based injectable hydrogels for tissue-engineered cartilage. Plastic and reconstructive surgery 1999;104:1014-22.

9. Passaretti D, Silverman RP, Huang W, Kirchhoff CH, Ashiku S, Randolph MA, et al. Cultured chondrocytes produce injectable tissue-engineered cartilage in hydrogel polymer. Tissue engineering 2001;7:805-15.

VITA

\section{RUPAK DUA}

Born, Lucknow, India

Aug 2003 - May $2007 \quad$ B.Tech, Biomedical Engineering Sathyabama Institute of Science and Technology

Chennai, Tamil Nadu, India 
Aug 2007- Dec 2008

Aug 2009 - Aug 2014

May 2012- Aug 2012

Feb 2013

Apr 2013

Apr 2013

Aug 2013

Jan 2014 - August 2014
M.S, Biomedical Engineering Florida International University Miami, Florida

Doctoral Candidate, Biomedical Engineering

Florida International University

Miami, Florida

MBRS RISE, 2012 Summer Biomedical Research Initiative Award, FIU

Miami, FL, USA

Outstanding Paper Award

ASME Global Congress on Nano Engineering for Medicine and Biology

Boston, MA, USA

University Graduate School (UGS) Provost Award

Florida International University

Miami, FL, USA

$2^{\text {nd }}$ at Statewide Graduate Student Research Symposium

University of South Florida

Tampa, FL, USA

Dean's Leadership and Service Scholarship

College of Engineering and Computing, FIU

Miami, FL, USA

Dissertation year fellowship (DYF)

University Graduate School, FIU

Miami, FL, USA

\section{PUBLICATIONS AND PRESENTATIONS}

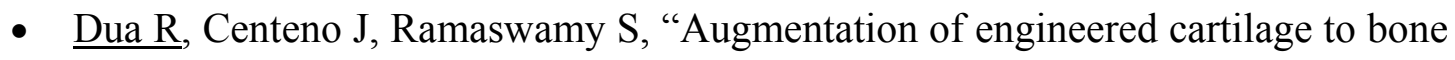
integration using hydroxyapatite", Journal of Biomedical Materials Research: Part B - Applied Biomaterials, 2013, Nov. epub. DOI: 10.1002/jbm.b.33073.

- $\quad$ Dua R, Ramaswamy S, "Relative survivability of human osteoblasts is enhanced by $39{ }^{\circ} \mathrm{C}$ and ascorbic acid after exposure to photopolymerization ingredients", Cytotechnology, 2012, Nov; 65(4):587-96. 
- Dua R, Ramaswamy S, "Strategies for Integration of Tissue Engineered Constructs to Native Cartilage and Bone" in Tissue Engineering: Fundamentals, Techniques and Applications, October, 2012. ISBN: 978-1-62257-062-1

- Lahiri D, Dua R, Zhang C, Novoa I, Bhat A, Ramaswamy S and Agarwal A, "Graphene Nanoplatelet-Induced Strengthening of Ultra High Molecular Weight Polyethylene and Biocompatibility In vitro", ACS Applied Materials and Interfaces, 2012 Apr; 4(4):2234-41.

- Gill P, Munroe N, Dua R, Ramaswamy S, "Corrosion and Biocompatibility Assessment of Magnesium Alloys", Journal of Biomaterials and Nanobiotechnology, 2012 Jan; 3(1):10-13. (3 more papers are under review in peer reviewed journals) 